\title{
Printing People.
}

Heterogeneous Multi-Property Printing of Humanoid Anatomics.

Samantha Whitham. 

A 90 point research portfolio submitted to the Victoria University of Wellington in fulfilment of the requirements for the degree of Master of Design Innovation.

Samantha Whitham

Victoria University of Wellington School of Design 2019 
Abstract. 
Film and television (TV) have been a way to view unthinkable worlds for many years. Physical props are a fundamental part of many films as they help to portray the story in the real world, which results in a more believable experience for the audience. The technology used in the production of props and creatures has evolved with the changes in the manufacturing process to allow for more computer-controlled designs. This begs the question; what could multi-property, 3D/4D printing bring to the way the film prop manufacturing industry creates physical props? Printing in the fourth dimension (dynamic) is a relatively new concept and is being researched by leading 3D printing companies. This area of study has yet to apply the four-dimensional (4D) capabilities of multi-property printing to the creation of heterogeneous humanoid anatomic's.
Heterogeneous 3D printing is the combination of multiple elements and material qualities in one print, which is possible by using the Stratasys $\mathrm{J} 750$ Polyjet printer. This printer allows for both hard and soft components to be incorporated into one design by blending the full-colour hard Vero material with soft, translucent Agilus material. The final humanoid objects have varying material hardness throughout the design, representing the different densities and materiality that is found in the finger joint. By taking the basic parameters of a section of human anatomy, the ability to create a creature by merely changing the size, colour, or the number of joints is achievable. With this technology, the ability to rapidly produce and easily edited final on-screen props is possible.

Keywords- 3D/4D printing, Heterogeneous printing, Human anatomy, Film and TV, Design. 


\section{Motivation.}

During my Bachelors of Design Innovation, majoring in Industrial Design, 3D printing was a big part of the way products and designs were manufactured throughout the three years. Going into this research portfolio, I had a good understanding of how 3D printing works and what needs to be done to produce a successful digitally constructed design. Throughout my degree, I had the chance to work with the multi-property Connex Objet 350 polyjet printer, as well as, having the opportunity to send files away to Stratasys and print on the full-colour J750 polyjet printer. In between the completion of my undergraduate studies and starting the master's program I was fortunate enough to be awarded a summer scholarship position at Weta Workshop. I learnt about how they are currently using 3D printing and mass-produce props and how props are manufactured. This experience inspired me to study the new technology and materials of the $\mathrm{J} 750$ printer and relate that into a fully printed, movable prop for film. 


\section{Acknowledgements.}

. Thank you to my supervisor's Ross Stevens and Bernard Guy for guiding me through this research portfolio.

. To MADE thank you for the financial support in the creation of these designs.

. A big thanks to Phil Jarrett and Keith Davies for the technical support and printing.

. To my Parents, I am so grateful to have you there behind me giving me encouragement and pushing me to do my utmost best in everything I try.

. Thanks to the 2018-2019 cohort for the input and support of my 'creepy' project and thank you to Charlotte for editing my thesis. 


\section{Contents.}

Abstract. III

Motivation.

Acknowledgements.

List of illustrations/images/

diagrams.

Introduction.

Definitions.

Aims \& Objectives.
IV

V 1 5 6 8

\section{Part One.}

1.1 Background and

Precedent Review.

- Introduction

- Anatomy of a finger.

- Additive-

Manufacturing.

- Multi-material.

- Dynamic Printing projects.

- Prop Manufacturing. - CGI.

- Conclusion.

1.2 Methodology.

- Research Methods.
Part Two.

2.1 Design Criteria.

2.2 Evaluation of Anatomical Movement.

- Hand movement experiment.

- Chicken feet experiment.

2.3 Stratasys Connex Objet350 Printing.

- Tensile tests.

- Movement.

- Anatomical Testing of Varying Material Blends.

2.4 Stratasys J750 Printing.

- Test Swatch.

- Recreation testing.

- Material and movement tests. 
Part Three.

3.1 Human.

3.2 Creature.
Part Four.

4.1 Discussion.

4.2 Further Research.

4.3 Conclusion.
Part Five.

5.1 References.

5.2 Appendix. 


\section{List of illustrations/images/diagrams.}

(p. 15) Figure 1, diagram of finger anatomy.

(p. 16) Figure 2, human skeleton.

(p. 17) Figure 3, diagram of blood supply, fat and tendon movement.

(p. 18) Figure 4, multi-property print.

(p. 19) Figure 5, render of 3D printed file in orientation.

(p. 20) Figure 6, 3D printed pattern flattened out.

(p. 21) Figure 7, cross section renders of the flowers.

(p. 21) Figure 8, cross section of

Heaven flower with assigned material combination.

(p. 22) Figure 9, flexible creature Prosthetic.

(p.24) Figure 10, The uncanny valley, diagram.

(p.26) Figure 11, Research Through Design, diagram. (p.28) Figure 12, The 4 D's, diagram.

(p.36) Figure 13 a, Finger, bent.

Figure 13 b, Finger, halfway bent.

Figure $13 \mathrm{c}$, Finger, slightly bend.

Figure $13 \mathrm{~d}$, Finger, straight.

(p.37) Figure 14 a, Chicken foot, extensor tendon.

Figure $14 \mathrm{~b}$, Chicken foot, flexor tendons. Figure $14 \mathrm{~b}$, Chicken foot, pulling on tendons.

Figure $14 \mathrm{c}$, Chicken foot, detail.

(p.39) Figure 15 a, fully pulled.

Figure 15 b, brake.

Figure $15 \mathrm{c}$, halfway.

Figure $15 \mathrm{~d}$, starting position.

(p. 40) Figure 16 a, one, straight. Figure $16 \mathrm{~b}$, one, bent.

(p. 40) Figure 17 a, two, straight. Figure 17 b, two, bent.

(p. 40) Figure 18 a, three, straight.

Figure $18 \mathrm{~b}$, three, bent.

(p. 41) Figure 19 a, anatomical, render. Figure 19 b, anatomical, all tests.

(p. 41) Figure 20 a, anatomical, one.

Figure $20 \mathrm{~b}$, anatomical, two.
Figure $20 \mathrm{c}$, anatomical, three.

Figure $20 \mathrm{~d}$, anatomical, four.

(p. 43) Figure 21, Test Swatch.

(p. 44) Figure 22 a, recreation one, bent. Figure $22 \mathrm{~b}$, recreation one, side. Figure $22 \mathrm{c}$, recreation one, front Figure $22 \mathrm{~d}$, recreation one, back.

(p. 45) Figure 23 a, Recreation two, bent Figure $23 \mathrm{~b}$, Recreation two, bent back.

Figure 23 c, Recreation two, side.

Figure $23 \mathrm{~d}$, Recreation two, front.

(p. 46) Figure 24 a, one, right bent.

Figure $24 \mathrm{~b}$, one, left bent.

Figure $24 \mathrm{~b}$, one, side.

Figure $24 \mathrm{c}$, one, front.

(p. 47) Figure 25 a, two, right bent. Figure $25 \mathrm{~b}$, two, left bent.

Figure $25 \mathrm{~b}$, two, bent.

Figure $25 \mathrm{c}$, two, front.

(p. 48) Figure 26 a, three, right bent. Figure $26 \mathrm{~b}$, three, left bent.

Figure $26 \mathrm{c}$, three, side.

Figure $26 \mathrm{~d}$, three, front. 
(p. 49) Figure 27 a, four, bent. Figure $27 \mathrm{~b}$, four, partially bent. Figure $27 \mathrm{c}$, four, bent back.

Figure $27 \mathrm{~d}$, four, side.

(p. 50) Figure 28 a, five, bent Figure $28 \mathrm{~b}$, five, bent back.

Figure $28 \mathrm{c}$, five, side.

Figure $28 \mathrm{~d}$, five, front.

(p. 51) Figure 29 a, six/seven, bent. Figure $29 \mathrm{~b}$, six/seven, bent back.

Figure 29 c, six/seven, side.

Figure $29 \mathrm{~d}$, six/seven, front.

(p. 52) Figure 30 a, tendon one, straight. Figure $30 \mathrm{~b}$, tendon one, bent. (p. 52) Figure 31 a, tendon two, straight. Figure $31 \mathrm{~b}$, tendon two, bent.

(p. 52) Figure 32 a, tendon three, straight.

Figure $32 \mathrm{~b}$, tendon three, bent.

(p. 53) Figure 33 a, eight, bent.

Figure $33 \mathrm{~b}$, eight, side.

Figure $33 \mathrm{c}$, eight, front

Figure $33 \mathrm{~d}$, eight, tendon, bent.

Figure 33 e, eight, tendon, side.

Figure $33 \mathrm{f}$, eight, tendon, front. (p. 54) Figure 34 a, nine, side bent. Figure $34 \mathrm{~b}$, nine, side.

Figure $34 \mathrm{c}$, nine, front

Figure $34 \mathrm{~d}$, nine, tendon, bent. Figure 34 e, nine, tendon, side.

Figure $34 \mathrm{f}$, nine, tendon, front

(p. 55) Figure 35 a, ten, bent

Figure $35 \mathrm{~b}$, ten, side.

Figure $35 \mathrm{c}$, ten, front.

Figure $35 \mathrm{~d}$, ten, tendon, bent.

Figure 35 e, ten, tendon, side

Figure $35 \mathrm{f}$, ten, tendon, front.

(p. 56) Figure 36 a, tendon five, bent Figure $36 \mathrm{~b}$, tendon five, bent back. Figure $36 \mathrm{c}$, tendon five, side.

Figure $36 \mathrm{~d}$, tendon five, front.

(p. 57) Figure 37 a, eleven, bent. Figure $37 \mathrm{~b}$, eleven, side. Figure $37 \mathrm{c}$, eleven, front (p. 57) Figure 38 a, twelve, bent. Figure $38 \mathrm{~b}$, twelve, side.

Figure $38 \mathrm{c}$, twelve, front

(p. 58) Figure 39 a, thirteen, bent. Figure $39 \mathrm{~b}$, thirteen, side. Figure $39 \mathrm{c}$, thirteen, front. (p. 58) Figure 40 a, fourteen, bent. Figure $40 \mathrm{~b}$, fourteen, side. Figure $40 \mathrm{c}$, fourteen, front. (p. 59) Figure 41 a, fifteen, bent Figure $41 \mathrm{~b}$, fifteen, side.

Figure $41 \mathrm{c}$, fifteen, Front.

Figure $41 \mathrm{~d}$, fifteen, broken tendon.

(p. 60) Figure 42 a, sixteen, render. Figure $42 \mathrm{~b}$, sixteen, physical.

(p. 60) Figure 43 a, sixteen A, front Figure $43 \mathrm{~b}$, sixteen $\mathrm{A}$, angled. (p. 60) Figure 44 a, sixteen B, front. Figure $44 \mathrm{~b}$, sixteen $\mathrm{B}$, angled.

(p. 61) Figure 45 a, seventeen, bent. Figure $45 \mathrm{~b}$, seventeen, side.

Figure $45 \mathrm{c}$, seventeen, front.

Figure 45 d, seventeen, broken detail.

Figure 45 e, seventeen, tendon exiting point.

Figure $45 \mathrm{f}$, seventeen, injection point.

(p. 62) Figure 46 a, eighteen, bent.

Figure 46 b, eighteen, side.

Figure $46 \mathrm{c}$, eighteen, front.

Figure $46 \mathrm{~d}$, eighteen, tendon support.

Figure 46 e, eighteen, tore section.

Figure 46 f, eighteen, stint stuck.

(p. 63) Figure 47 a, tendon six, render. Figure $47 \mathrm{~b}$, tendon six, physical.

Figure $47 \mathrm{c}$, tendon six, side view.

Figure $47 \mathrm{~d}$, tendon six, close up detail. 
(p. 64) Figure 48 a, nineteen A, bent. Figure 48 b, nineteen A, slightly bent. Figure $48 \mathrm{c}$, nineteen $\mathrm{A}$, side.

Figure $48 \mathrm{~d}$, nineteen $\mathrm{A}$, front.

(p. 65) Figure 49 a, nineteen B, side bent. Figure 49 b, nineteen $B$, side.

Figure 49 c, nineteen B, front.

Figure 49 d, nineteen $B$, tendon brake.

(p. 66) Figure 50 a, Lubrication water, dry.

Figure 50 b, Lubrication water, wet.

(p. 66) Figure 51 a, Lubrication water, submersion.

Figure 51 b, Lubrication water,

submersion.

(p. 66) Figure 52 a, Lubrication water, injected.

Figure 52 b, Lubrication water, injected.

(p. 67) Figure 53 a, Lubrication

ArmorAll dry.

Figure 54 b, Lubrication Armor-All wet.

(p. 67) Figure 54 a, Lubrication

ArmorAll, submersion.

Figure 54 b, Lubrication Armor-A1l, submersion.

(p. 67) Figure 55 a, Lubrication

ArmorAll, injected.

Figure 55 b, Lubrication Armor-All, injected. (p. 68) Figure 56 a, twenty, bent Figure 56 b, twenty, side.

Figure $56 \mathrm{c}$, twenty, top.

(p. 68) Figure 57 a, fingertip test, angled. Figure 57 b, fingertip test, side.

Figure $57 \mathrm{c}$, fingertip test, front.

(p. 69) Figure 58 a, twenty-one, side

bent.

Figure 58 b, twenty-one, side.

Figure $58 \mathrm{c}$, twenty-one, top.

Figure $58 \mathrm{~d}$, twenty-one, tear on the side.

(p. 70) Figure 59 a, twenty-two, side bent.

Figure 59 b, twenty-two, side.

Figure 59 c, twenty-two, top.

Figure 59 d, twenty-two, detail of brake.

(p. 71) Figure 60 a, watertight, in water. Figure 60 b, watertight, no water.

Figure 60 c, watertight, close up no

water.

Figure 60 d, watertight, close up water.

(p. 72) Figure 61 a, twenty-four, one tendon.

Figure $61 \mathrm{~b}$, twenty-three, both tendon.

Figure $61 \mathrm{c}$, twenty-three, side.

Figure $61 \mathrm{~d}$, twenty-three, top. (p. 73) Figure 62 a, A \& B, food colouring.

Figure 62 b, A \& B, food colouring.

(p. 73) Figure 63 a, C, food colouring. Figure 63 b, C, food colouring.

(p. 73) Figure 64 a, D, acrylic.

Figure 64 b, D, acrylic.

(p. 74) Figure 65 a, twenty-four, bent. Figure 65 b, twenty-four, side.

Figure 65 c, twenty-four, top.

Figure 65 d, twenty-four, tear.

(p. 75) Figure 66 a, twenty-five, bent.

Figure 66 b, twenty-five, about to pull.

Figure 66 c, twenty-five, side.

Figure 66 d, twenty-five, top.

(p. 76) Figure 67 a, twenty-six, bent.

Figure 67 b, twenty-six, side.

Figure 67 c, twenty-six, top.

Figure 67 d, twenty-six, tear.

(p.77) Figure 68 a, twenty-seven, broken detail.

Figure 68 b, twenty-seven, side.

Figure 68 c, twenty-seven, top.

Figure 68 d, twenty-seven, internal detail. 
(p. 78) Figure 69, lubrication, stent. (p. 78) Figure 70, lubrication, liquid entrance path.

(p. 79) Figure 71, all tests, render.

(p. 83) Figure 72, human, coming to life.

(p. 84) Figure 73, human, touch

(p. 84) Figure 74, human, emerging.

(p. 84) Figure 75, human, berth

(p. 84) Figure 76, human, skin.

(p.85) Figure 77, creature, it's alive.

(p.86) Figure 78, creature, first contact. (p.86) Figure 79, creature, coming for you.

(p.86) Figure 80, creature, growing from that depths.

(p.86) Figure 81, creature, coming for you in the dark.

(p.100) Figure 82, body world, tendons. (p.100) Figure 83, body world, bone \& blood.

(p.100) Figure 84, body world, no skin.

(p.101) Figure 85, existing models, renders of hand

(p.101) Figure 86, making process, casting of the face. (p.102) Figure 87, eyes on hand, drawing.

(p.103) Figure 88, cleaning, removing the support material.

(p.103) Figure 89, printing process, on

the print bed.

(p.103) Figure 90, printing process, detail of support lattice pattern.

(p.103) Figure 91, printer, print head. 
Introduction. 
The demand for elaborate props in 'out-of-this-world' concepts has gained popularity. To this day, props have been produced in a similar way to how they were back in the 1900s, using an assembly of connected parts. Advancement of Computer Numerical Control (CNC) machinery and 3D printing has allowed for techniques and detail that were not possible by hand. These technologies have functioned as a mechanism for rapid prototyping; however, traditional assembly of multiple parts remains. Computer-generated images (CGI) has allowed filmmakers to make characters and objects on screen that are so elaborate that it would be impossible to fabricate them by hand. However, the advancements of multiproperty full-colour 3D/4D printing may allow these digital creatures to extend out of the screen and become physical.

This research will explore the new technology of three dimensional (3D)/ four-dimensional (4D) dynamic printing with the use of multiproperty materials that can be combined to form both a soft and rigid model in one print. This technology will be applied to the film industry in the production of puppeteered props or for medical simulation. This research portfolio argues, through iterative design experiments, that future prop makers may use a heterogeneous printing technique, where multi-property $3 \mathrm{D} / 4 \mathrm{D}$ printing technology replaces the assembly of parts.

3D printing started to appear in the industry as a way to create rapid prototype designs to be assessed and developed. However, the full potential of 3D/4D multi-property printing in this field is yet to be fully explored. This research portfolio will follow the idea of heterogeneous 3D printing in the creation of a finger, aiming to take all the parts that make up the human finger/knuckle joint and combine them into one print that does not need assembling. The definition of heterogeneous is different kinds, degrees, or dimensions within a group. Multi-property dynamic printing allows for heterogeneity to occur as it can combine different elements; in this case, material properties.

Projects from Victoria University of Wellington and Massachusetts Institute of Technology (MIT) 3D lab have looked at how filmmakers, costume or product designers, may be able to use multi-material 3D printing technology to produce 4D moveable objects with emotion. Nonetheless, 3D multi-property printing has yet to explore the possibilities of humanoid recreation with minimal cleaning, where the outcome is produced in one versatile piece.

This research portfolio aims to create new knowledge about how 3D/4D multi-property printing can affect the way movable props are manufactured by reducing the amount of time a design is constructed and the steps needing to be completed ready for the film industry. From this, the research portfolio question is: What could multi-property, 3D/4D printing bring to the way the film prop manufacturing industry creates physical props?

This research portfolio will use the Stratasys J750, polyjet, fullcolour printer to produce a finger, utilising the ability to print hard and soft materials in one design. The research will focus on the potential of creating a heterogeneous anatomical object through the use of an iterative Research Through Design methodology and the four D's plan. 


\section{Definitions.}




\section{D printing,}

The manufacturing process, where layer by layer of material is placed to form into a physical object.

\section{D printing,}

The combination of 3D printing with materials that can move and change form through touch or change of environment.

\section{CAD- Computer-Aided Design,}

The use of computer software in the design of an object.

\section{Stratasys,}

A 3D manufacturing/printing company based out of America and Israel.

\section{J750 Polyjet printer,}

A six cartridge 3D printer manufactured by Stratasys, which can print in soft, hard and full-colour resin in high detail that is cured by ultraviolet light.

\section{Shore Hardness,}

A value given to the ratio of Vero and Agilus material when combined, the higher the number the more rigid material, form 30 (soft) to 95 (almost hard).

\section{Agilus,}

The soft and flexible (now stronger) material by Stratasys (Shore Hardness 30).
Vero,

The hard rigid material by Stratasys.

\section{CGI- Computer Generated Imagery,}

Special effects constructed by a computer.

\section{Heterogeneous,}

Diverse in the sense of a large and varied collection, a range of different items or materials in one group.

\section{Humanoid,}

Resembles a human without actually being one. 
Research Overview. 


\section{Aims \& Objectives.}

Aim 1, Form the research foundation. Investigate the current use of human anatomy in the creation of physical models and character enhancements in the prop manufacturing industry:

a) Analyse the way muscles, bones, ligaments, fat and skin create the body through the use of medical information, observation and literature experiments.

b) Investigate the art of prop manufacturing and how emotions are created by assessing videos and literature.

c) Create design criteria that will be used to assess the final output against what is required from a film or TV prop.

Aim 2, Creating design activities. Explore the capabilities of multi-property, colour 3D printing in the production of dynamic, anatomical finger joint for film. To create an iterative prop efficiently, that can be easily adapted into different forms:

a) Conduct material testing through iteration and assessment to determine which combination of hard and soft materials performs equivalent to human anatomy.

b) Create prototypes in response to material testing focusing on the cleaning, tolerance, lubrication, stents, colour, and tension/contraction impact on the surface texture.

c) Film prototypes from testing, evaluation to determine the success of material combination and how they perform when manipulated. Make progressive changes to the CAD model according to the experiments. 
Part 1.

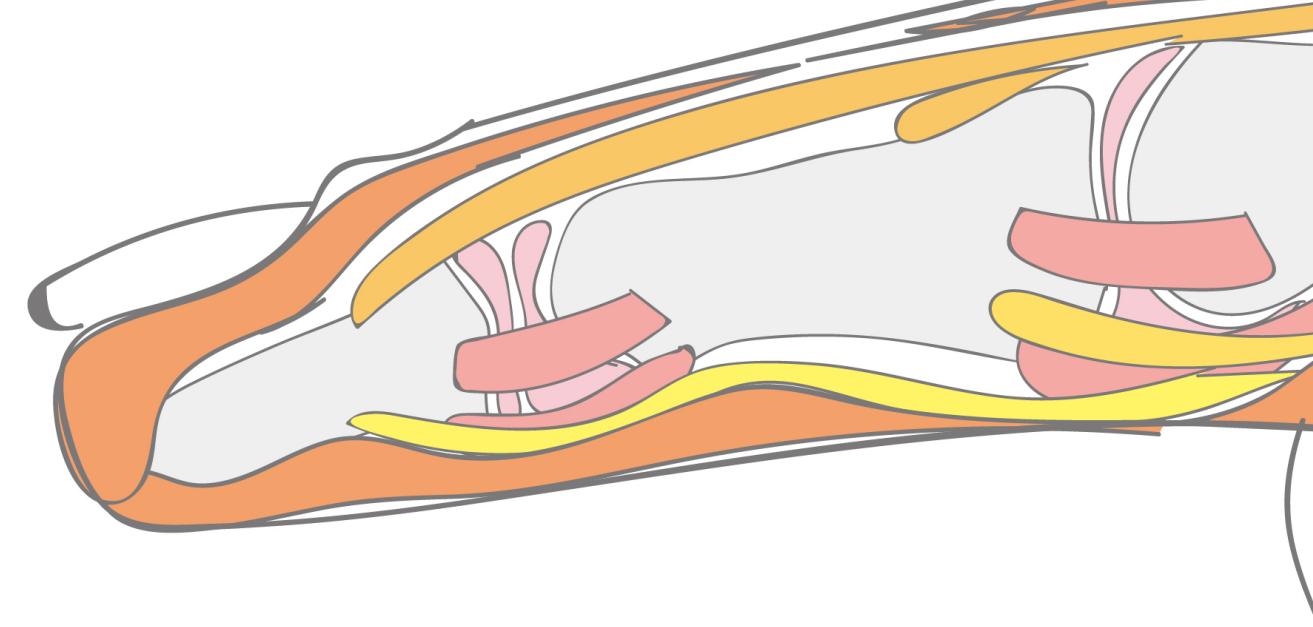




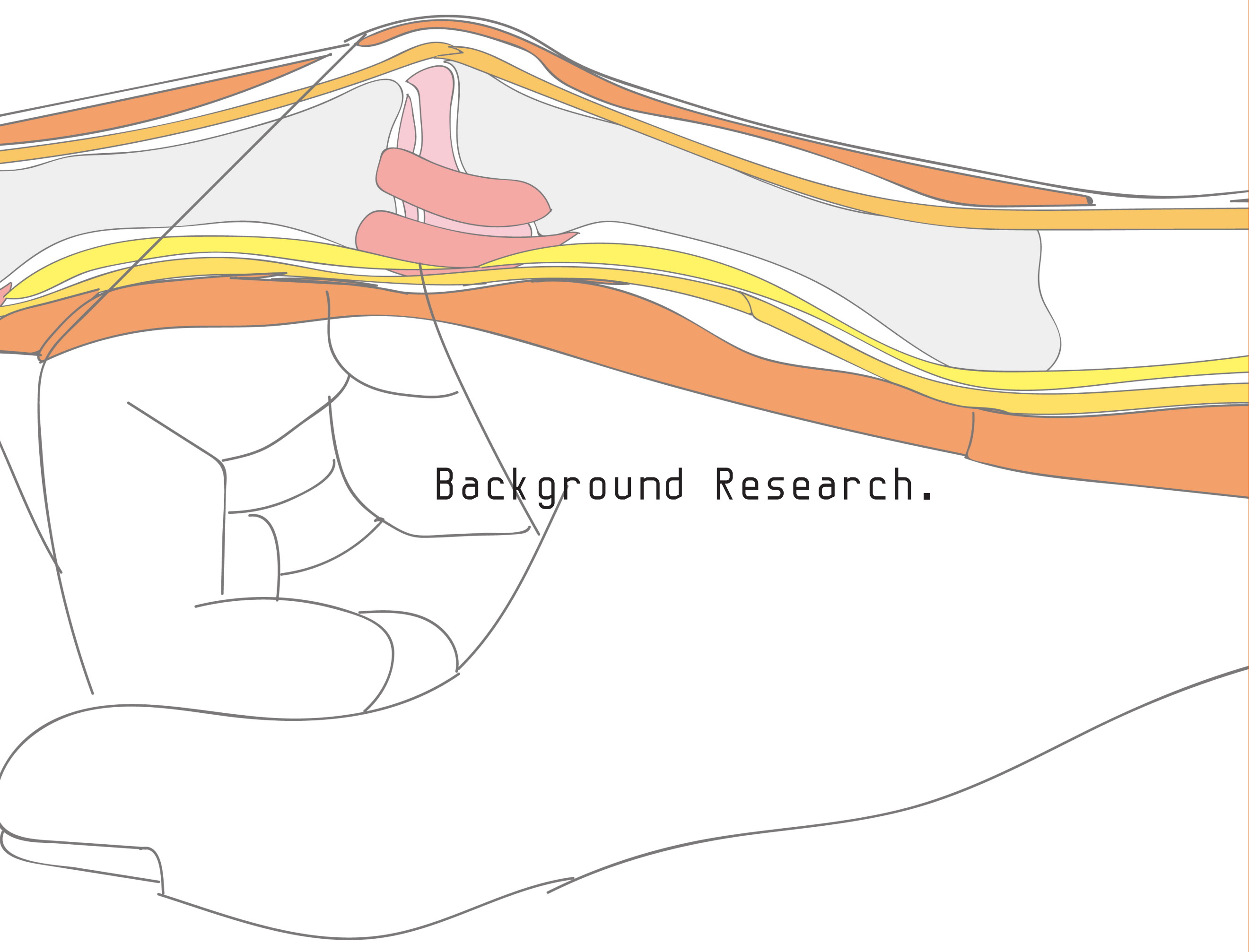


1.1 Background and Precedent Review. 


\section{Introduction.}

This research portfolio will provide information gathered from text, images, videos and past projects related to the topic in which this research is looking to study. The question this research aims to answer is: What could multi-property, $3 \mathrm{D} / 4 \mathrm{D}$ printing bring to the way the film prop manufacturing industry creates physical props?

\section{Anatomy of a Finger.}

As this research aims to use additive manufacturing technology in the recreation of human anatomy, an area of the body needs to be selected. Printing a full body even to a small scale would be overly ambitious for this research portfolio. As this project aims to create a movable 3D print, the decision was limited to joints. Due to the constrictions of print bed size, the middle finger was chosen. The middle finger is an essential part of the hand as it is the first contact when picking up an object and can portray emotive qualities. A finger is a simple joint with multiple elements that control fine motor movements and grip.

Six main material groups make up a finger. These are the bones, cartilage, ligaments, tendons, muscles, fat and skin. Most of these elements have been well established for many years but were only officially documented and expanded on by Leonardo Da Vinci in 1486 (Clayton, Phiol, 2012). Da Vinci performed many autopsies in the hope to establish how the internal structures of the human
This background review will cover information from past resources that will aid in the knowledge of the anatomy of a hand/finger joints, additive manufacturing, three-dimensional (3D) multi-material printing and four-dimensional (4D) dynamic printing. It will also explore prop manufacturing and the creation of a computergenerated image (CGI) and the Uncanny Valley. This project will look at how these elements might affect the outcomes.

and animal bodies work. Being an artist, Da Vinci was able to document his findings through highly detailed drawings which have allowed people to understand anatomy better. Today, these illustrations can still be viewed in Clayton \& Phiol's (2012) book 'Leonardo Da Vinci: Anatomist' while the Royal Collection Trust holds the original drawings.

The work that has been carried out by Leonardo Da Vinci, and many scientists after, are widely available for public consumption. Readings, drawings and videos all contain information built upon by the earlier workings of Da Vinci. Websites such as Inner Body (Inner Body, n.d), Hand Anatomy Animated Tutorial video (Sechrest, 2012) and books such as The Scientific Bases of Human Anatomy (Oxnard, 2012) document the complete workings of human anatomy. These collective resources inform the following information. 


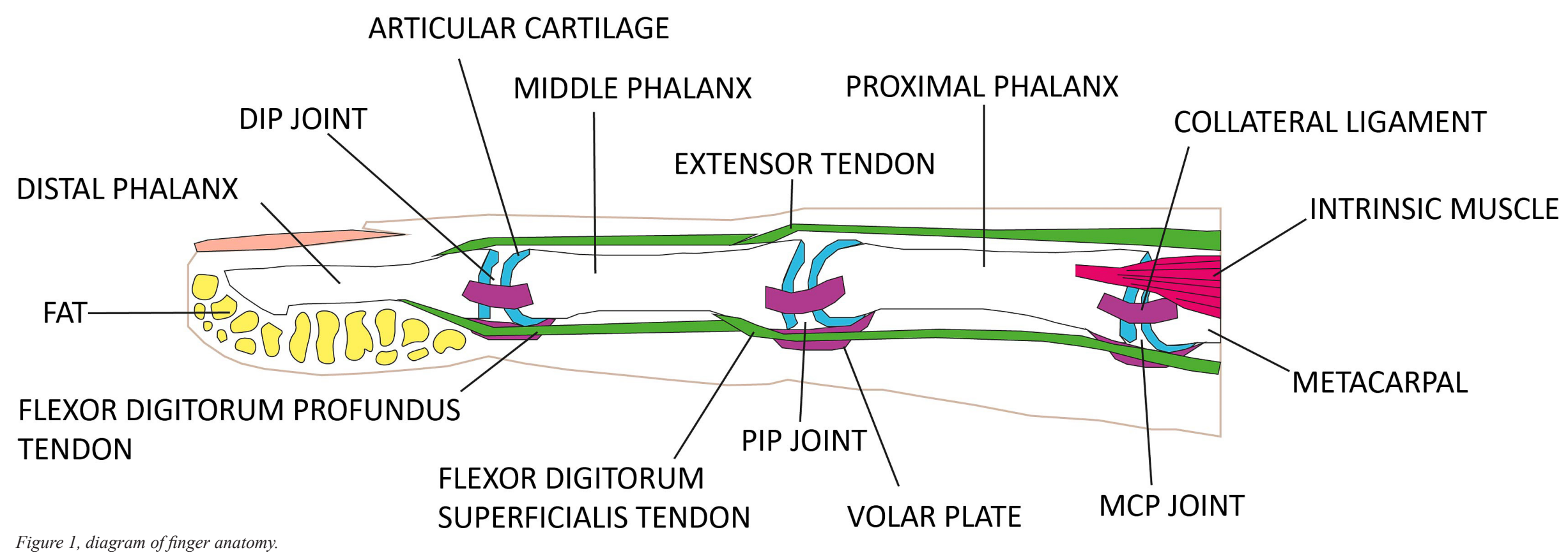




\section{Structure (Bones).}

The workings of a finger begin with the bone. A single finger is made up of four bones; three phalanges and one metacarpal found in the palm connecting to the wrist and forearm bones. A single-digit is made up of three joints, as shown in Figure 1. The metacarpophalangeal joint (MCP), located between the metacarpal and the proximal phalanx. The proximal interphalangeal joint (PIP), which lies between the proximal and middle phalanx and the distal interphalangeal joint (DIP), found between the middle and distal phalanx (Sechrest, 2012). This research portfolio will focus on the MCP joint or knuckle, which is a condyloid joint. The condyloid joint works similar to a ball and socket but the two bones are ovalshaped resulting in constricted movement side to side.

\section{Moving Surfaces/ Lubrication (Cartilage).}

Every bone that comes in contact or rubs against another bone has articular cartilage. The purpose of cartilage is to provide a soft, smooth surface which works to reduce the amount of friction that would occur if the two or more bones were to rub together. Cartilage works alongside the water (lubrication) that is supplied to the joints via the vascular system to produce a smooth, pain-free movement. If this is damaged or worn down, it can cause damage to brittle bones and pain, commonly known as arthritis (Maroudas, Bullough, Swanson, Freeman \& M. A. R., 1968).

\section{Flexible Connectors/Alignment (Ligaments).}

The main elements that hold each bone in place are the ligaments. These three ligaments are bands of tough, elastic, fibrous connective tissue. The collateral ligaments are on either side of the bone, which can be seen in Figure 2. The volar plate is positioned on the palm side of the joint and blocks the finger from hyperextending. Each volar plate has a tendon holder that allows for the tendon to move while keeping it flush to the joint. The extensor hood, which is made up of similar materials, attaches to the collateral ligaments and holds the extensor tendon in place.

\section{Actuation Cables (tendons).}

The finger movement is controlled by three tendons that connect to the muscles in the forearm. Each tendon is connected to a different place in the middle and distal phalanx. The tendons are the main controls for the grip and extension of the fingers. There is one tendon on the dorsal side (back of the hand) and two on the palmar side (palm).

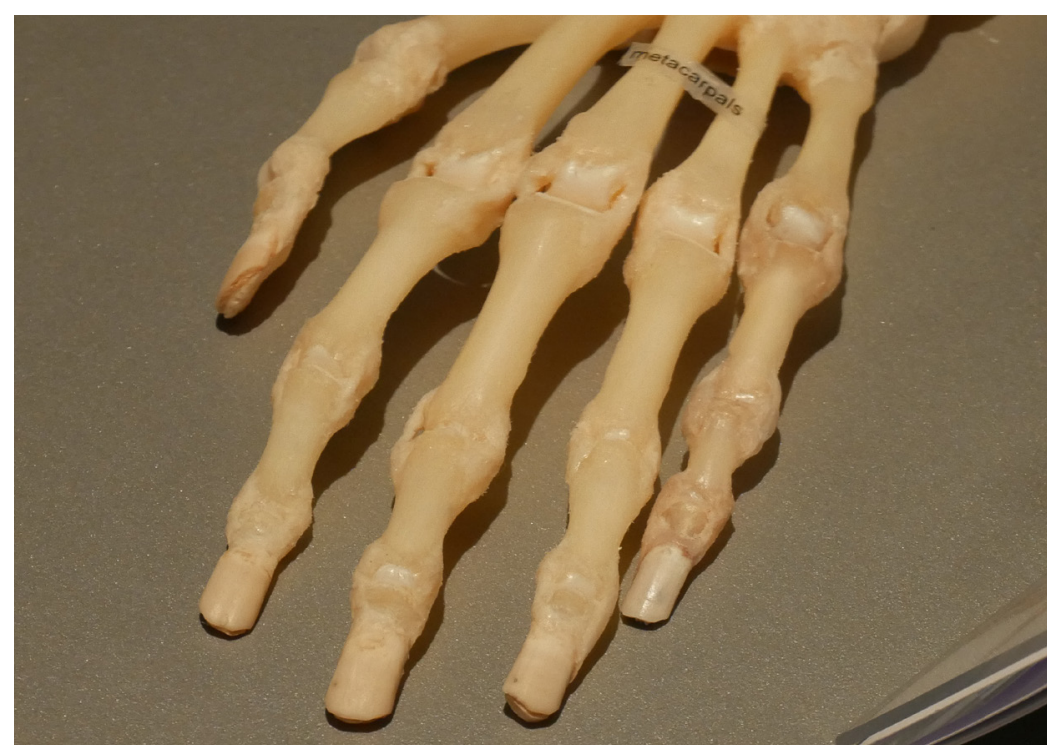

Figure 2, human skeleton. 


\section{Movement (Extension).}

The tendon on the dorsal side is called the extensor tendon and controls the straightening of the finger joints. This tendon has two connection points, one on the distal phalanx and the other on the middle, where the tendon splits into two sections depicted in green in Figure 1.

\section{Movement (Flexion/Grip).}

The two flexor tendons, found on the palm side, overlap one another. The tendon closer to the bone is the flexor digitorum profundus connected to the distal phalange. The tendon superficialis, which connects to the middle phalange, shown in green in Figure 1. Both tendons direct the closing of the fingers and grip strength. Along the bone on the palm side are other connection points that hold the two tendons in place.

\section{Actuators (Muscles).}

The only muscles found in the hand/ fingers are two intrinsic muscles placed on either side of each metacarpal bone in the palm. Both muscles connect to the extensor hood and control the side to side action at the knuckle joint.

\section{Feeling and Lubrication (Nervous System/ Blood supply).}

Within the hand and fingers, several nerve responders send information to the brain when items are touched, or damaged. The hands have some of the most sensitive nerve responders to pain and texture in the body. Alongside the nervous system is the blood supply. This transports blood through the veins, demonstrated in Figure 3. Its purpose is to provide adequate heating, lubrication and oxygen to the fingers.

\section{Protection and Shock Absorbers (Skin/Fat).}

All of these internal workings are housed within a layer of fat Working as shock absorption, fat creates a soft cushioning so that the bones do not shatter when contact is made. The skin is a protective layer that forms wrinkles and creases around joints which stretch the skin over the internal workings. Three layers of the derma surround the fat. The epidermis is the outermost layer of skin. The second layer is the dermis which is made up of tough connective tissue, hair follicles and capillaries where the deeper hypodermis tissue is a combination of fat and connective tissue.

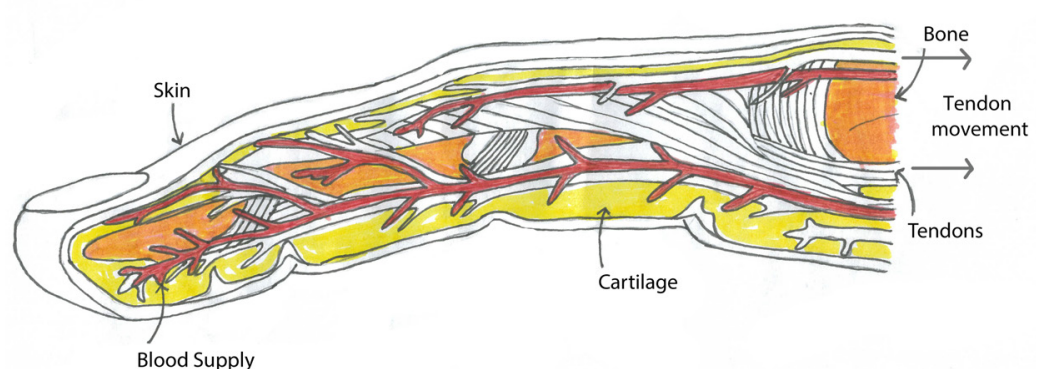

Figure 3, diagram of blood supply, fat and tendon movement. 


\section{Additive-Manufacturing.}

With the proposition for heterogeneous printing, additive manufacturing will play a vital role in the production of the final designs. Three dimensional (3D) printing was initially used for the creation of toys or proof of concept prototyping (Tibbits, 2014). The idea of 3D printing through the use of Fused Deposition Modeling (FDM) printing, where a material is heated up and placed layer by layer, was created by Scott Crump in 1988. He was the co-founder of the company Stratasys, which later merged with Objet (Lonjon, 2017). The design was patented to be then developed by Stratasys once the technology developed.

FDM printers quickly became the most popular printing method. However, almost all of the printing up until the last ten years have been mono-material. Nadernezhad, Khani, Skvortsov, Toprakhisar, Bakirci, Menceloglu \& Koc, (2016) states that "current fabrication methods are mostly limited to one type of material or only provide one type of functionality"(p. 1). What is developed is very limited in its abilities. With mono-material printing, the material is usually hard, rigid plastic or resin. It is mainly used to create static objects or to replace parts of other designs. The main limitations for FDM printing are the restriction in materials used, how these materials perform, and that high-quality prints are challenging to achieve without wasting materials on testing which can be pricey as each two-kilogram roll cost from $\$ 50$ upwards. These printers also use the same material for the printing support, which results in the support material occasionally becoming stuck, making it difficult to remove

\section{Multi-material.}

To combat the problems with FDM printing, high detail Polyjet technology was developed in 2000 by the Israeli company Objet Geometries, which merged with Stratasys in 2012 (Hurst, N., 2012). Polyjet printing combines a printhead that produces 14 or 28-micron droplets of liquid photopolymers into thin layers, cured by bright UV light. This style of printing allows for multi-property manufacturing, as demonstrated in Figure 4, where black flexible material is combined with hard white material. More recently, the ability to print in full-colour has allowed 3D printing to be realistic representations of the desired product. With this technology, it results in little to no post-production besides the removal of the soft gel-like support material.
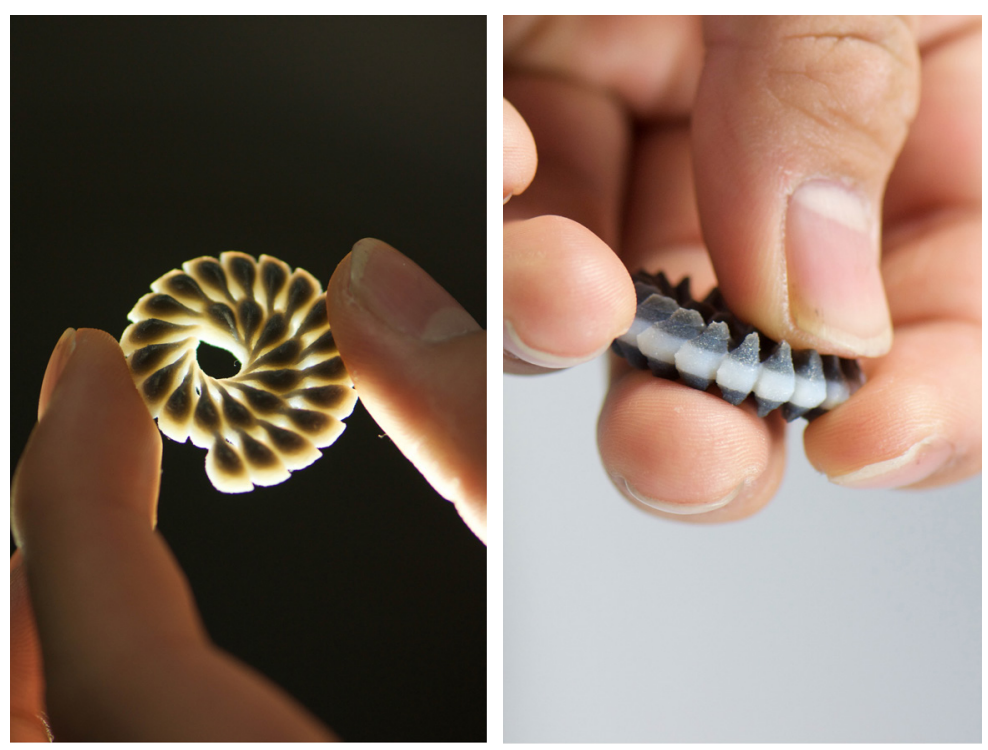

Figure 4, multi-property print. 
Stratasys has been improving their technology with the recent release of the $\mathrm{J} 750$ and $\mathrm{J} 735$ that can print in vibrant full-colour high detail with the stronger flexible Agilus material. Lipson \& Hurman (2013) discuss how multi-material Polyjet printing is " ideal for industrial or medical applications, where 'high-resolution' shapes and fast printing can be mission-critical" (p.70). Rapid production through the use of 3D printing has allowed for easy prototyping in hours rather than days. Nonetheless, all technology has limitations. Polyjet printers are big, use specialised materials and are extremely expensive. Additionally, the hard material is relatively brittle with the soft being prone to tearing. With the fragile nature of the materials, Stratasys has been working on a new, robust and flexible material Agilus which bonds better to itself and other harder elements.

When creating designs for any Polyjet printer, it is essential to consider how the orientation of printing will affect the longevity and fragility of an object. Das, Ranganathan \& Murugan, (2018) tested the effect of build orientation on the strength and cost of polyjet 3D printed parts. They determined how the print placement will affect the brittleness of a test swatch. Test swatches were created and placed on three different axes X, Y and diagonal, in either a flat or upright position, as demonstrated in Figure 5. By studying the microstructure of the swatches, the team revealed that there were many cracks or voids along the structure, resulting in the material not bonding to itself properly.

Printing along the $\mathrm{X}$-axis in a flat position is the most successful. Das, Ranganathan \& Murugan (2018) states that "the cracks/voids are parallel to the direction of application of force" (p.838), so they do not separate as easily. This orientation also minimizes material use and the build/manufacturing time.
When the material is blended with the hard Vero, the flexibility reduces as expected. Pure Agilus can withstand manipulation but has no colour, whereas Vero has full colour but no flexibility. What was found is that as the two blend together, the colour fades. This is where it is essential to conduct testing to determine the material structure. A test swatch will be produced in part two, experimentation section of this research portfolio.

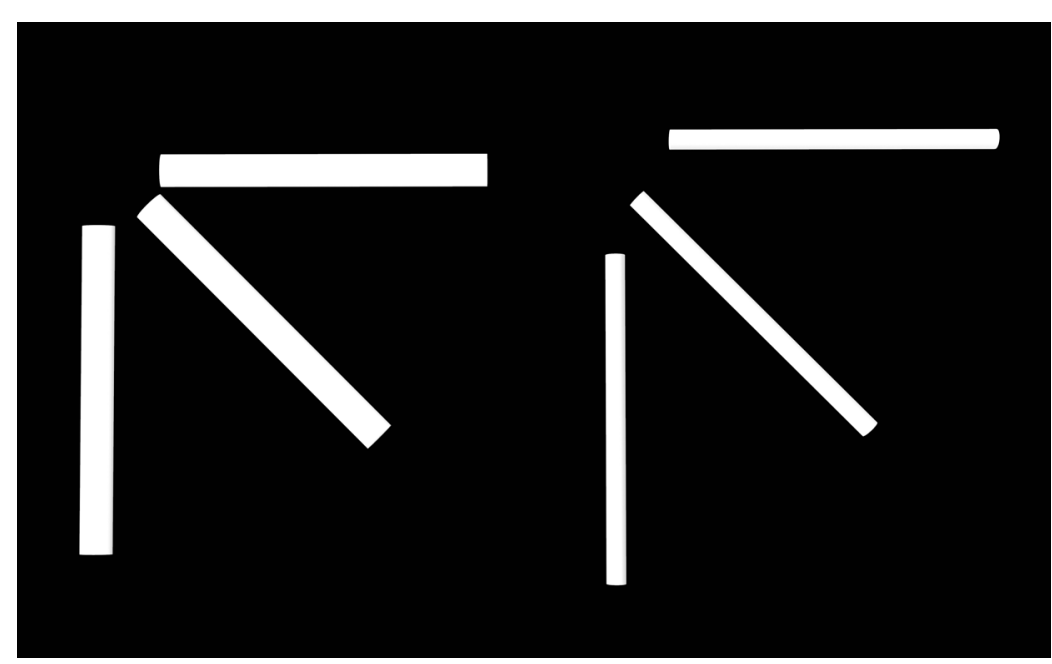

Figure 5, render of $3 D$ printed file in orientation. 


\section{Dynamic Printing projects.}

Currently, Massachusetts Institute of Technology (MIT), Victoria University of Wellington and Stratasys Ltd are at the forefront in the dynamic printing field. In regards to additive-manufacturing, the fourth dimension is described by Tibbits (2014) as the "transformation over time, emphasising that printed structures are no longer simply static, dead objects; rather, they are programmable active and can transform independently" (p.119). Tibbits is refining the smart materials that react to a change in environment, such as a temperature difference which is also talked about in Pei (2014) article.

Many of the 4D testings were done in water, where the water represents the changes in the temperature as well as changing the absorption rate of the material. The reactive material expands when exposed to a different environment resulting in dynamic movement. Dynamic in this context means constant change, activity, or progress. A change in shape, either independently or by interaction, is classified as a dynamic or $4 \mathrm{D}$ movement. Dynamic printing is not just limited to materials that change independently. 4D printing can be a change in shape by an external interaction from a human or another object. Pei (2014) article mentions the Kinematics Dress by Nervous System (2013) as it is an excellent example of dynamic movements due to being worn by a person. This project also shows how software programming can affect the way an object is printed by controlling the overall size of the final printed piece.

The Nervous System Kinematics dress is described on the Nervous System (2013) website as "composed of thousands of unique interlocking components, each dress is 3D printed as a single folded piece and requires no assembly" (p.1). The dress shows a new way of manufacturing by combining the ability of design, simulation, textile studies and digital fabrication to create a custom design of complex forms. Figure 6 is a representation of the interlocking design that was used for the final dress. A human is a $3 \mathrm{D}$ form where clothing is made out of two-dimensional pieces of fabric sewn together. One of the main issues with this idea was that a dress to fit a human, printed in one piece, would be too big for a standard printing bed. To combat this, Nervous System created the folding strategy through CAD software. This software allows for efficient fabrication of garments that are larger than a 3D printer bed, allowing for more flexibility in the size and shape of the dress.

Along with the creation of $4 \mathrm{D}$ clothing through the use of single material printing, one of the first projects to combine multi-property printing and dynamic movements from human interaction was Richard Clarkson's, Seamless Blossom.

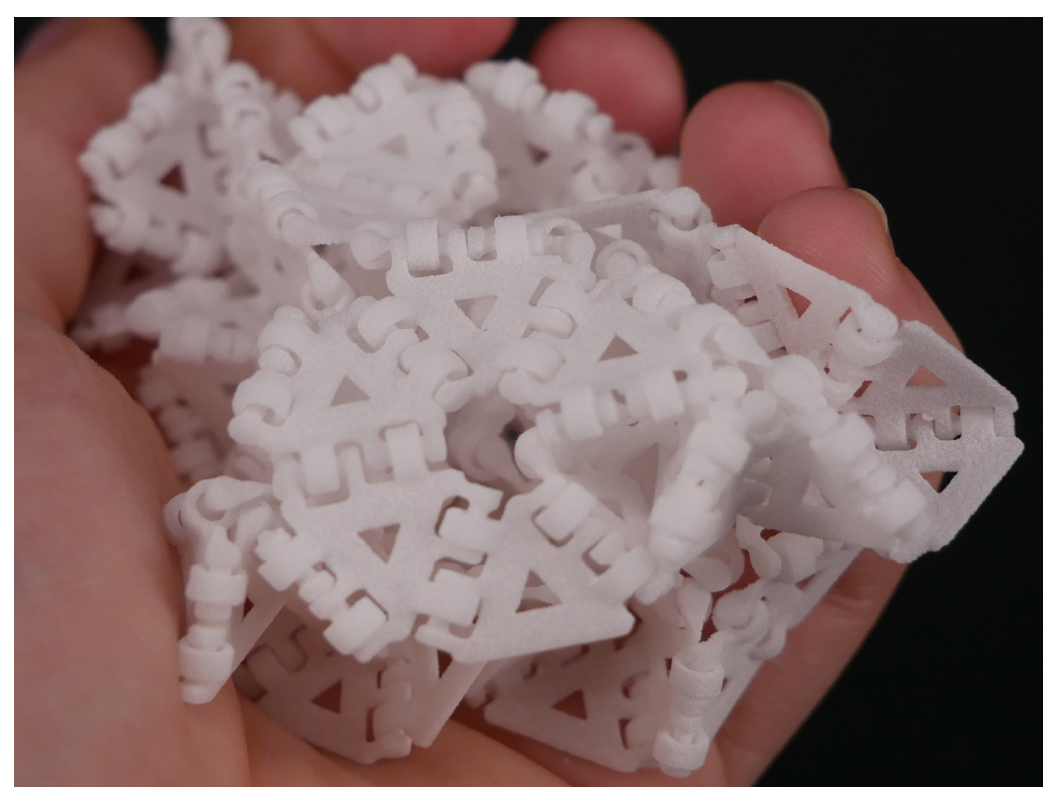

Figure 6, 3D printed pattern flattened out. 
Seamless Blossom was completed during the industrial paper Creative Digital Manufacturing at Victoria University of Wellington. The flowers show the ability to change shape through the combination of hard and soft elements when air is blown into the hollow cavity within the print as shown by the cross-section in Figure 7. Pei (2014) comments that "Clarkson's design consists of a hollow flexible chamber which is filled with air that inflates, causing the petal to react. However, perhaps, for now, time as the fourth dimension in $4 \mathrm{D}$ printing could refer to both paradigms" (p. 126). Blossom explores the blending of two materials with varying physical properties transitioning from flexible to rigid. The variation offers an opportunity to generate complex forms and dynamic structures that are difficult to make by any other means of fabrication.
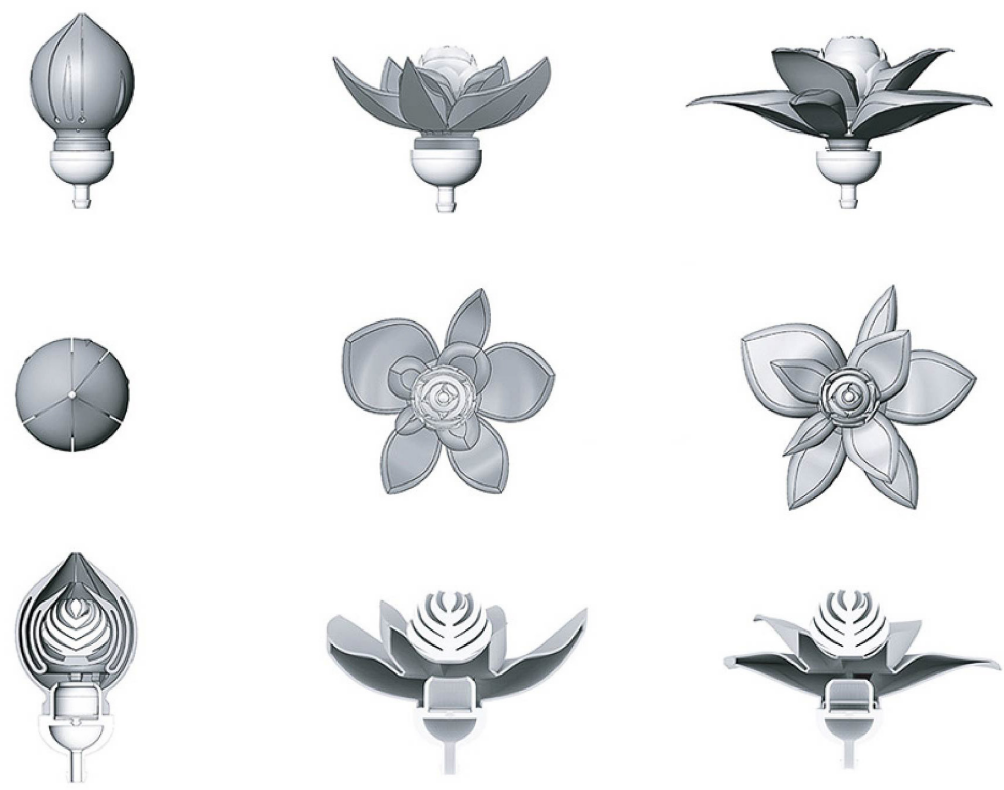

Figure 7, ross section renders of the flowers, from Behance, Clarkson, R., (2012) Retrieved from https://www.behance.net/gallery/17513219/Blossom, Copyright 2019 by Richard Clarkson.

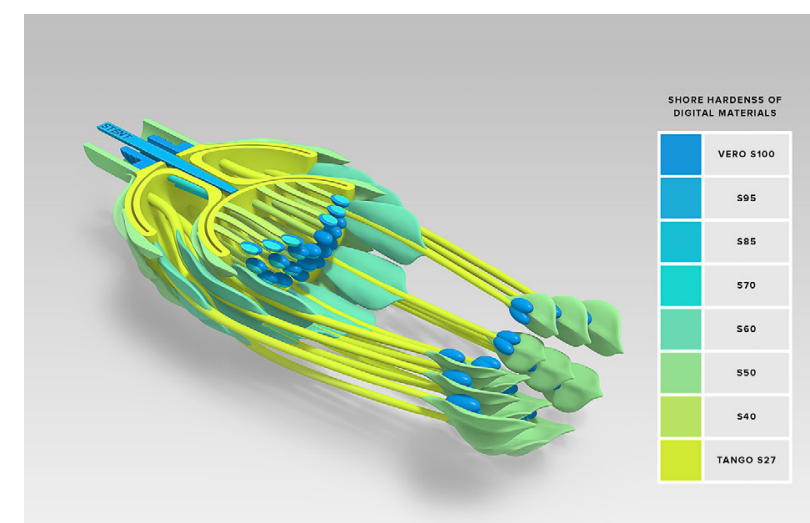

Figure 8, Cross section of Heaven flower with assigned material combination, from Nicole Hone industrial designer, Hone, N., (2018) Retrieved from, https://www.nicolehone.com/hydrophytes. Copyright 2019 by Nicole Hone.

Clarkson's project sparked widespread interest in the multiproperty printing field. A project that was recently created with the same idea but vastly improved was Nicole Hone's Tangible Animation research portfolio project. Her Hydrophytes creators exhibited 4D movement in a way that the creature appeared to be alive. This series of $4 \mathrm{D}$-printed futuristic aquatic plants and insects are as full of character as the natural organisms they mimic (Hone, 2018). Hydrophytes are activated similar to Seamless Blossom by pneumatic inflation in water, and transform into dynamic bodies that you could swear were alive (Hone, 2018). Figure 8 shows the material assignment and the complexity of the internal and external workings. What makes Hone's project different from others done before is the number of designs as well as her ability to create a sympathetic movement that was not fully defined. The way the soft and hard materials interact independently from the inflation with itself and the surrounds creates a mesmerizing change that was captured perfectly in the video she produced that can be found on her blog. 
With the ability to create movable creatures, such as Hone's Hydrophytes, there is also the capability to create extensions of human anatomy. Flexible Creature Prosthetic by Ross Stevens and Zach Challies (2017) looks at how the human index finger and thumb can be turned into a prosthetic for film by using the polyjet Agilus materials to create a second skin shown in figure 9. This design was used to test the durability of the Agilus material and how well it would move and form over human anatomy. What was found was that the material withstood many manipulations but did restrict movement.

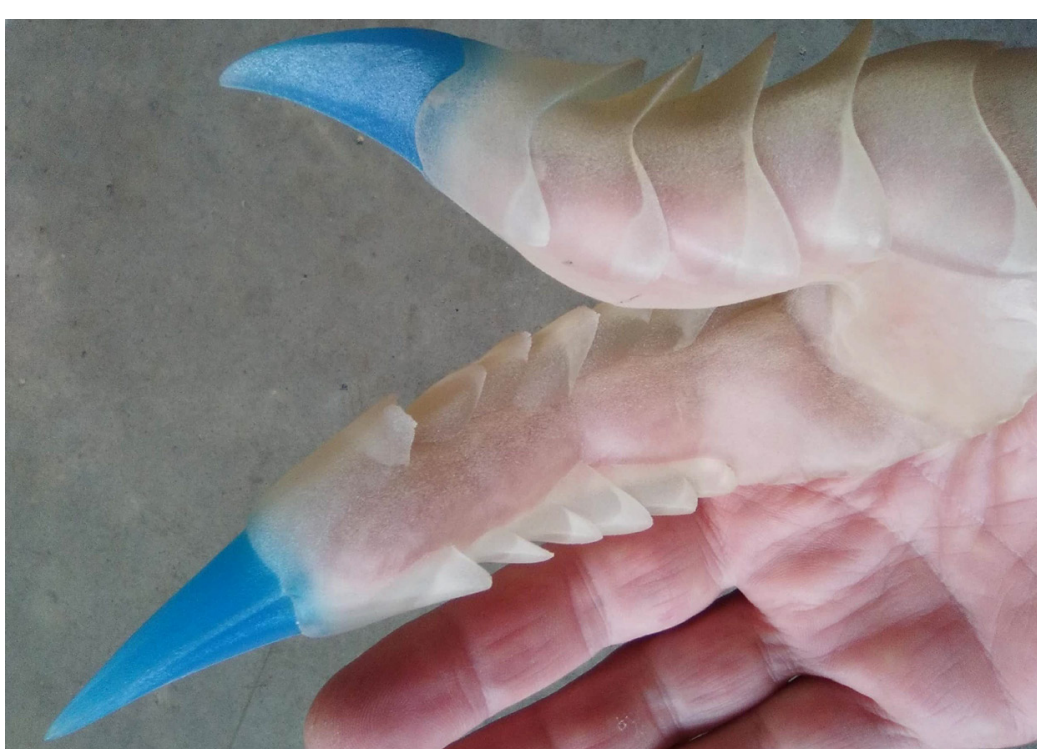

Figure 9, Flexible creature Prosthetic, Victoria University of Wellington, Challies, Z., \& Stevens, R. (2017) Copyright 2019 by Challies, Z., \& Victoria University of Wellington.

The main aim of this research portfolio is to take the ability to create a tough skin like form but build the internal mechanisms of the finger, so that is it a separate extension of the human hand rather than just a shell over top of the extremities. The ability to combine
Additive manufacturing technologies and 3D scanning or medical scanning has allowed for this technology to appear in the medical field. 3D Printing has started to appear in the creation of prosthetic limbs, experimental bioprinting and 3D printed organs (Lipson, \& Hurman, 2013). With this ability, 3D printing of anatomy can be related to the film industry as many of the physical props that appear in film need to interact with or be manipulated by a human. 3D manufacturing has been incorporated into the prop manufacturing industry by companies such as Weta Workshop as a way to rapid prototype props. This technology allows for efficient fabrication of test designs that will then be further developed into casts for the manufacturing process. However, both film and medical industries are not yet utilising the full capabilities of high detail multi-property printing.

\section{Prop Manufacturing.}

The manufacturing for entertainment prop first started with plays or live-action productions (Hart, E., 2012). This then developed into film and television (TV). It is hard to determine precisely the history of film as the definition is somewhat unclear. Film's started to appear for public consumption in the late 1800s, early 1900s. One of the most famous films from this time is A Trip to the Moon (Melies 1902). This iconic movie has intricately painted backgrounds, science fiction props and costuming that left audience stunned as this level of the craft had not been seen in theatres before. The incorporation of physical props has a significant role in defining the genre and aesthetic of a film. (Smuszkiewicz, Kwaśniewski, \& R. M. P, 1987). Props are essential for setting the scene, without props A Trip to the Moon would not have been as successful in the portrayal of space travel. 
The presence of props is not only crucial for the viewer but the actors as well. Without something to hold, see or interact with it can be very difficult for the actors to determine precisely how they should interact/react with the prop and the believability of a scene (Kaneria, R., 2015, October 26,). Traditionally prop manufacturing was conducted entirely by hand with physical labour in a workshop. Artists would paint, sculpt and mould designs for hours, with the whole process takes days or weeks to produce a final design. This style of making has changed very little over the last couple of centuries. Workshops such as Weta Workshop use techniques such as casting and sculpting very similar to how props were manufactured in the 1900s. The only significant changes are the materials used and the use of computer-controlled machinery. The incorporation of new technologies, such as automated machinery and 3D printing for rapid prototyping, has increased the productivity of the workshop and the iteration process has quickened due to the slight ease of making. This technology seems to mainly be used for the beginning stages of the making process as a form to rapid prototype so that multiple, sometimes expensive, casts do not need to be produced until the final design is chosen. Occasionally small prints will appear on the master props such as embellishments that could not be quickly produced traditionally.

\section{CGI.}

The film industry has started to shy away from mass physical prop manufacturing as it is costly, time-consuming and requires large numbers of people. The advances in processing technology computer-generated imagery (CGI) became a popular way to add props and characters into live-action films. CGI can create creatures without needing to build anything physical. Many physical props nowadays are used in the background were animating a large number would take longer than making the real objects; these are usually bulk designs in large, easy to produce amounts. This is shown in the way Whissel (2014) speaks about how the computergenerated or digitally enhanced viewers experience. "Visual effects that give spectacular expression to the major concepts, themes, anxieties, and desires both of the films in which they appear and of the historical moments in which they were produced" (p. 171) these help in the portrayal and overall feel of the film, making the story and characters more realistic and relatable to the audience. Avatar (2009) is an excellent example of the ability to blend the real with digital. The digital character with the high detailed backgrounds created a visually stunning movie. Many of the films that have been produced in the last 20 years use some form of CGI in the enhancement of the environment or character appearance. Gollum from Lord of the Rings is another example of the cross between the real character and digital creation.

CGI does have its limitations. One of the significant downfalls is that the characters or props are clearly CGI, mainly when the computer-generated image is low quality or poorly rendered. Some of the areas that are the most obvious were when a live-action actor needed to interact with a CGI prop or character. When the texture on the prop does not change with the contact from the actor or correct shadowing does not appear, it can cause a break in realism. Although CGI requires fewer people when compared to a workshop, it can result in a lack of connection between the audience and the story or characters. However, sometimes the CGI or animation can be so realistic it falls into the realm of the uncanny valley making audiences uncomfortable.

Rouse (2016) states that "The uncanny valley is a common unsettling feeling people experience when androids (humanoid robots) and audio/visual simulations closely resemble humans" (p.1). 


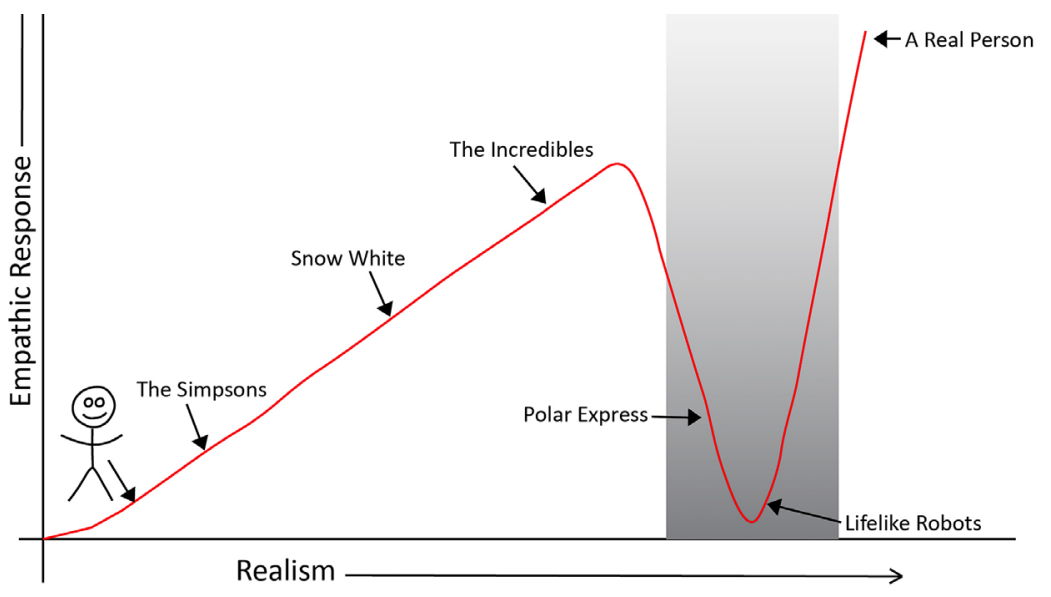

Figure 10, The uncanny valley, diagram.

The robotics engineer, Masahiro Mori first identified this concept of the uncanny valley in 1970 (Mayor, 2018). He talked about how humans can experience unease when animations or robotics look close to a human but does not fully encapsulate the correct features, which he explained in the graph depicted in Figure 10. Historically speaking, several movies and video games have fallen into the realm of the uncanny valley. One film in particular that came under scrutiny was Mars Needs Moms by Walt Disney pictures (Kim, 2017). The 3D animated movie made audiences uncomfortable as the animation was hyper-realistic while still having fantasy elements, such as the aliens. Some of the most popular characters that fall into the uncanny valley are ones such as zombies, corpses or hyper-realistic robots. The uncanny valley, however, can be avoided by changing proportions or features such as how the Navi in Avatar was created human-like but still very different.

\section{Conclusion.}

Understanding the history of the design and product is essential in the success of the final output. When creating a living design, having an understanding of basic anatomy is vital as proportions play a big part in the realism of a humanoid recreation. By analysing the various layers of materials, a rough blueprint can be created to determine what elements are essential to get a lifelike movement and appearance. The uses of additive manufacturing technology will enhance the ability to form the final design in one print by utilising the multi-property capabilities of the J750 printer. By assessing the past projects within the 4D printing field, an understanding of materiality and what aspects in the environment might affect the outcome resulting in more informed testing.

For this research, knowledge of prop manufacturing and props within the film industry is necessary. The final output will be situated in this industry and use the technique of puppetry in the creation of human-like movement. Props for entertainment have been in production for many years and mainly use the same methods now as they did back in the early 1900s. However, technologies such as CGI and 3D printing have been incorporated and more popular in the last 20 years. With the advancements of CGI and computergenerated objects that can be printed, the prop manufacturing companies have changed the way they design objects. However, the capabilities of 3D and 4D printing have yet to be fully explored by this industry. This research portfolio will digitally make and evaluate each layer of tissue, bone and ligament through the use of 3D software to create an adjustable knuckle joint of a finger. 
1.2 Methodology. 


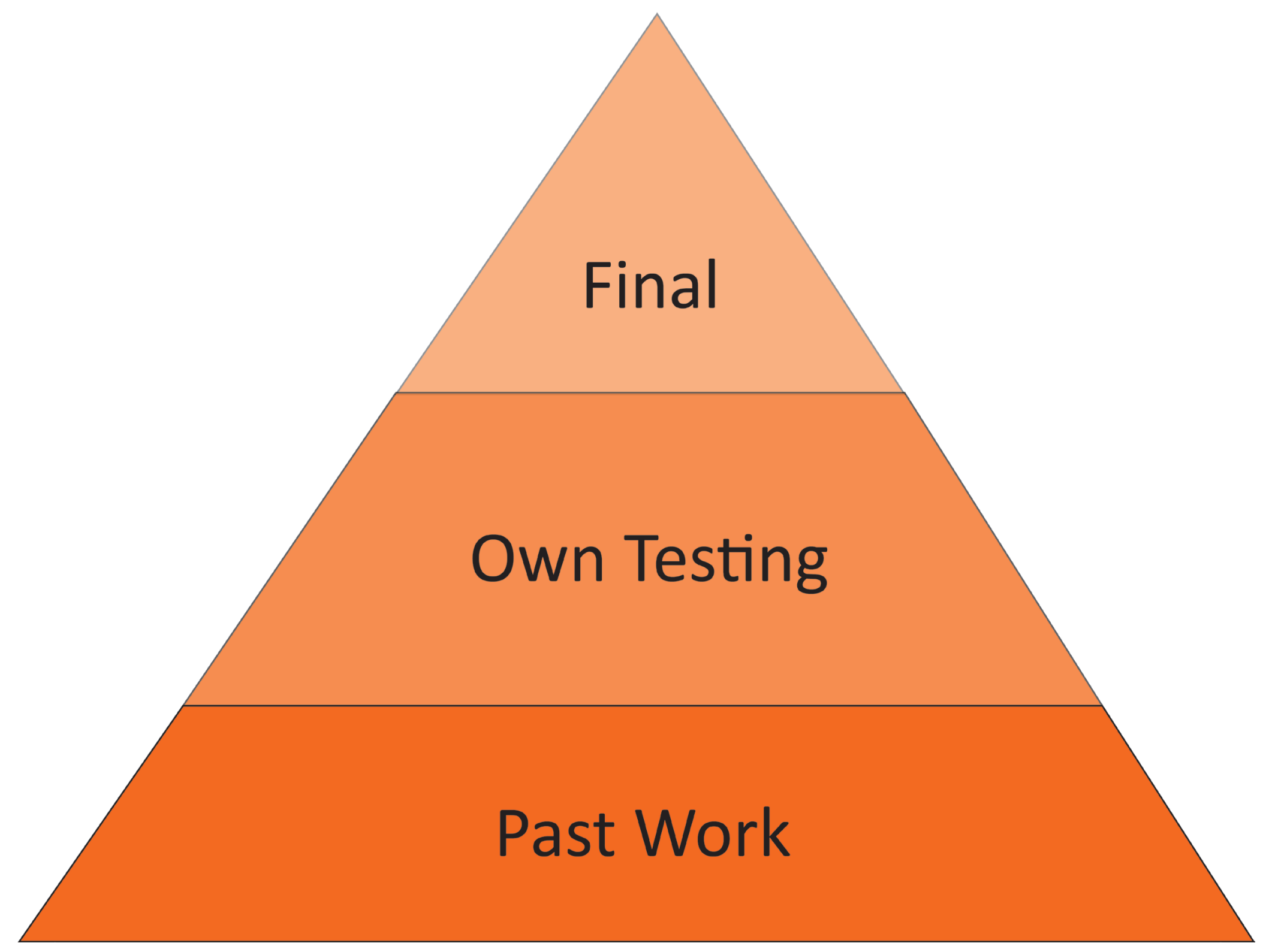

Figure 11, Research through design, diagram. 
To determine the area of study, and how it will fit into a specific industry, an understanding of past research in these fields is needed. An establishment of context is necessary through a background review to help in the creation of the final design materials as well as understanding the context in which the outcome will be placed. Both qualitative analysis and research through design will be used. Aim 1 shows the process needed to gain a theoretical understanding of human anatomy, the importance of each working part, and where prop manufacturing place in film creation. Particularly in regards to interactive props and creature design. Aim 2 shows how knowledge will be gained of the Stratasys J750 printer, and learn the best way to apply that knowledge to the Prop manufacturing industry. Both aims have aspects that integrate, allowing for information to crossover.

This research portfolio will use the overarching design research method, Research Through Design. As Frayling (1993) notes "Research always involves going over old territory, while art, craft and design are of course concerned with the new." (p.1) As a designer, it is crucial to create new products, but an understanding of past projects is essential. They influence the current designer's choices, reducing the potential for failure or repetition. By examining tools and previous processes, a connection between theory and building knowledge enhances the design practices (Martin \& Hanington, 2012).

Research through design follows a process of iterative design where new knowledge is gained from the response to the original product or interface through testing. This process follows a create and evaluate loop which has built upon prior knowledge and research conducted by the designer. Figure 11 shows that the previous work and designer tests support the outcome. One way to explain the process of research through design is Stone's (2010) design process which uses this technique of the four D's. This process looks at the steps taken to get a final product through the use of research in the early stages. The four D's are: discover, define, develop and deliver. Each step is broken down into two phases demonstrated in Figure 12.

This method of development is an efficient way for designers to work as it allows for research and evaluation of the product efficiently in the first stages of the product design. This research portfolio will use the collaborative method of Research Through Design and the four D's to digitally make a dynamic knuckle joint. 
Stage one, an establishment of the basic project parameters.

Stage two, the orientation of the design in the area it will appear, and background research is conducted. In this phase, the objectives and goals are clarified.

Stage three, the creation of the strategy of making and design approach.

Stage four, exploration and generated preliminary ideas phase, were the first concepts are evaluated.

Stage five, the development of first testings, further develop ideas, which are reviewed at the end of each test design and selection final design direction.

Stage six, the refinement of all testing and the final design approved for the next step.

Stage seven, the production of the final design.

Stage eight, the manufacture/launch of the final project.

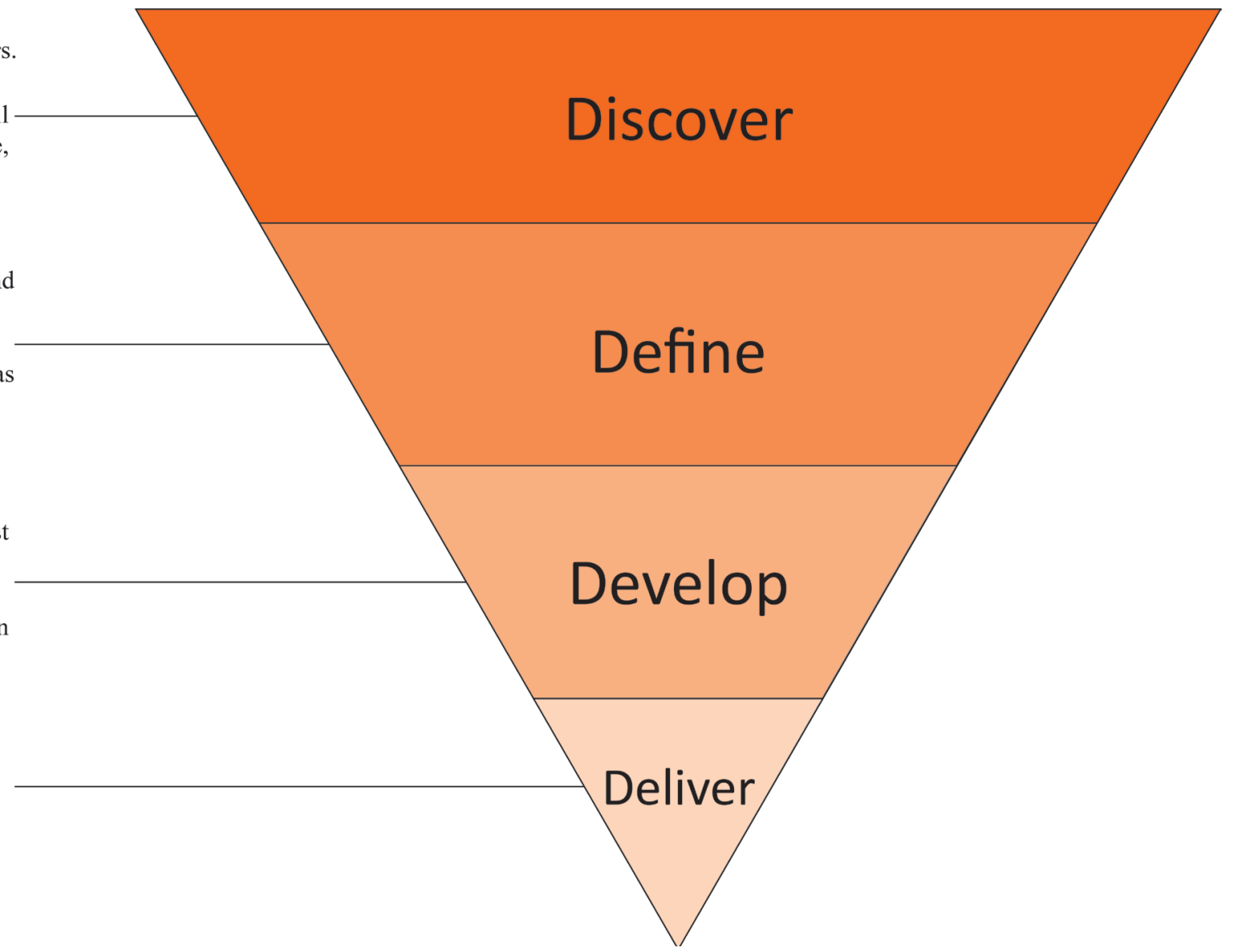

Figure 12, The 4 D's, diagram. 
1.3 Research Methods. 


\section{Aim one.}

. Artefact Analysis: Reading the academic text and viewing visual information such as videos and images (Martin \& Hanington, 2012). The aim of this is to use background knowledge creation of the final design.

. Design criteria: allows for narrowing down the field of research, creating a clear final goal that can be achieved in the time frame. This allows others to assess where there might be issues, such as being too ambitious. Past work experience at Weta Workshop will be used to construct the design criteria.

\section{Aim two.}

. Software/Technology Analysis: to create the desired 3D design, there first needs to be a way to compute the $2 \mathrm{D}$ drawing of the idea into data that can be sent to the printer. These systems are known as computer-aided design (CAD) programs. Choosing the right program is vital as there are many software programs with different strengths and weaknesses. This research portfolio will use Solidworks as it allows for easy changes to a single parameter that other software does not.

. Concept visualisation: sketches, collaging, 3D drawings - CAD, visual and physical to see how this project would appear.

. 3D Printing: Stratasys J750 printer will be used in the production of all prototypes and final output. Initial testing will be created on the Connex Objet 350 as that is the printer available at this time.

. Rapid Iterative Testing \& Evaluation (RITE): A method that helps teams identify and remove significant problems (Martin \&
Hanington, 2012). Testing and evaluations will become an essential part of the experimentation section of the research portfolio project.

.Final Evaluation: after the testing, a written assessment is conducted determining what went well and can be placed in the next iteration and what needs to be changed. This is then taken back to the CAD file and adapted for the following physical prototype. Once the design criteria are fully met, and the final design is produced in the evaluation phase of this research portfolio project will be complete.

. Documenting: photographing and filming will be used so that an extensive collection of visual information is gathered so that the prototyping and testing process can be viewed, as well as read. A short video will be produced to accompany this research to show the final output in the intended environment of a film. 


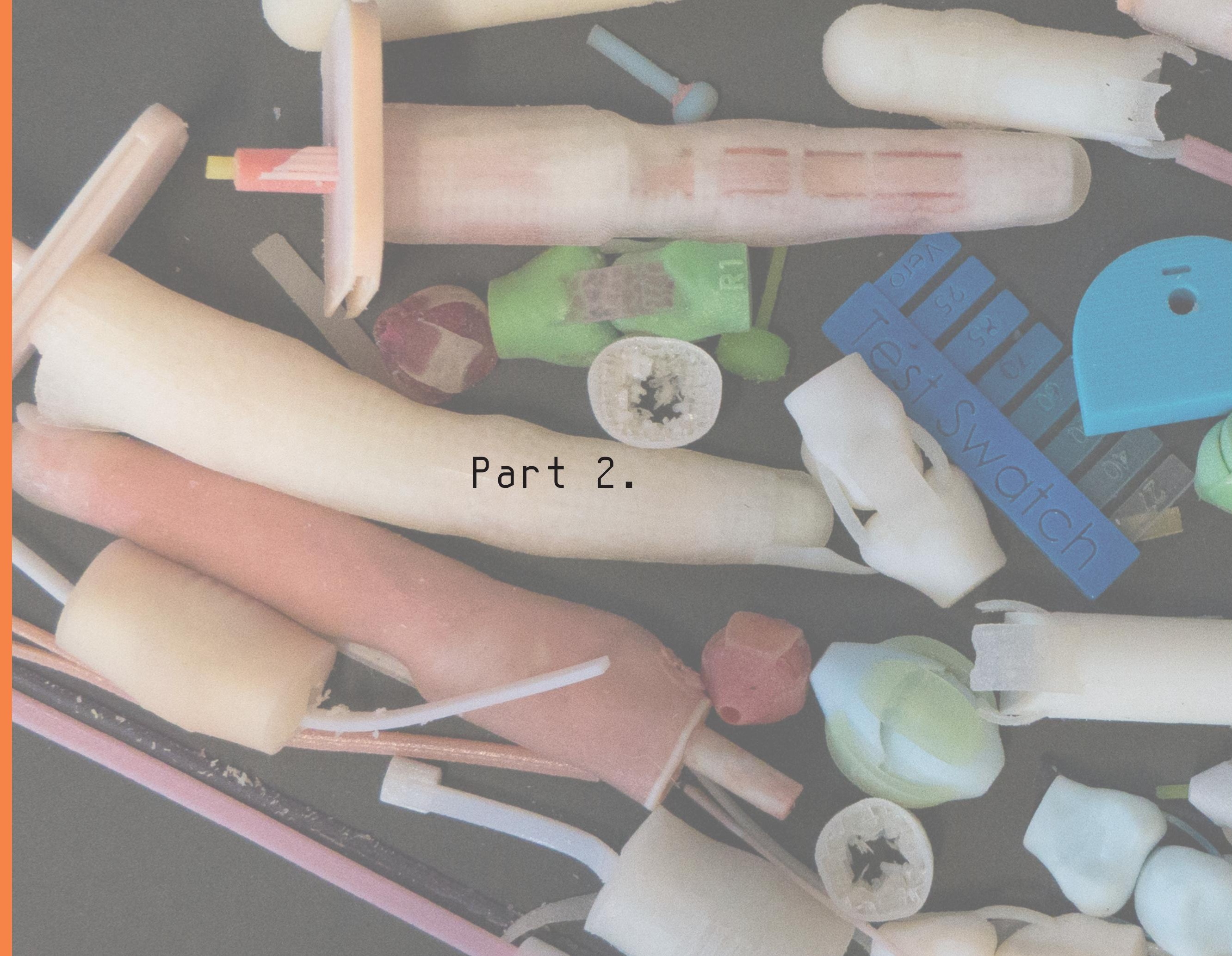


2.1 Design Criteria. 
Before any physical designing can start a guideline or criteria is necessary. A design criteria is formed usually from past knowledge or experience. When in a professional environment, the criteria is created by the client and designer to take into consideration all that is needed and wanted in the outcome.

Without criteria, there is the potential for straying too far out of the area of study resulting in unclear or useless information that does not contribute to the final research and outcome. For this research, the design criteria were formed through experience of working within the film industry at Weta Workshop, conversations with supervisors and technicians about what is expected from this research portfolio and the limitations of the technology. From this, the following guidelines have been put in place.

\section{Criteria.}

1. The outcome is to be manufactured all in one print, creating a heterogeneous design similar to human creation.

2. Only focus on one area of human anatomy that will mimic the movement. It is vital that the final outcome looks and moves as close to a real human finger as possible.

3. Be durable and withstand multiple manipulations without breaking or minimal tearing.

4. Utilise CAD program that allows for easy adaptation of file for rapid prototyping and change of dimensions, colour, and external appearance. It must also demonstrate the abilities of Stratasys polyjet colour $\mathrm{J} 750$ printer and the Agilus material.

5. The outcome must have minimal post-production work with only necessary cleaning of the support material needed, no internal cleaning required.

6. The outcome needs to present well on film and react well to actors interaction. 
2.2 Evaluation of Anatomical Movement. 


\section{Human Hand Experiment.}

This test is to show how the skin moves over the internal workings.

- Dots were placed on the surface of the skin to assess how far they move or distort.

- The distance between the dots does not change drastically.

- The bottom dot on the knuckle joint shifts to the right when bent.

- The finger bends 90-degrees at all three joints.

- The three axes for each joint are at the second, fourth and sixth dot.

Documented in figure 13 a to $\mathrm{d}$

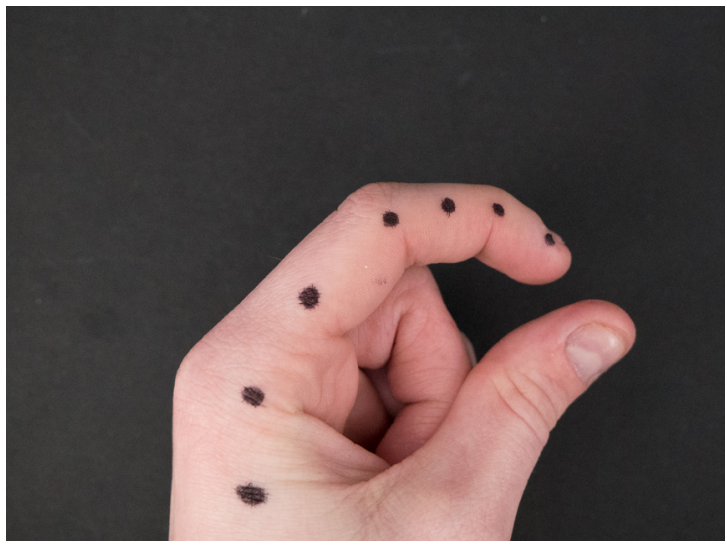

Figure 13 b, Finger, slightly bend.

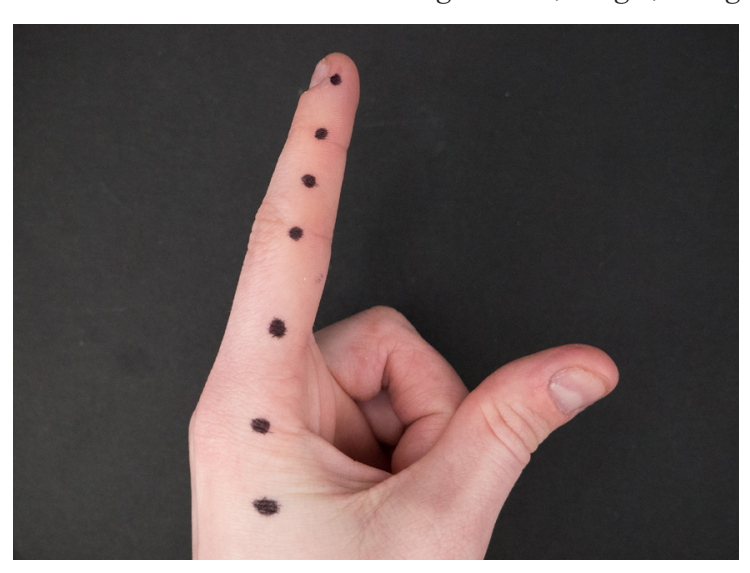

Figure 13 c, Finger, halfway bent.
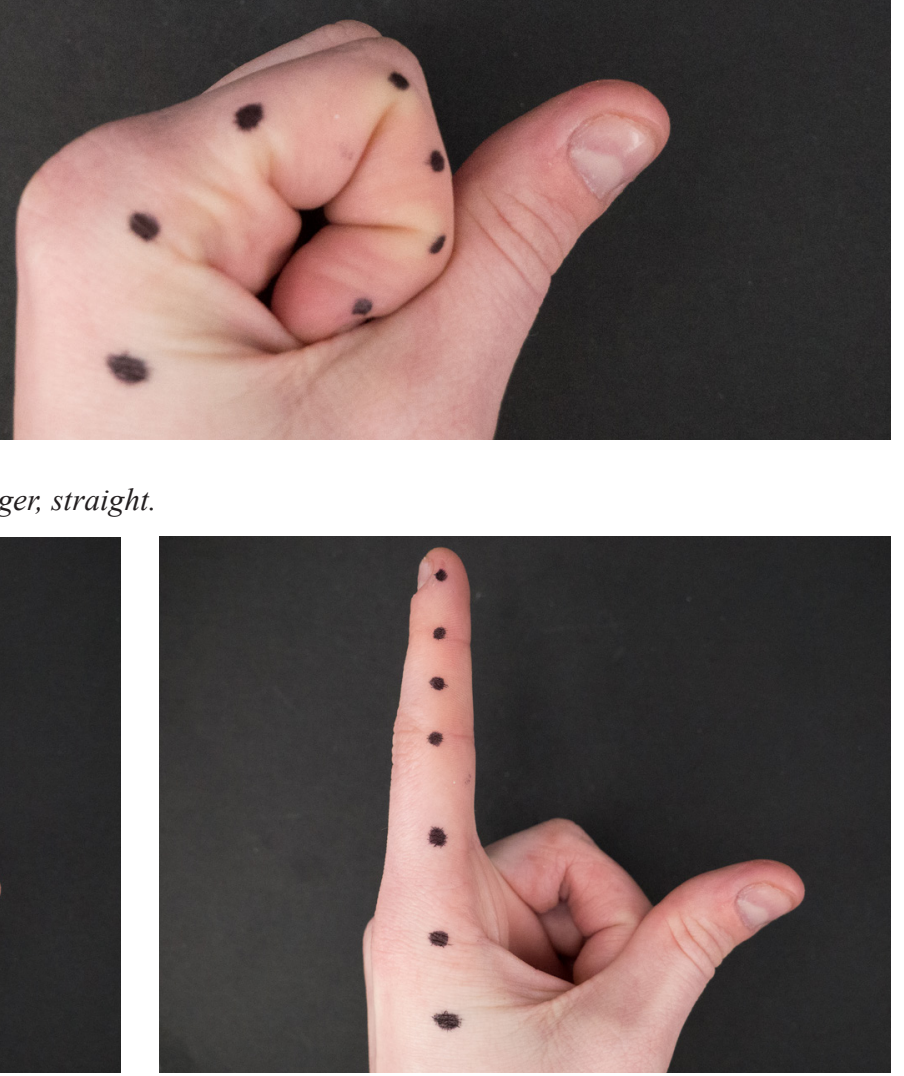

Figure 13 , Finger, bent. 


\section{Chicken Feet Experiment.}

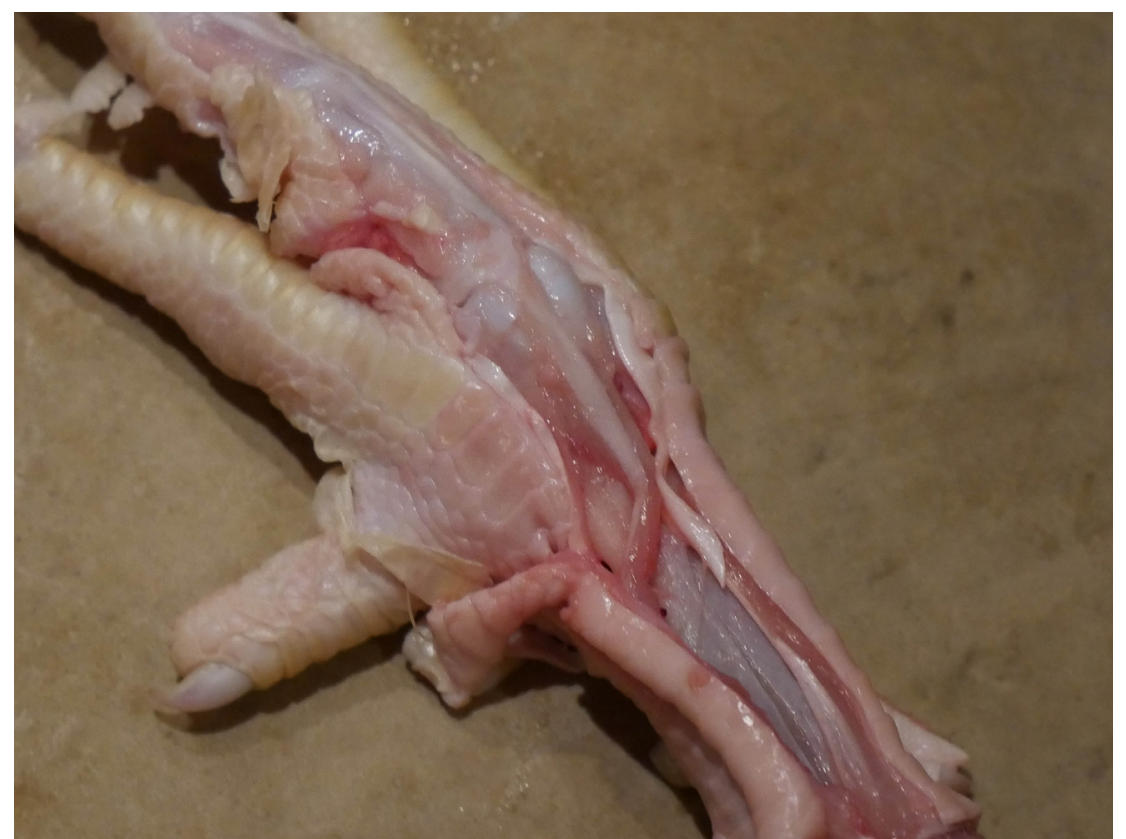

Figure 14 a, Chicken foot, extensor tendon.

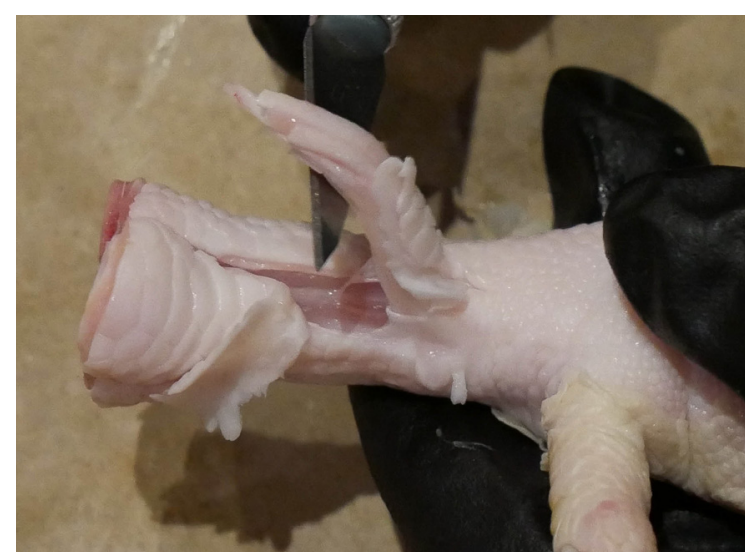

Figure 14 b, Chicken foot, flexor tendons.

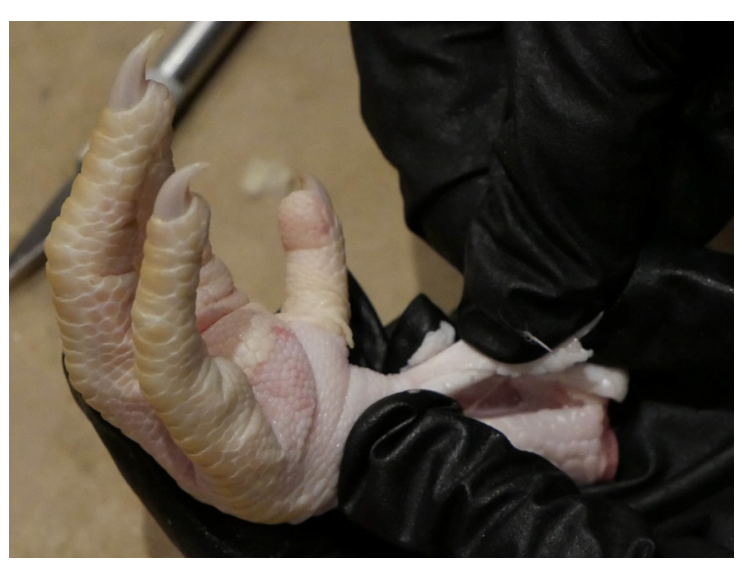

Figure 14 c, Chicken foot, pulling on tendons.

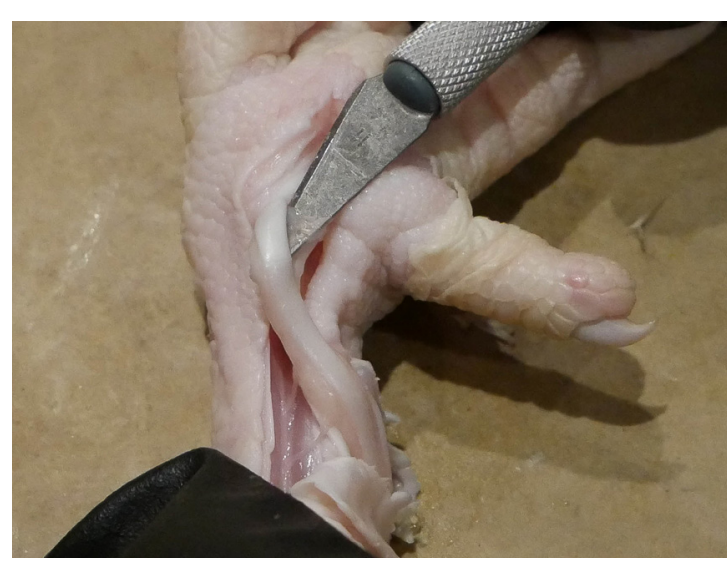

Figure $14 d$, Chicken foot, detail.

The purpose of this experiment is to determine how tendons manipulate the joints as the layout of chicken feet are similar to that of the human hand.

- Bones for stability.

- Cartilage for cushioning.

- Ligaments with volar plates.

- Three tendons: two palm side, one dorsal.

- Fat

- Skin

Documented in figure 14 a to $\mathrm{c}$. 
2.3 Stratasys Connex Objet350 Printing. 


\section{Tensile Testing.}

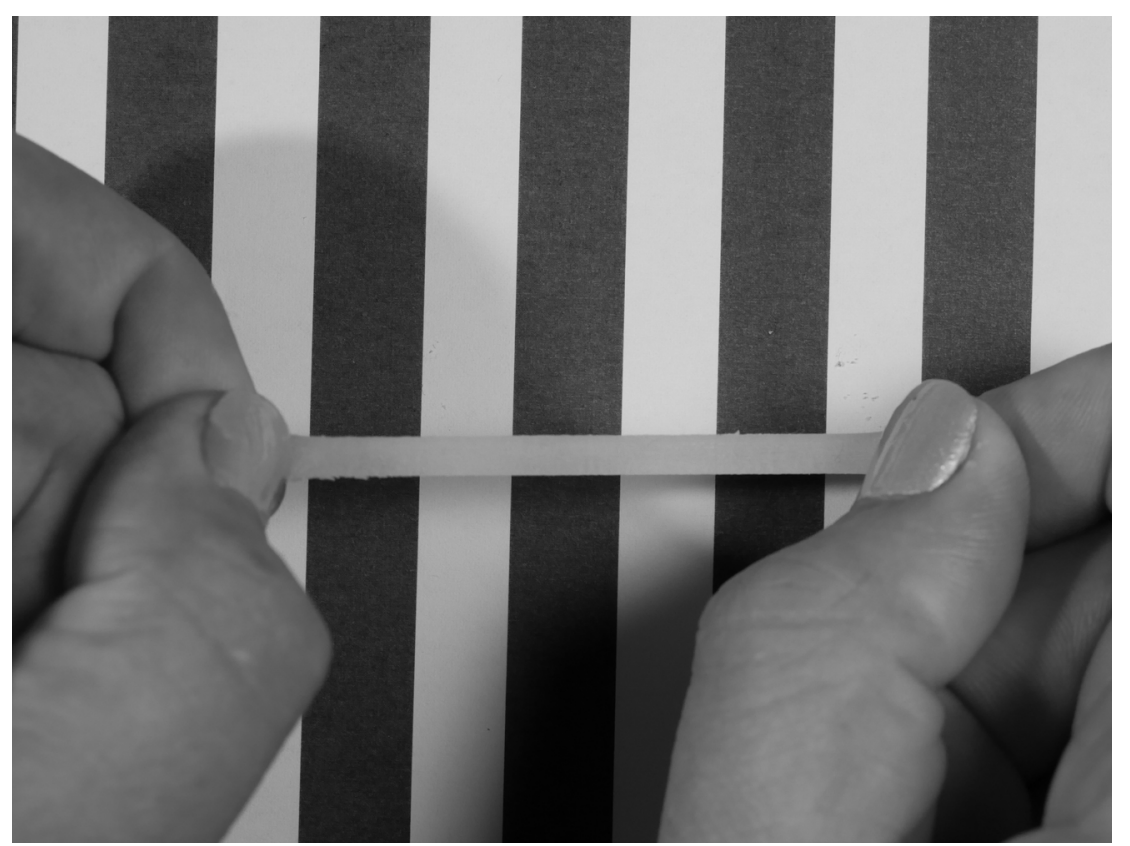

The purpose of this test was to assess what printing placement would produce the best strength from a single section of material. This testing was a reference to the work conducted in Das, Ranganathan \& Murugan (2018) study.

- $\quad$ Flat along the $\mathrm{X}$-axis as it is cost-effective and malleable in terms of stretch length.

- Connex Objet 350 was the only printer available sat time of testing.

Tango +

- $\quad$ Shore Hardness 50

- Cleaning process.

- Water Submersion for 48 hours.

- Time to dry.

Documented in figure 15 a to $\mathrm{f}$.

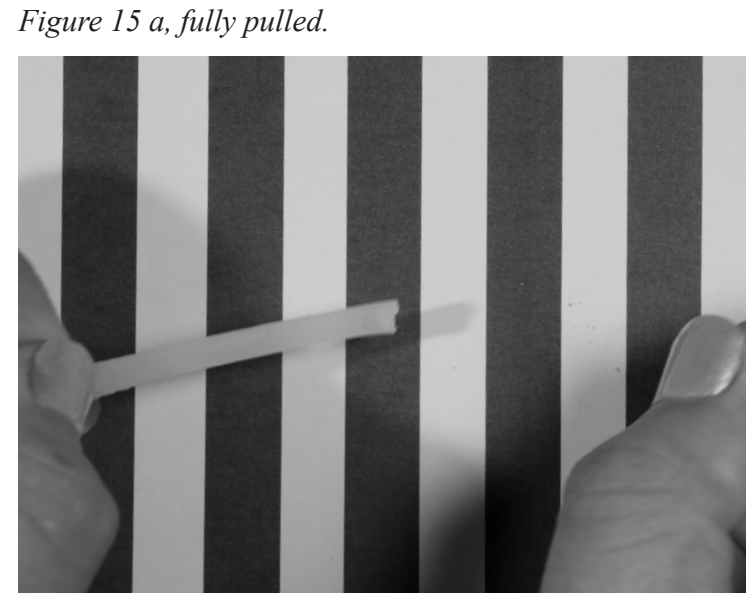

Figure 15 b, brake.

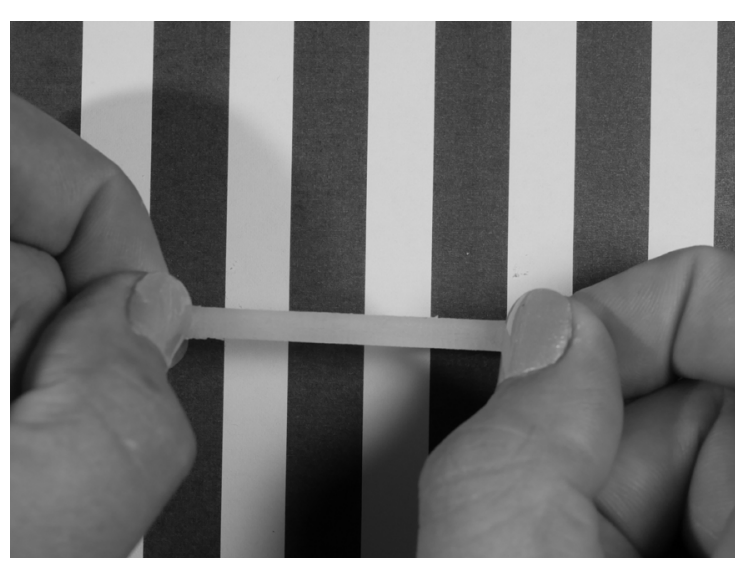

Figure 15 c, halfway.

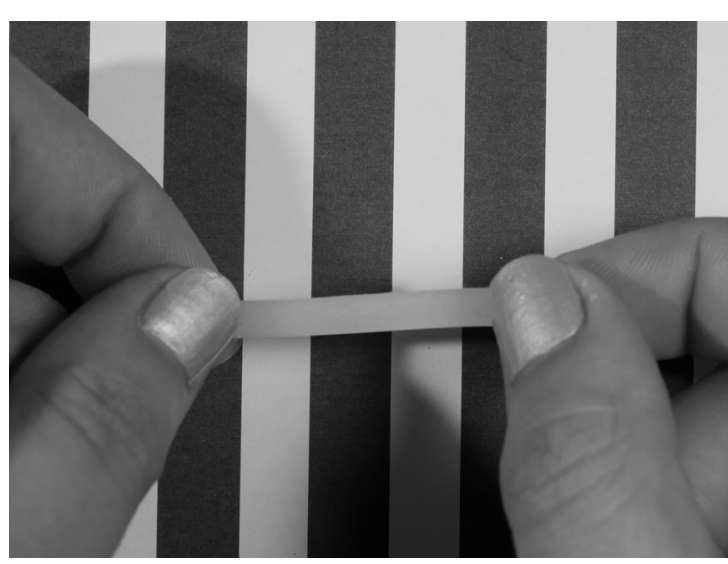

Figure $15 d$, starting position. 


\section{Movement.}

These tests were to see how bone and ligament structure align.

One.

Materials used:

- Bones, Vero white.

- Ligaments, Shore Hardness 50.

Tendon, Tango+ clear and Shore Hardness 60

- There was too much space between the bones as well as the ligament.

- Tango+ was found to be too fragile and broke within a couple of manipulations.

Documented in figure $16 \mathrm{a} \& \mathrm{~b}$

Two.

The materials used were the same as test one.

- Tendon slip was added.

- The connection between sections worked better.

- The tendon slip broke during the cleaning process.

- The ligaments broke during the cleaning and manipulation testing.

Documented in figure $17 \mathrm{a} \& \mathrm{~b}$.

Three.

- Additional joints added.

- The middle connection and tendon slip broke early in the

- bending process.

- The print was found to be too complicated for pulmonary testing.

- The next tests will focus on the joint rather than on the bone structure.

Documented in figure $18 \mathrm{a} \& \mathrm{~b}$.
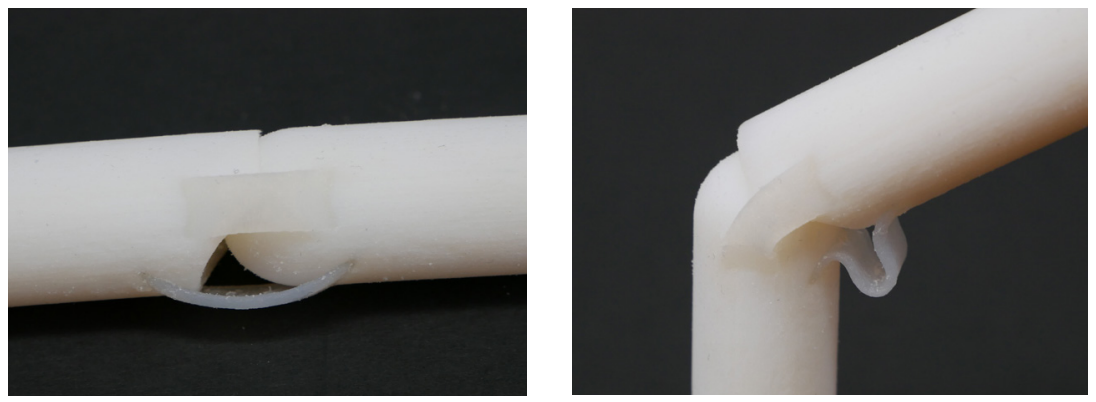

Figure 16 a, one, straight

Figure 16 , one, bent.

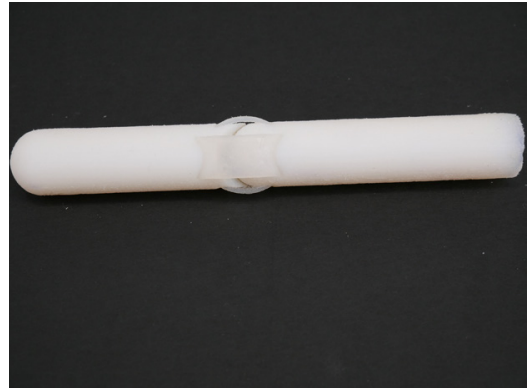

Figure 17 a, two, straight.

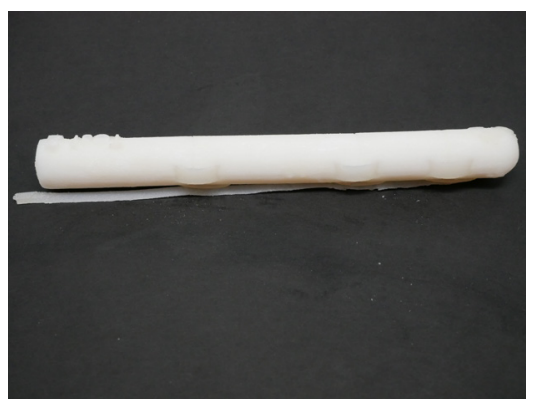

Figure 18 a, three, straight.

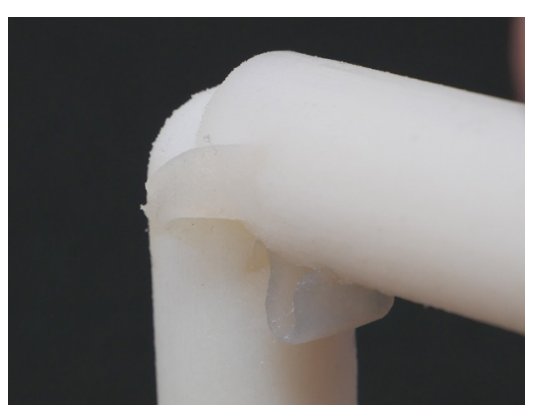

Figure 17 b, two, bent.

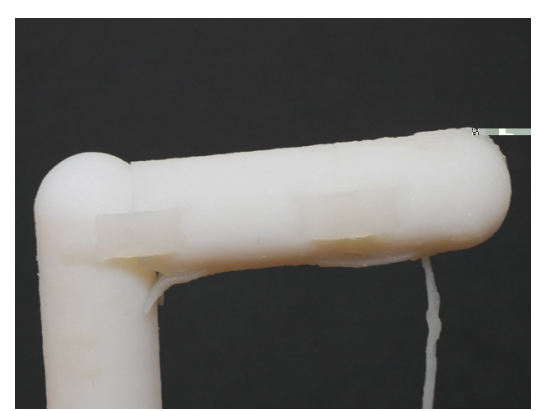

Figure 18 b, three, bent 


\section{Anatomical Testing of Varying Material Blends.}
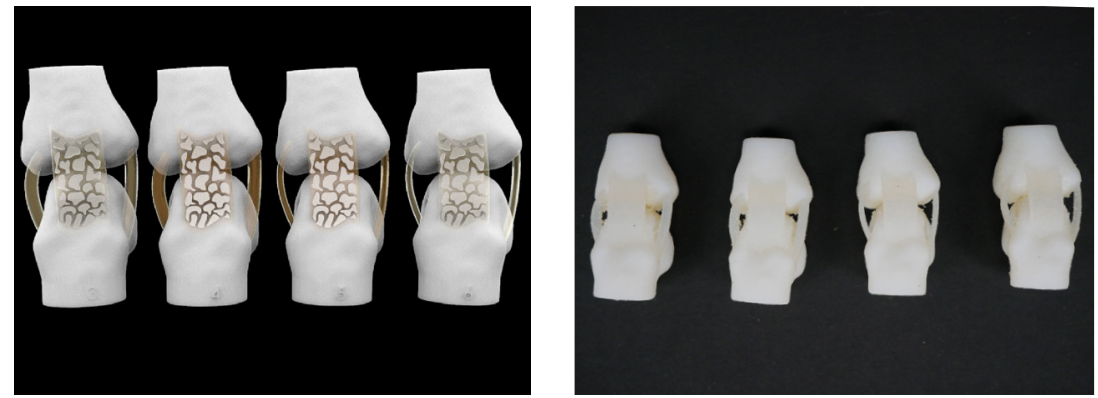

Figure 19 a, anatomical, render.

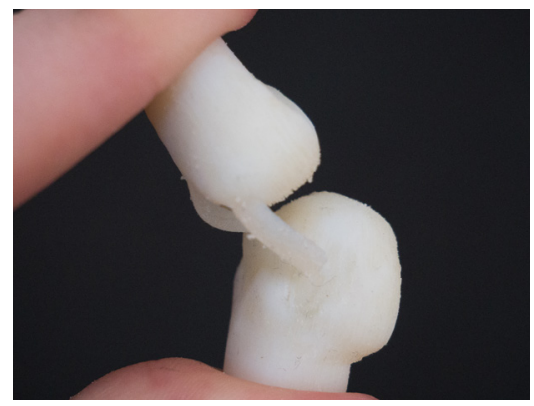

Figure 20 a, anatomical, one.

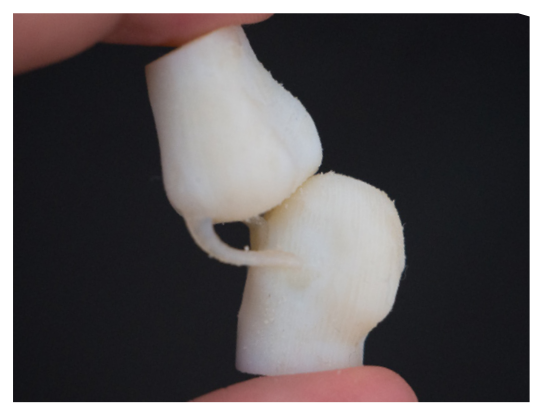

Figure 20 c, anatomical, three.
Figure 19 b, anatomical, all tests.

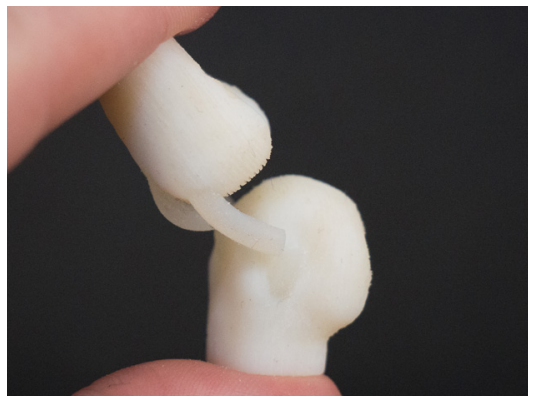

Figure 20 b, anatomical, two.

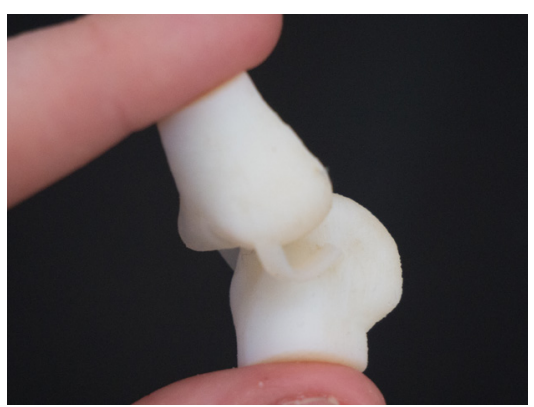

Figure 20 , anatomical, four.
The three tests were to see how anatomical bone and ligament structure align.

One.

- $2 \mathrm{~mm}$ thick ligaments

- $\quad$ Front ligament, Shore Hardness 60

- $\quad$ Side ligament, Shore Hardness 70.

Documented in figure $19 \mathrm{a}, \mathrm{b}$ and figure $20 \mathrm{a}$.

Two.

- $2 \mathrm{~mm}$ thick ligaments

- $\quad$ Front ligament, Shore Hardness 70.

- $\quad$ Side ligament, Shore Hardness 85.

Documented in figure $19 \mathrm{a}, \mathrm{b}$ and figure $20 \mathrm{~b}$.

One and Two were unsuccessful due to the side material splitting.

\section{Three.}

- $1 \mathrm{~mm}$ thick ligaments

- $\quad$ Front ligament, Shore Hardness 70

- $\quad$ Side ligament, Shore Hardness 85.

Documented in figure $19 \mathrm{a}, \mathrm{b}$ and figure $20 \mathrm{c}$.

There was a better range of movement with this test, but still splitting due to the material structure.

\section{Four.}

- $1 \mathrm{~mm}$ thick ligaments.

- $\quad$ Front Ligament, Shore Hardness 60.

- $\quad$ Side Ligament, Shore Hardness 70.

Documented in figure $19 \mathrm{a}, \mathrm{b}$ and figure $20 \mathrm{~d}$.

Test Four has proven to be the most successful as the softer material allowed for more movement. The bones will require more internal support to prevent separation. 
2.4 Stratasys J750 Printing. 


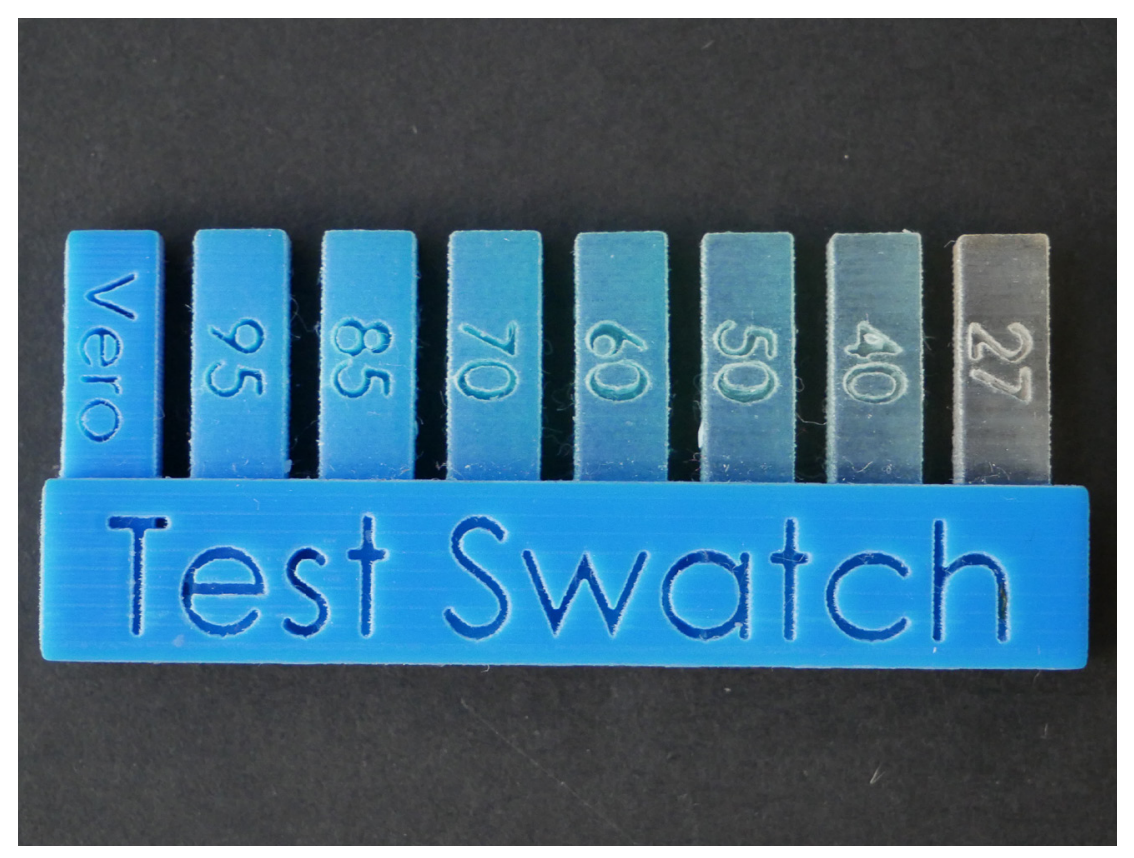

When the Stratasys $\mathrm{J} 750$ arrived at the VUW design school in January 2019, a swatch was needed to determine which materials blends will be used for the following testing. The name assigned to determine the different firmness is the Shore Hardness. This ranges from Vero (hard) through to shore hardness 30 (labelled as 27 in figure 21) which is pure soft Agilus material.

Figure 21, Test Swatch 


\section{Anatomical on J750 One.}

The test was a recreation of test four from the Objet350 Anatomical testing in Agilus material.

- Material used:

\section{Bone, white Vero.}

Front ligament, Shore Hardness 60. (blue)

Side ligament, Shore Hardness 70. (blue)

- $1 \mathrm{~mm}$ thick ligaments.

- No randomised support pattern.

- The width of the material caused the bones to separate rather than slide.

For the next test, wider side ligaments are required and the addition of a random pattern to test if this does affect the strength.

Documented in figure 22 a to $d$.

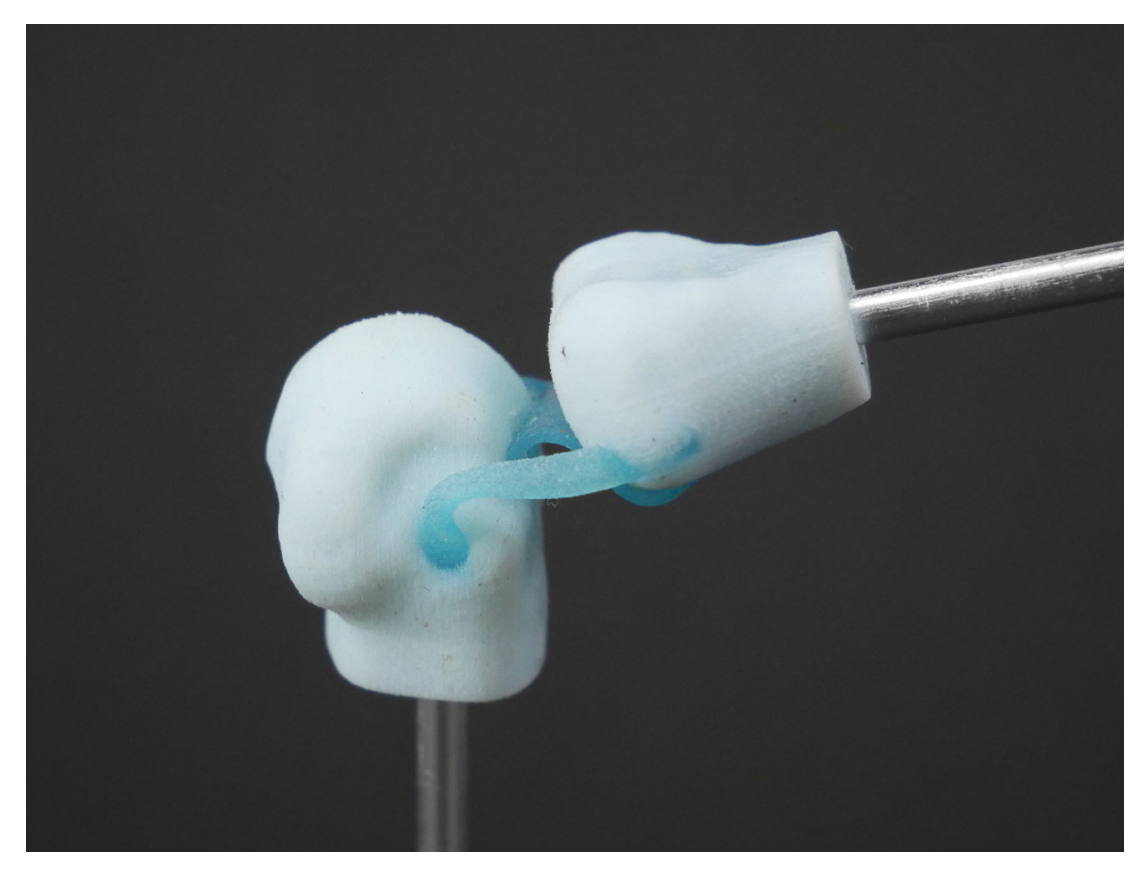

Figure 22 a, recreation one, bent.

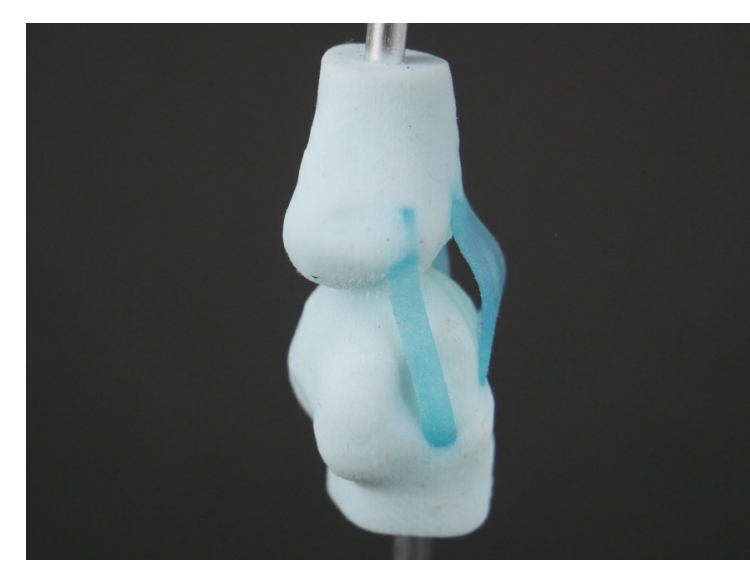

Figure 22 b, recreation one, side.

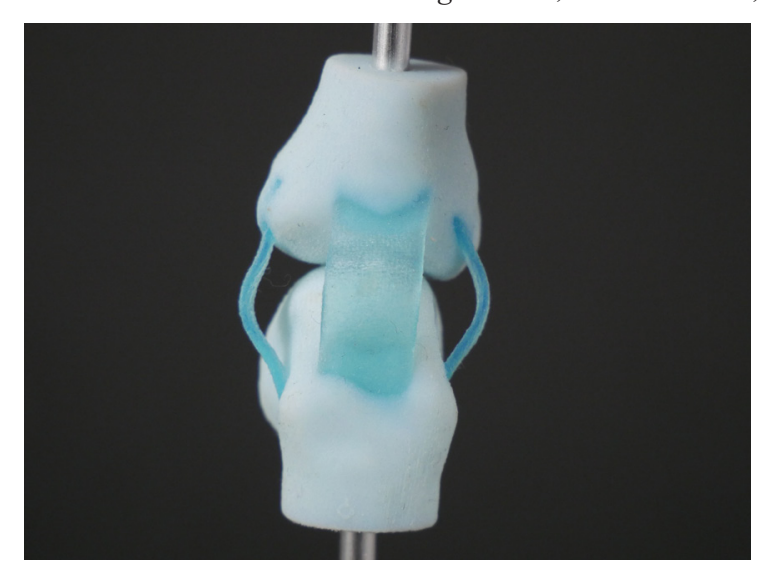

Figure 22 c, recreation one, front.

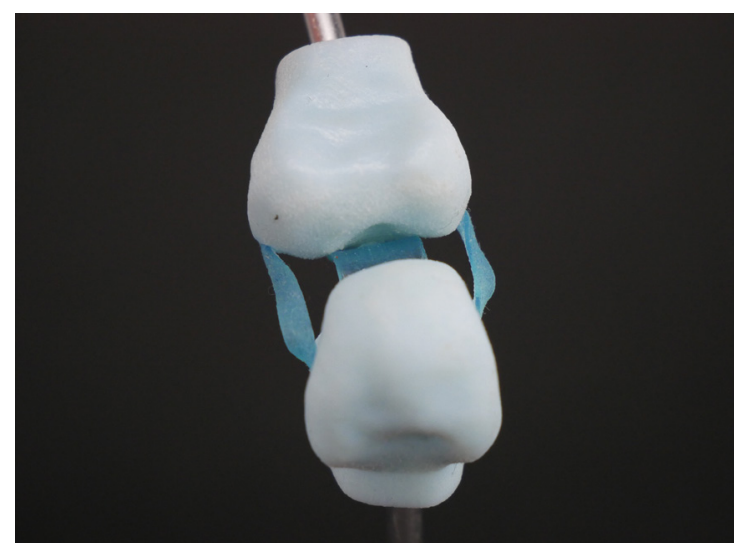

Figure 22 , recreation one, back. 


\section{Anatomical Two.}

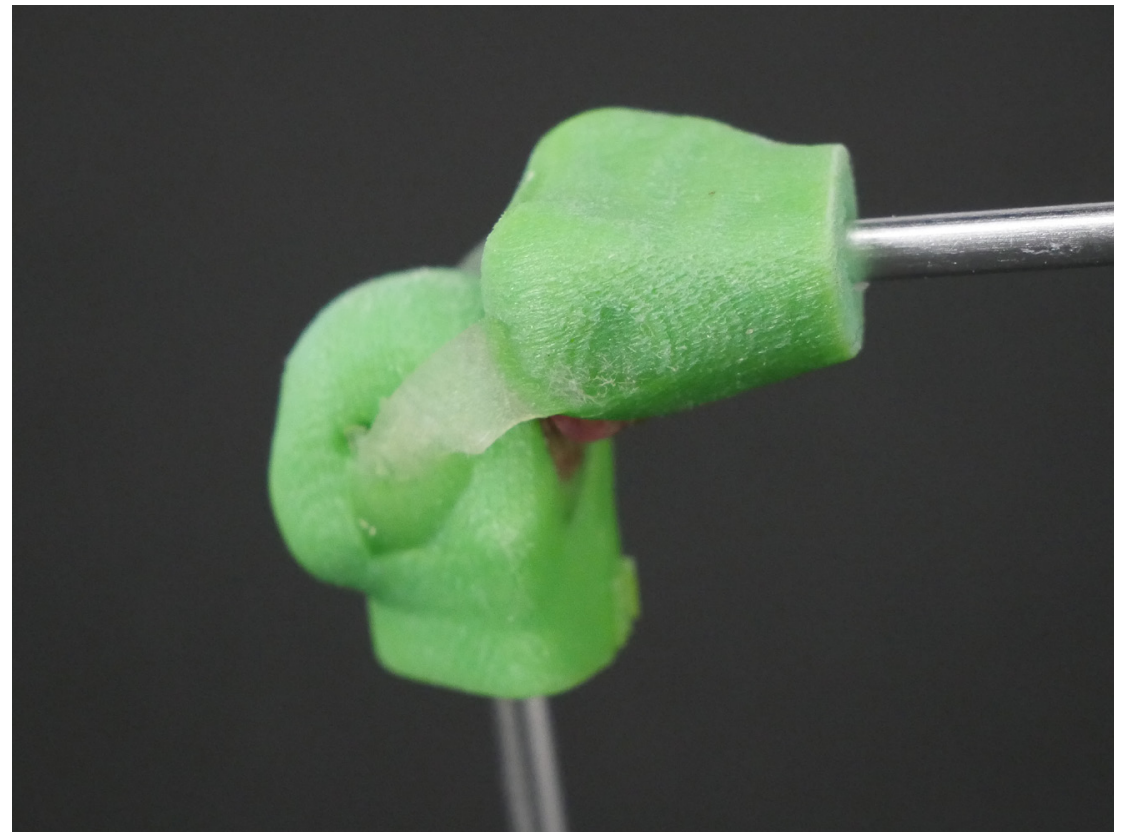

Figure 23 a, Recreation two, bent.

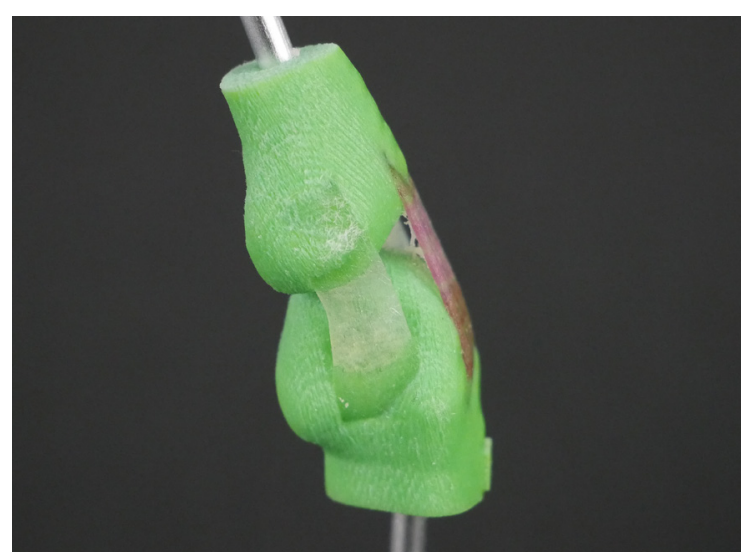

Figure 23 b, Recreation two, bent back.

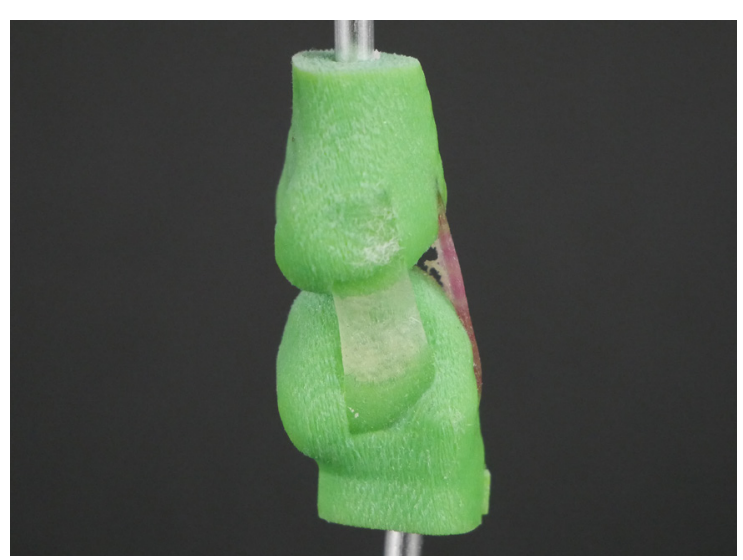

Figure 23 c, Recreation two, side.
The test was a recreation of test four from the Objet350 Anatomical testing in Agilus material to produce ideal movement.

- Material used:

$$
\text { Bone, Vero. (green) }
$$

Ligaments, Shore Hardness 40. (light green)

- Randomised support pattern, Shore Hardness 85. (orange)

- The side ligaments were extended further back to stop the

- two parts separating.

- The pattern did not seem to affect the strength of the

- $\quad$ ligament when it is bent.

- The two parts separated.

- The tension from separating resulted in the side ligaments tearing.

This anatomically correct model will no longer be used as the bone fragments are performing incorrectly. A simplified geometric design will instead be used. Documented in figure 23 a to d. 


\section{Simplified One.}

This test was to see how a reduced bone and ligament structure functions and how the new Agilus material reacts to manipulation.

- Materials used:

$$
\text { Bone, Vero. (red) }
$$

Ligaments, Shore Hardness 70. (orange)

- The print replicated the shape of a ball and socket joint.

- The side ligaments tore along the stretch point.

- The model was unable to bend the required 90-degrees for it to simulate a knuckle joint.

Documented in figure 24 a to $\mathrm{d}$.

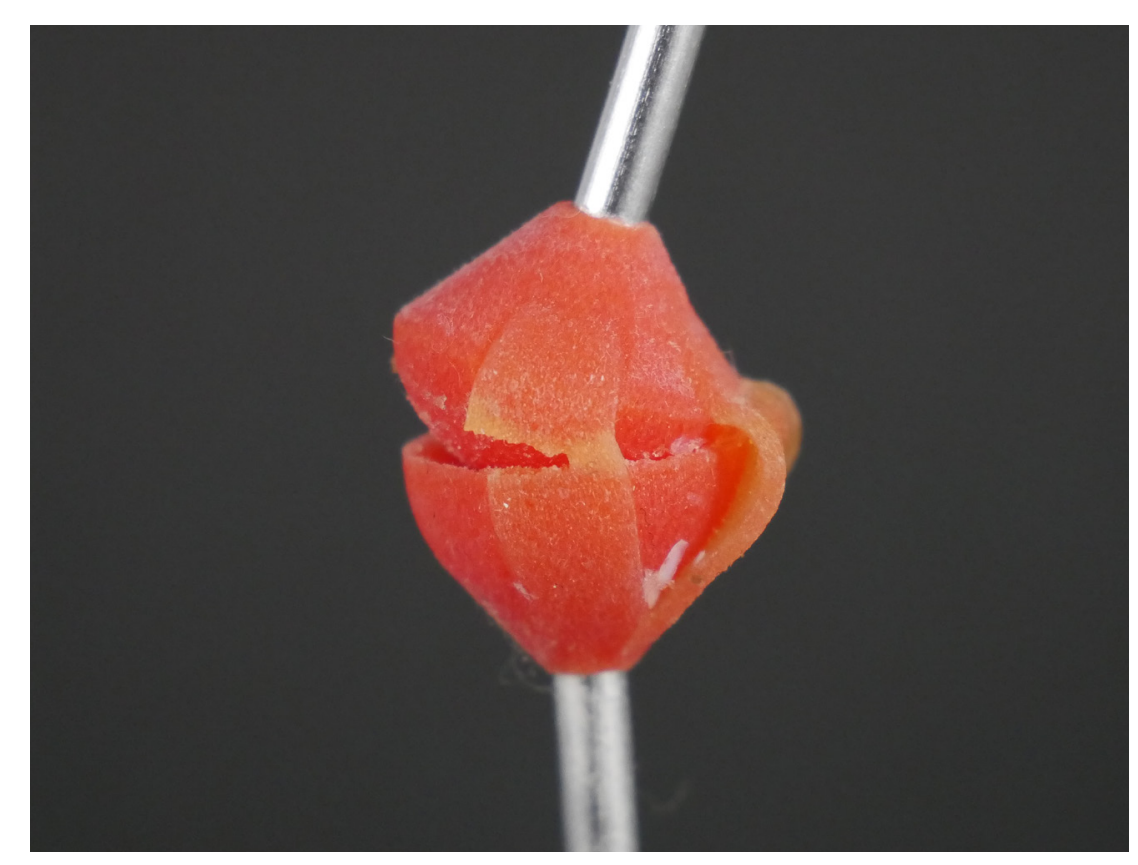

Figure 24 a, one, right bent.
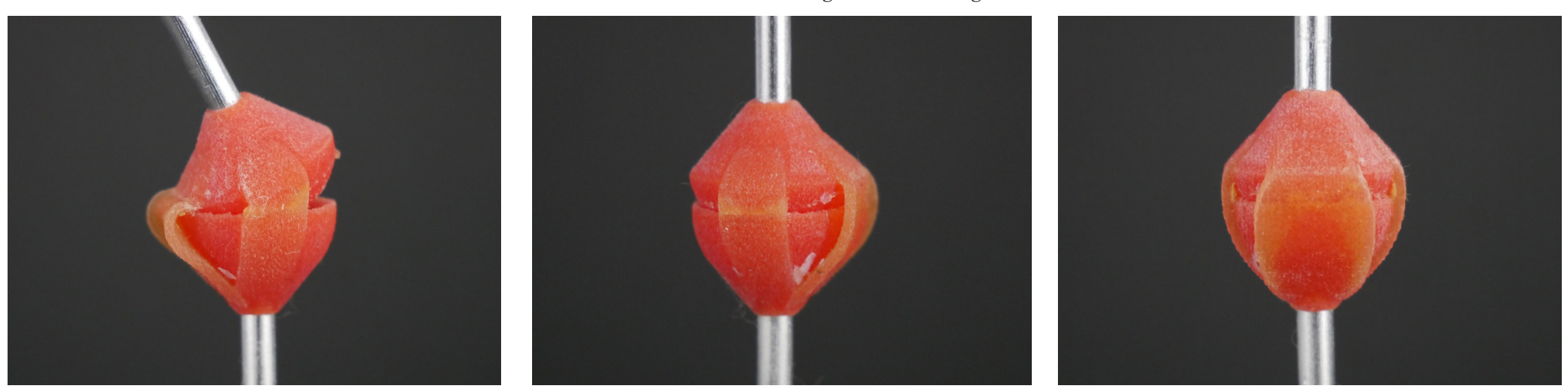

Figure 24 b, one, left bent.

Figure 24 b, one, side.

Figure 24 c, one, front. 


\section{Two.}

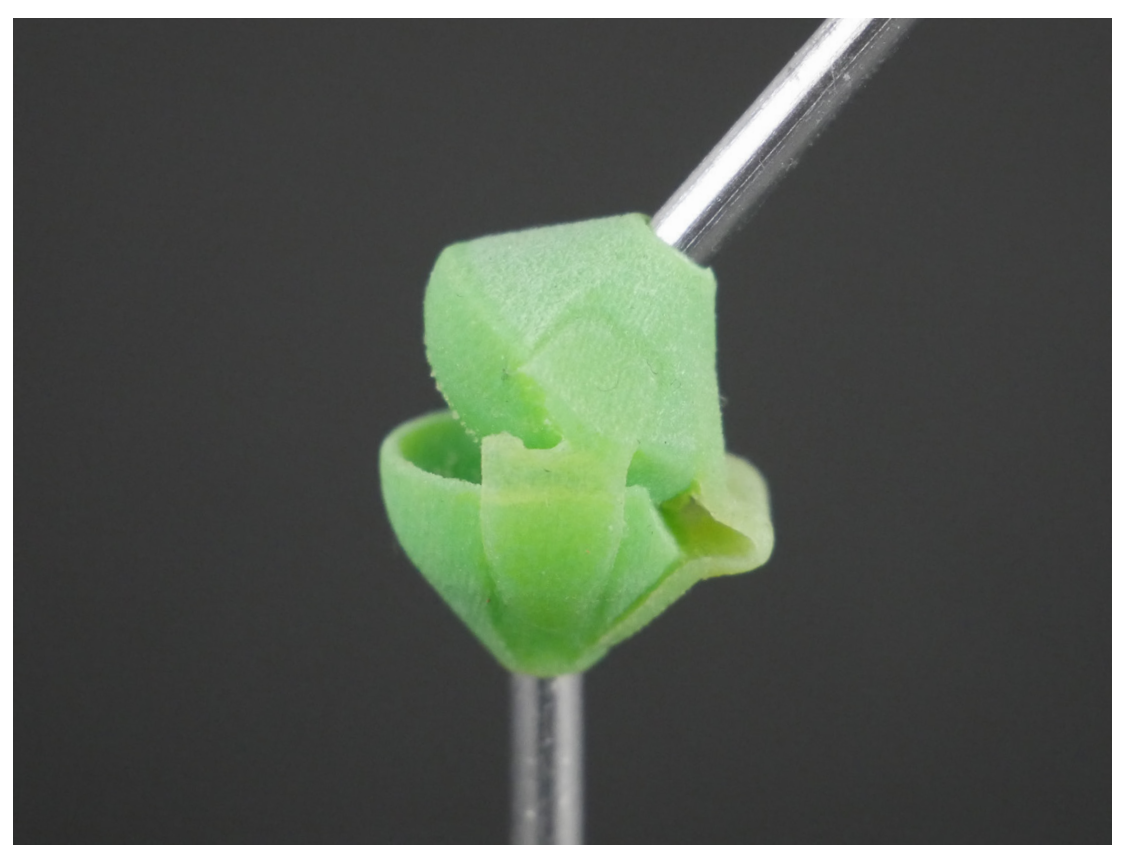

This test was to see how reduced bone and ligament structures and a cutout might react to manipulation.

- Materials used:

$$
\text { Bone, Vero. (green) }
$$

Ligaments, Shore Hardness 70. (yellow/green)

- A cut out was added to allow for additional flexibility.

- The print replicated the shape of a ball and socket joint.

- Shore Hardness 70 caused the material to break.

Documented in figure 25 a to $d$.

Figure 25 a, two, right bent.

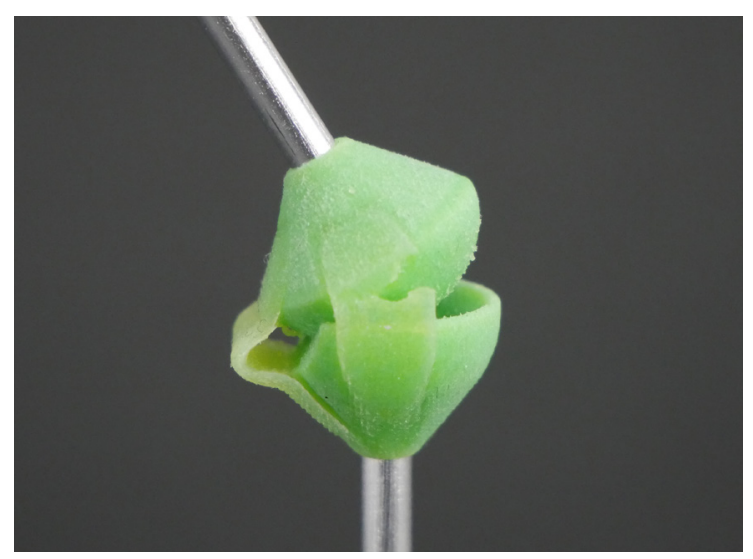

Figure 25 b, two, left bent.

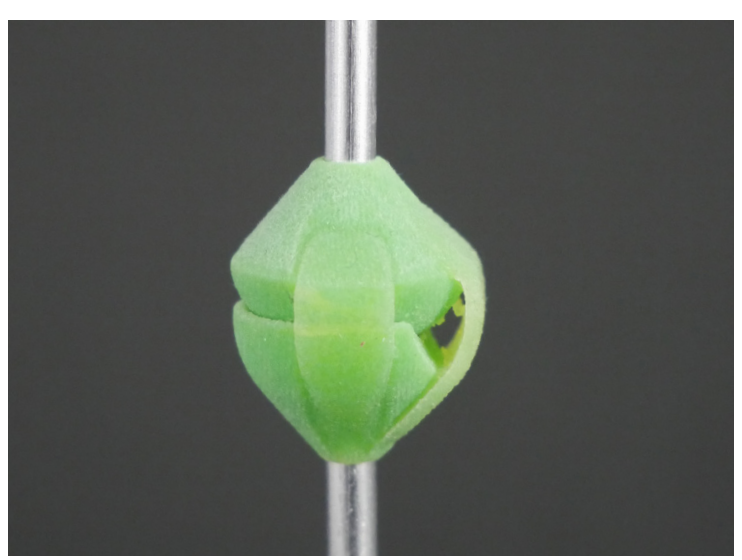

Figure 25 b, two, bent.

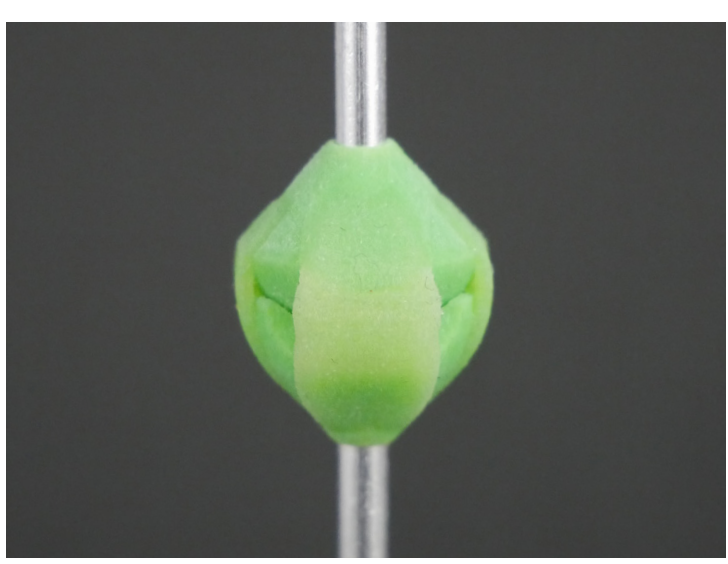

Figure 25 c, two, front. 


\section{Three.}

This test was to see how reduced oval bone and ligament structures with cutout react to manipulation.

- Materials used:

$$
\text { - Bone, Vero. (pink) }
$$

Ligaments, Agilus, Shore Hardness 70. (pink)

- The model was based on a condyloid joint as the ovoid shape is more accurate to the shape of the knuckle.

- The file shifted, resulting in a print that does not bend.

- The Shore Hardness 70 caused the material to break

The result of these tests is that the Shore Hardness 70 is an unsuitable material to be used to replicate ligaments. The condyloid joint, however, will be used for future prints as it allows for circular movement whilst restricting side-to-side movement.

Documented in figure 26 a to $\mathrm{d}$.
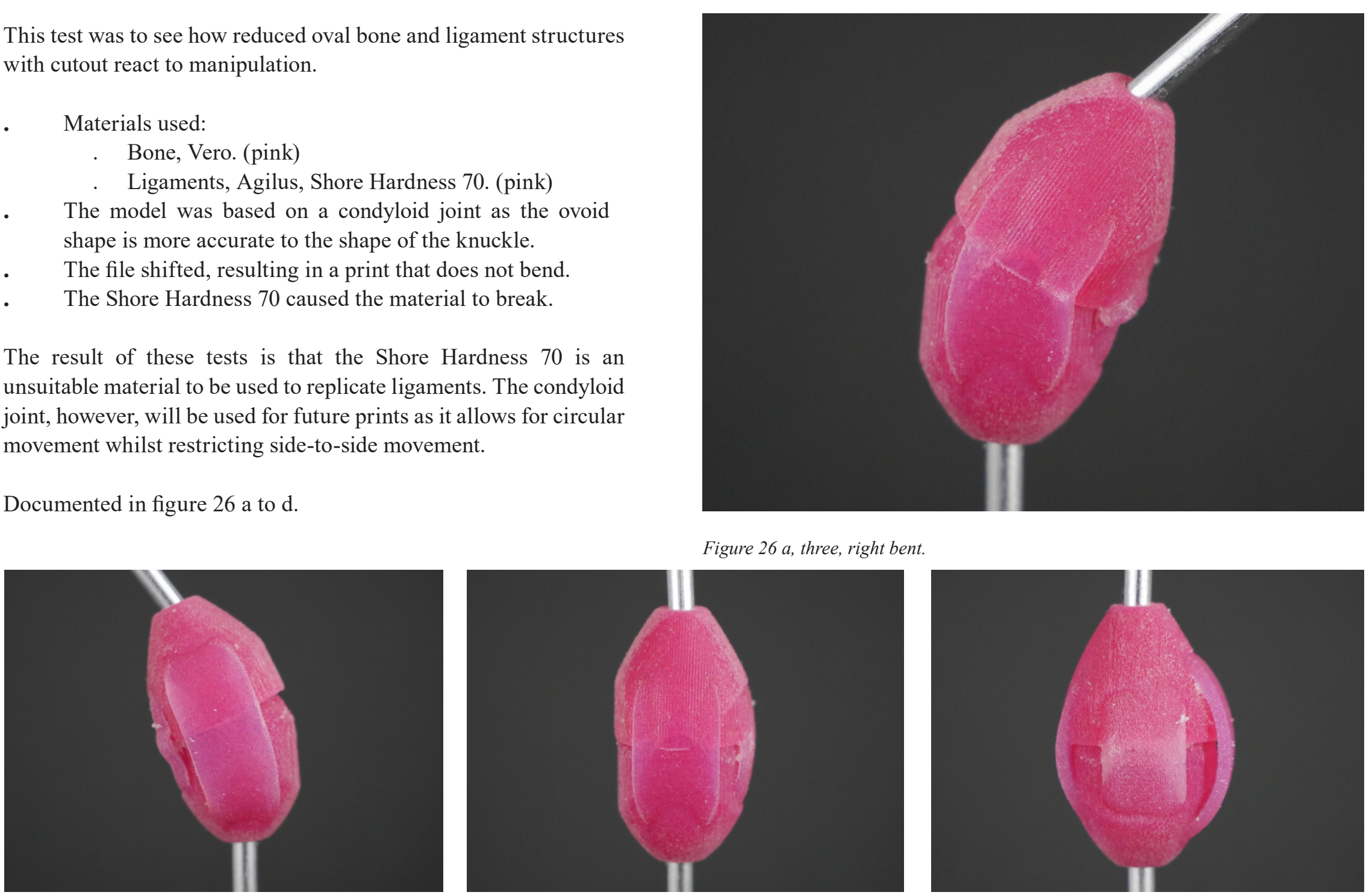

Figure 26 b, three, left bent. 


\section{Four.}

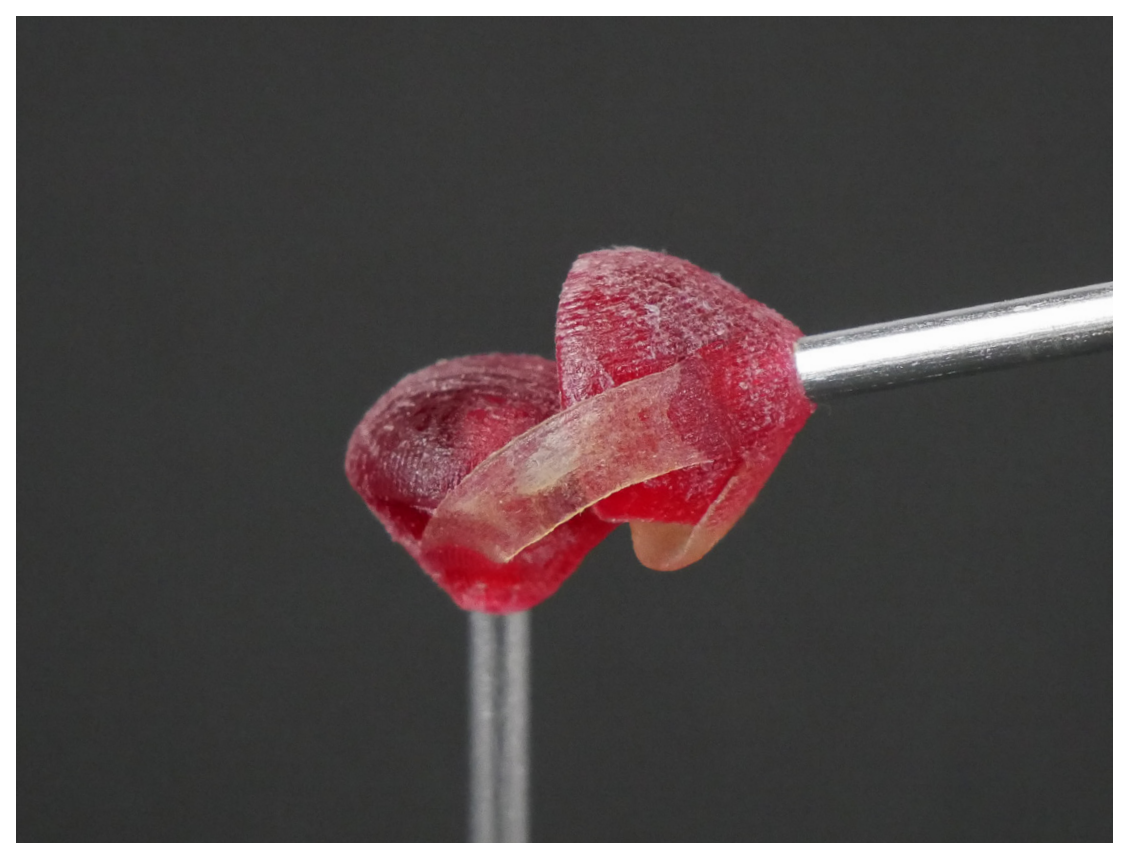

This test was to see how reduced bone and ligament structures with cutout and changed soft material react to manipulation.

- Materials used:

$$
\text { - Bone, Vero. (red) }
$$

Ligaments, Shore Hardness 30. (clear)

- $\quad$ Same shape as test two.

- $\quad$ The soft material did not tear and allowed for correct joint movement.

- This material has little structure causing the joint to fall aside in abnormal movement.

The movement of the two bone sections across each other is quite rough, thus restricting fluid finger movement. For the next test, soft material will be added between the two bones and a wider/harder material being used for the ligaments.

Figure 27 a, four, bent.

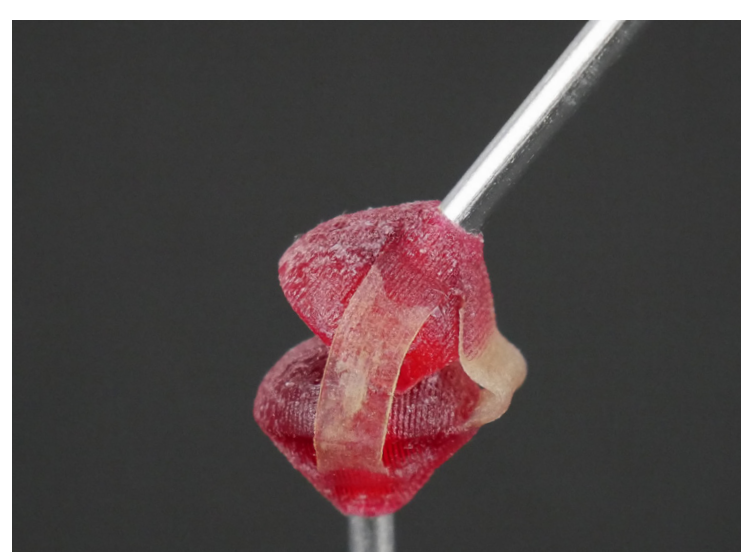

Figure 27 b, four, partially bent.

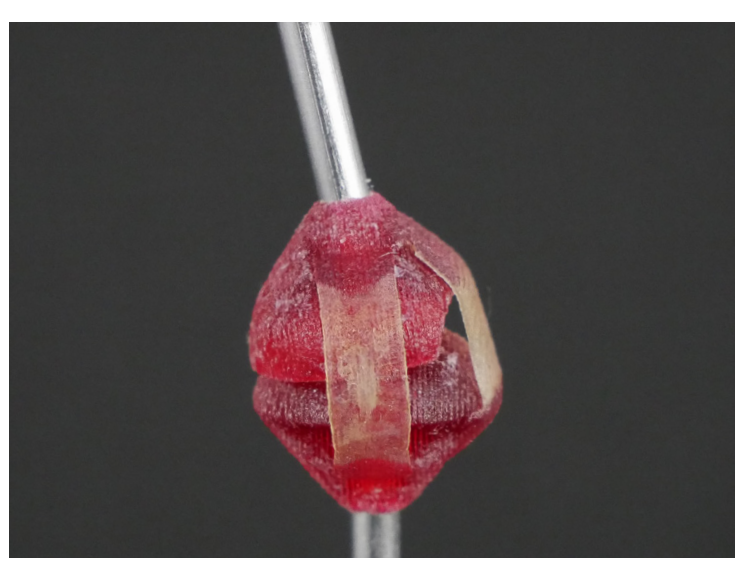

Figure 27 c, four, bent back.
Documented in figure 27 a to $\mathrm{d}$.

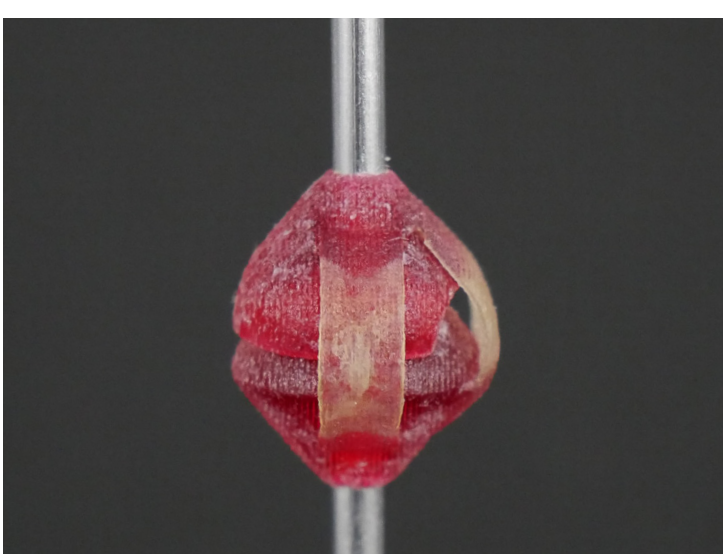

Figure 27 d, four, side. 


\section{Five.}

This test was to see how reduced oval bone and ligament structures with cutout and changed soft material react to manipulation.

- Materials used:

. Bone, Vero. (blue)

- Ligaments, Shore Hardness 40. (yellow)

- Cartilage, Shore Hardness 30. (clear)

- Material allowed for maximum flex and still has the strength to hold the parts together.

- $\quad$ Cartilage between the bones allowed for smooth movement.

- This is especially true when the model has been exposed to liquid as Agilus is porous and absorbent.

For the next test, a tendon slip will be added to the volar plate allow the tendon free lateral movement whilst staying close to the joint.

Documented in figure 28 a to $\mathrm{d}$.
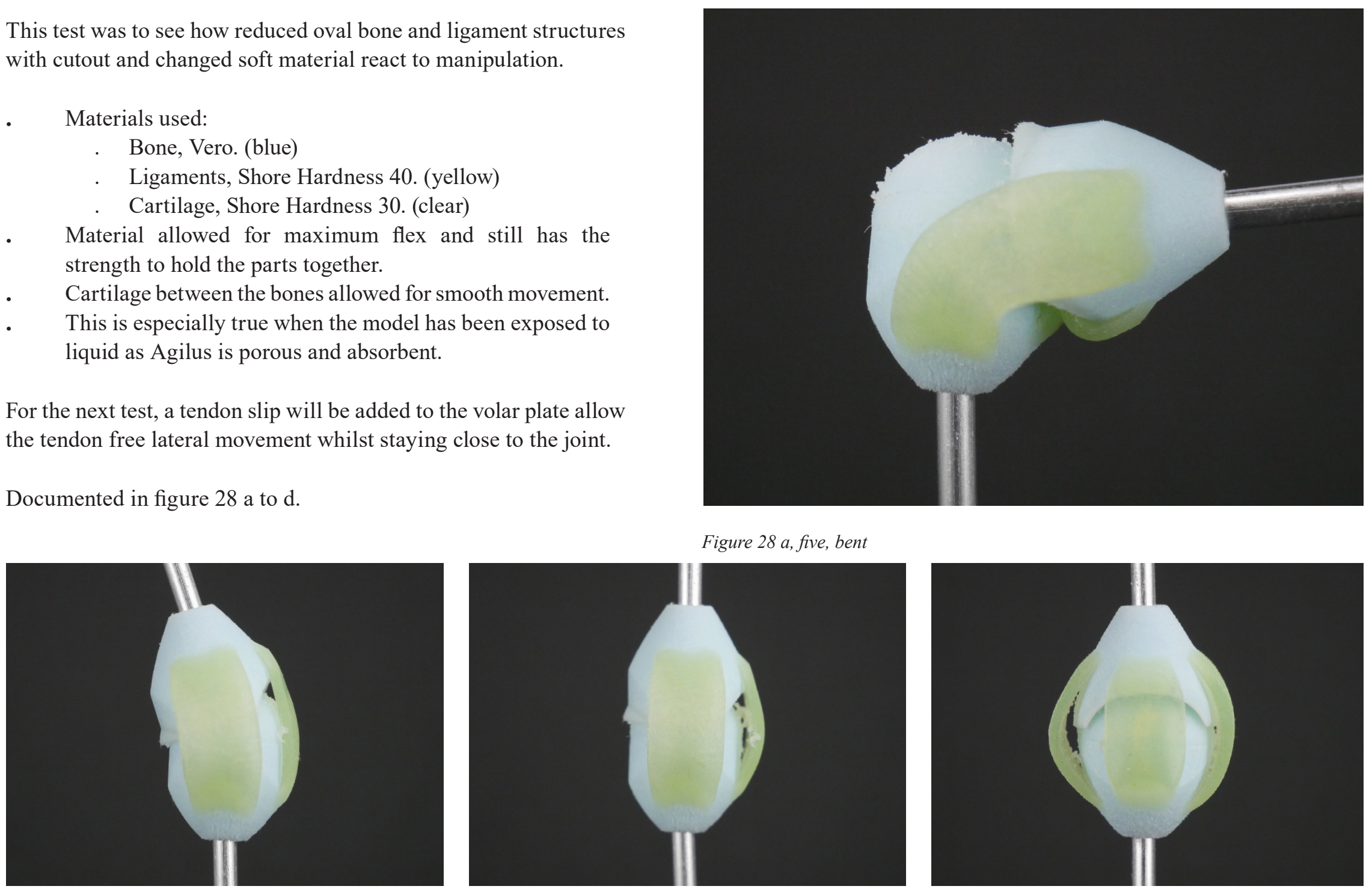

Figure 28 b, five, bent back.

Figure 28 c, five, side.

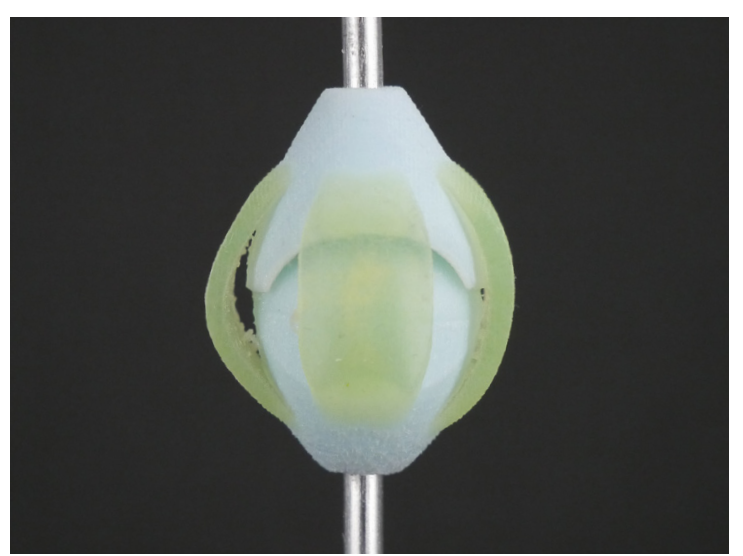

Figure 28 d, five, front. 


\section{Six \& Seven.}

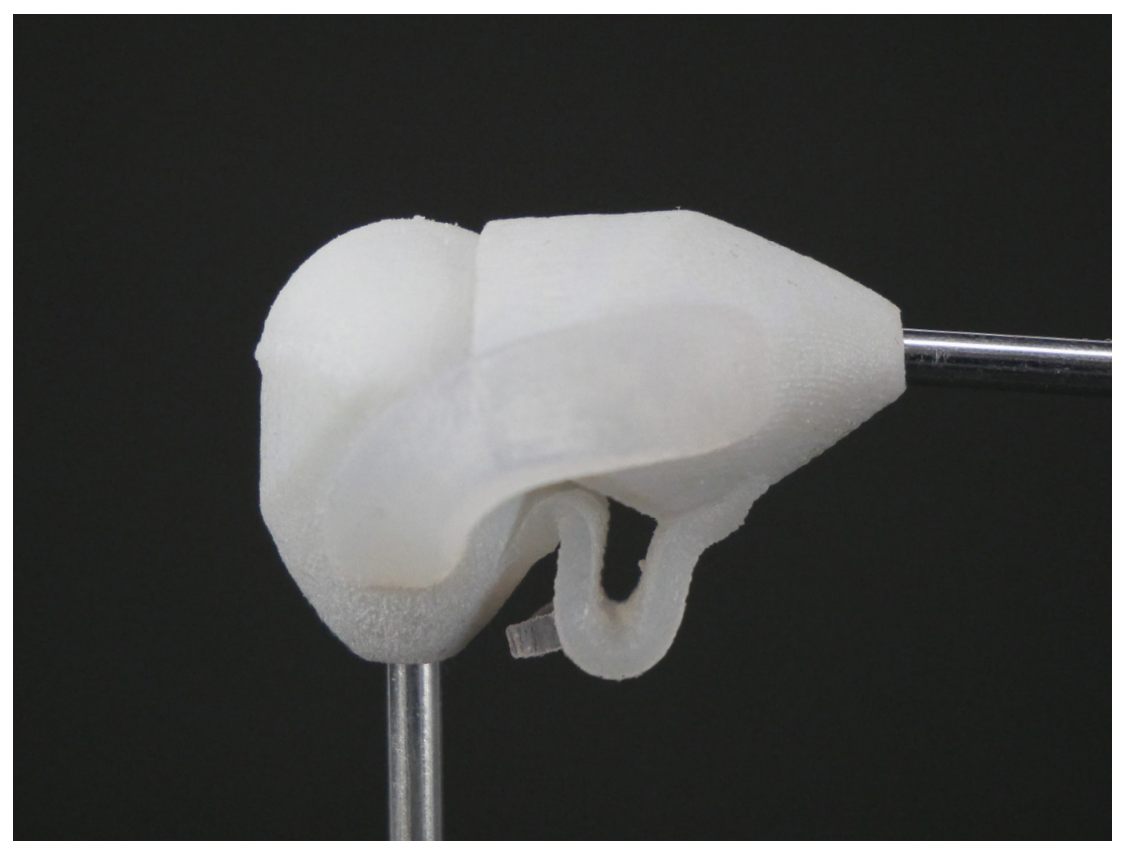

Figure 29 a, six/seven, bent.

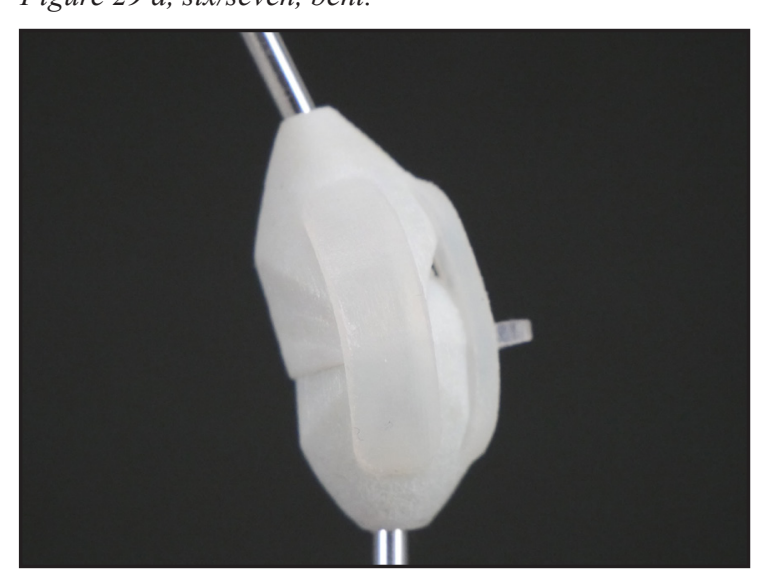

Figure 29 b, six/seven, bent back.

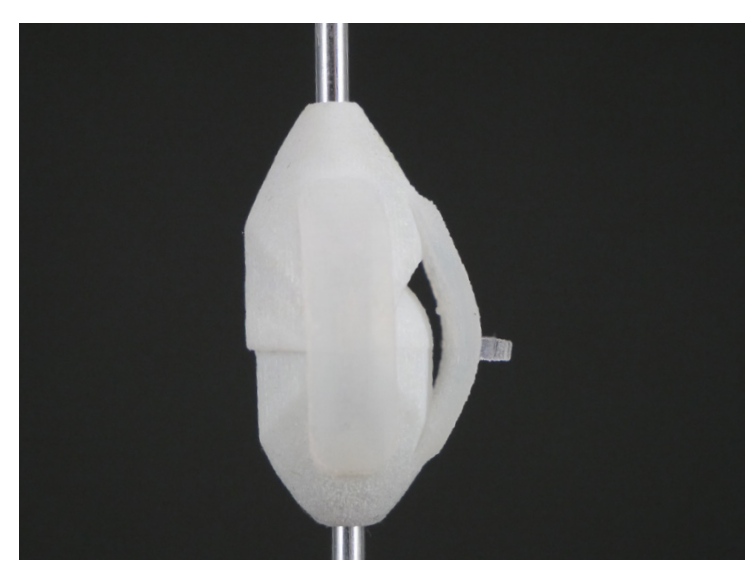

Figure 29 c, six/seven, side.
This test was to determine how the tendon slip will be integrated into the volar plate.

- Materials used:

Bone, Vero. (white)

Ligaments, Shore Hardness 40. (clear)

Six tendon slip, Shore Hardness 40. (clear)

Seven tendon slip, Shore Hardness 70. (white)

Cartilage, Shore Hardness 30 (clear).

- Tests six and seven were scaled down.

- A slip for the tendons was attached to the volar plate ligament.

- The gap between the two bones was too small, resulting in force needed to separate the parts.

- Both slips broke during cleaning due to thin material.

For the next tests, the slip needs to be redesigned to not fail by increasing the thickness. The ligaments need to be reassessed so that there is less folding when bent and a bigger distance between the bones. Documented in figure 29 a to $d$.

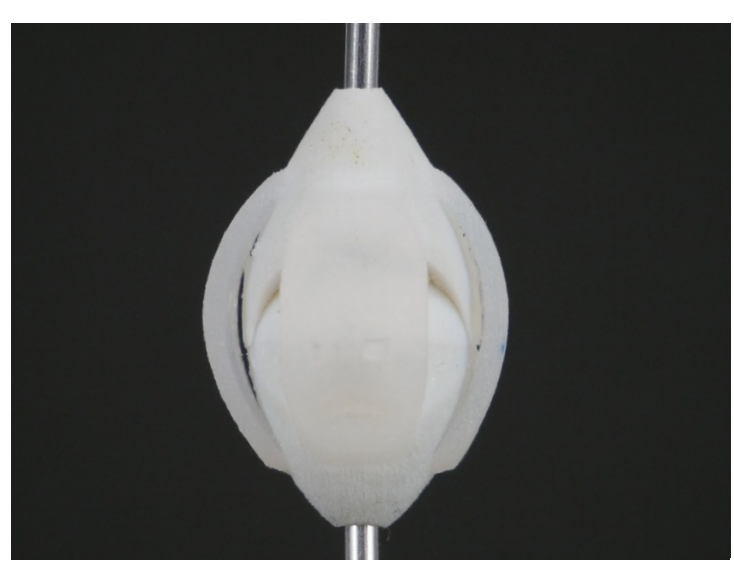

Figure 29 , six/seven, front. 


\section{Tendon Testing (One, Two \& Three).}

With the new Agilus materials, simple tests were needed to determine which material Shore Hardness performed the closest to a real tendon.

One.

- Shore Hardness 75 with a Vero top.

- This is flexible but stretches too much when pulled.

- Not suitable.

Documented in figure $30 \mathrm{a} \& \mathrm{~b}$.

Two.

- Shore Hardness 85 with a Vero top

- Most successful as it still bends.

- Only stretched a small amount whilst still retaining structure.

Documented in figure 31 a \& b.

Three.

- $\quad$ Shore Hardness 95 with a Vero top.

- Durable and does not stretch.

- The rigid nature of the material blend will not bend well around the internal working and potentially snap.

Documented in figure $32 \mathrm{a} \& \mathrm{~b}$.

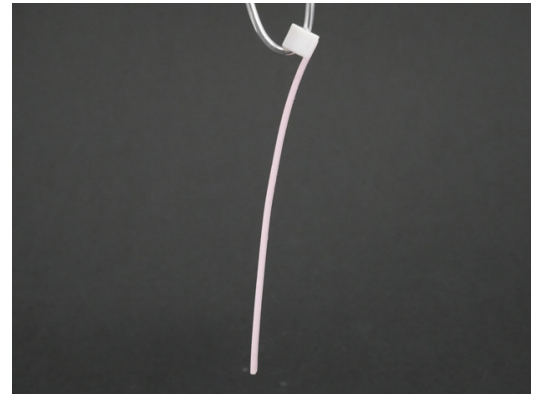

Figure 30 a, tendon one, straight.

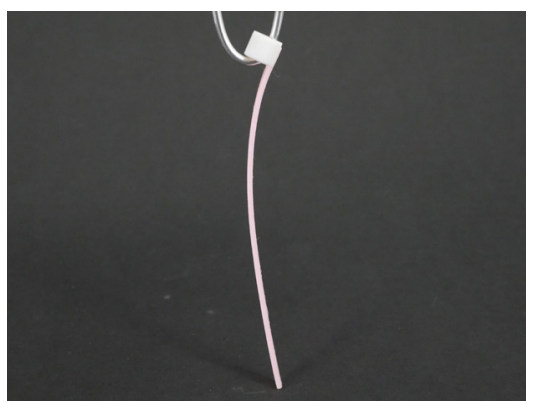

Figure 31 a, tendon two, straight.

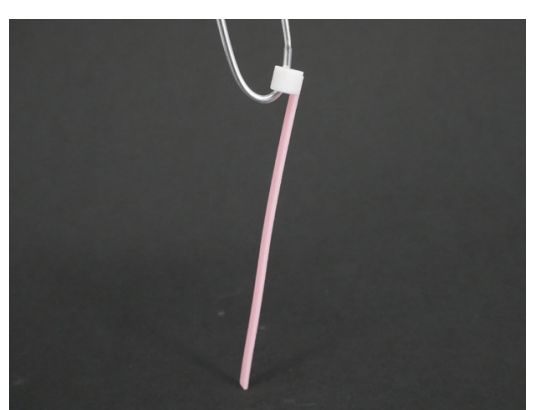

Figure 32 a, tendon three, straight.

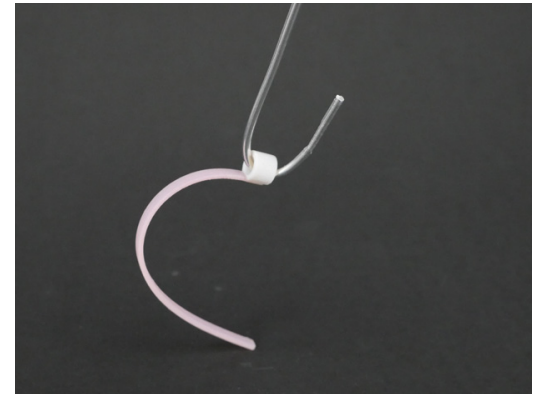

Figure 30 b, tendon one, bent.

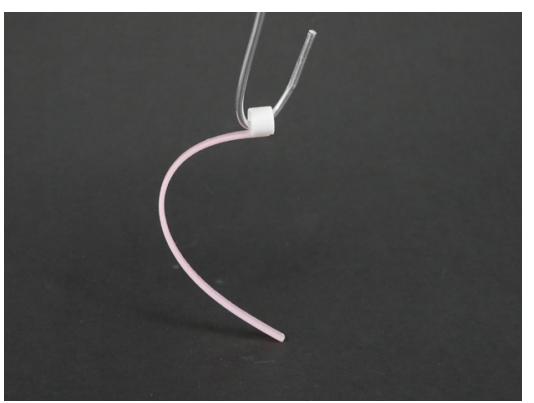

Figure 31 b, tendon two, bent.

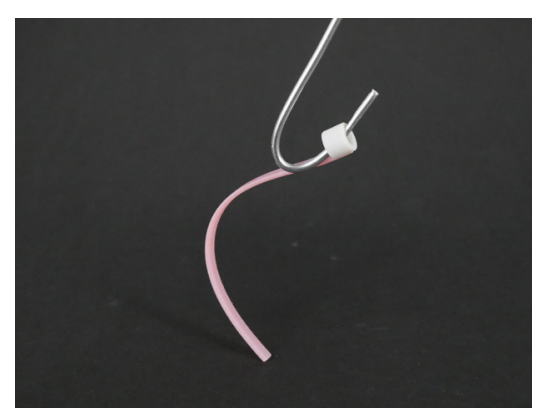

Figure 32 b, tendon three, bent. 


\section{Eight \& Tendon Four.}

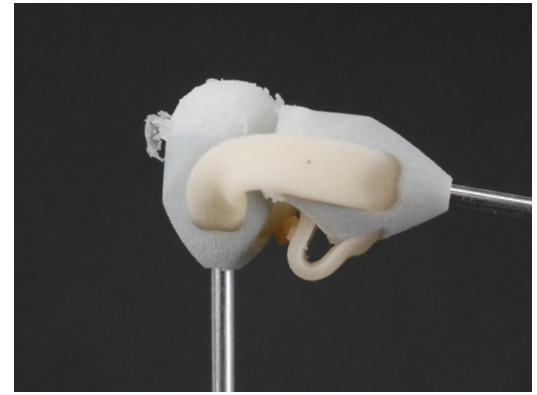

Figure 33 a, eight, bent.

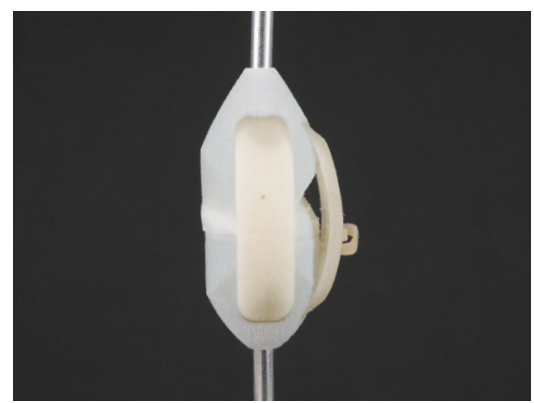

Figure 33 b, eight, side.

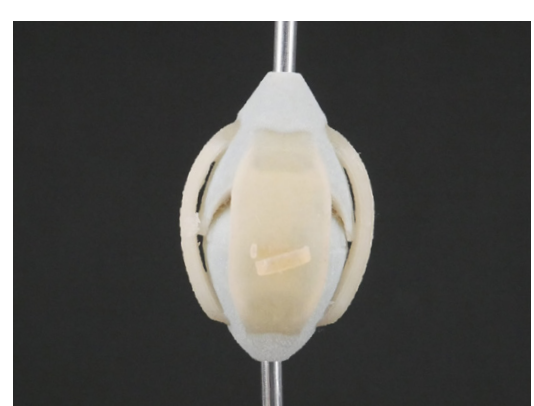

Figure 33 c, eight, front.

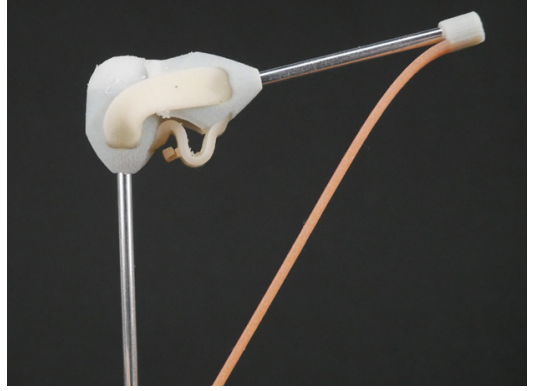

Figure 33 d, eight, tendon, bent.

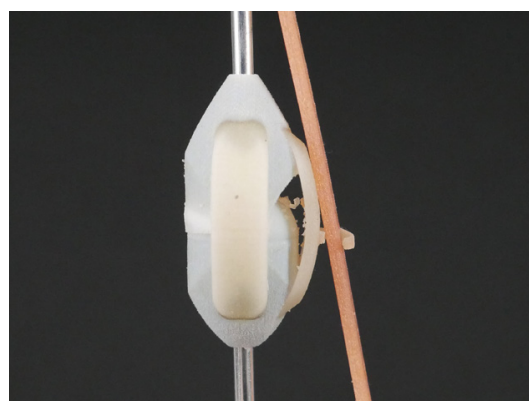

Figure 33 e, eight, tendon, side.

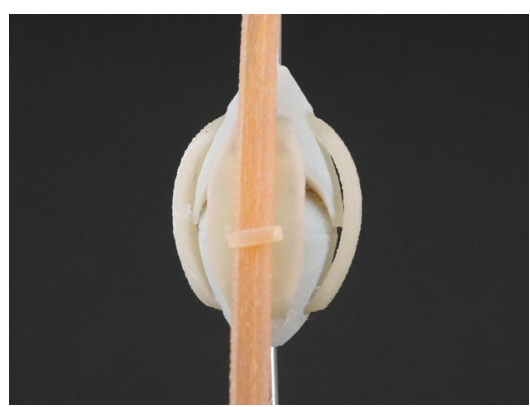

Figure $33 f$, eight, tendon, front.
This test was to determine how the tendon slip will be integrated into the volar plate and the overall shape of the bone structure.

- Materials used:

- Bone, Vero. (grey)

- Ligaments, Shore Hardness 40. (off white)

- Tendon slip, Shore Hardness 85. (off white)

Cartilage, Shore Hardness 30. (white)

- The distance between the bone section was increased and

- was successful.

- It broke during the cleaning process.

- $\quad$ Front ligament becomes bulky when folded.

Documented in figure 33 a to c.

Next test will have a smaller thickness for the ligaments.

\section{Tendon Four.}

This was to determine how the tendon will perform along with the bone and ligament structure.

- The top of the tendon was adapted to connect with the wire.

- $\quad$ Shore Hardness 85.

- $\quad$ Tested on joint eight.

- The tendon material was strong enough to cause proper movement.

Documented in figure $33 \mathrm{~d}$ to $\mathrm{f}$. 


\section{Nine.}

To determine what thickness and shape the tendon slip needs to be to perform correctly.

Materials used:
Bone, Vero. (grey)
Ligaments, Shore Hardness 40. (off white)
- Tendon slip, Shore Hardness 85. (off white)
Cartilage, Shore Hardness 30. (white)

- $\quad$ Front ligament thickness was changed to one millimetre.

- The position was changed to reduce the amount of folding material.

- Side ligaments were moved in further as the previous placement was not needed.

- The slip was the same material as test eight and did break when the tendon was pulled.

Documented in figure 34 a to $\mathrm{c}$.

The slip needs to be redesigned so that it does not break as early when the tendon is pulled.

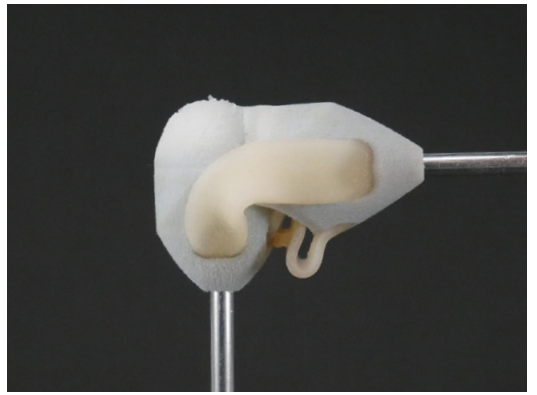

Figure 34 a, nine, side bent.

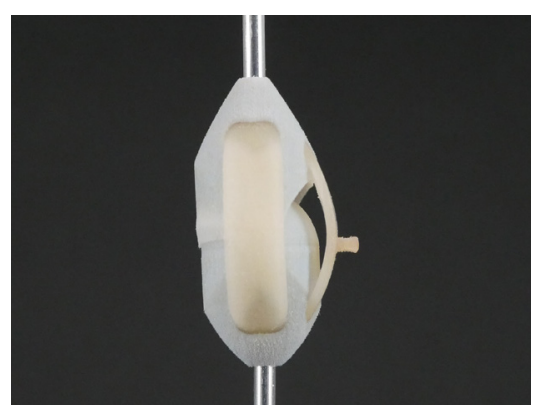

Figure 34 b, nine, side.

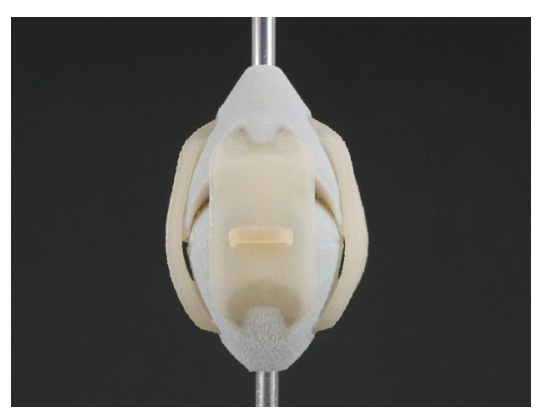

Figure 34 c, nine, front.

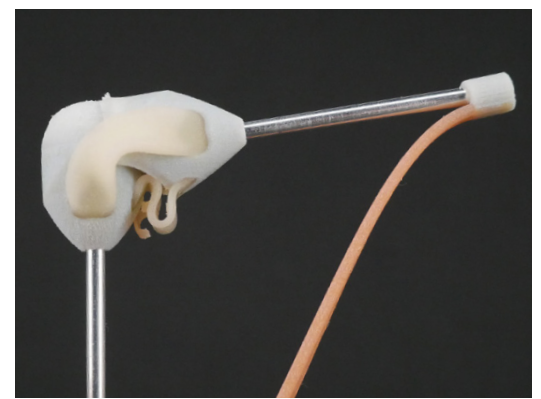

Figure $34 d$, nine, tendon, bent.

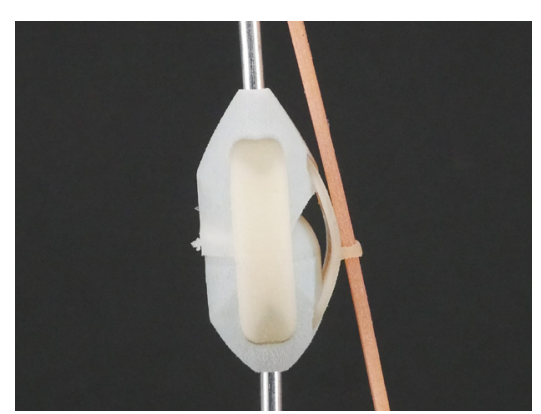

Figure 34 e, nine, tendon, side.

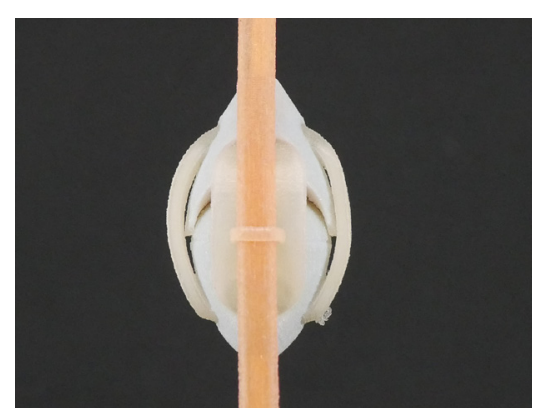

Figure $34 \mathrm{f}$, nine, tendon, front. 


\section{Ten.}

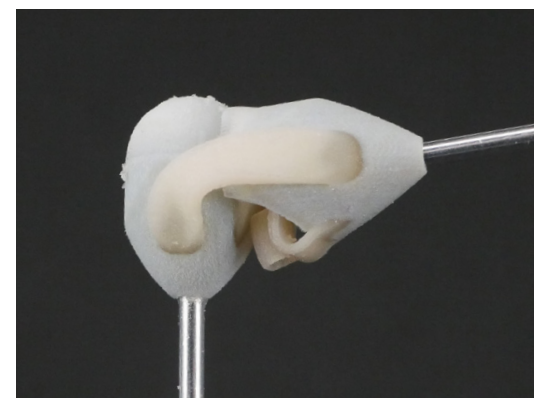

Figure 35 a, ten, bent.

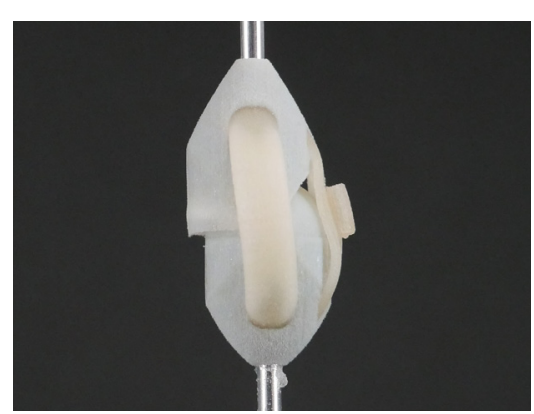

Figure 35 b, ten, side.

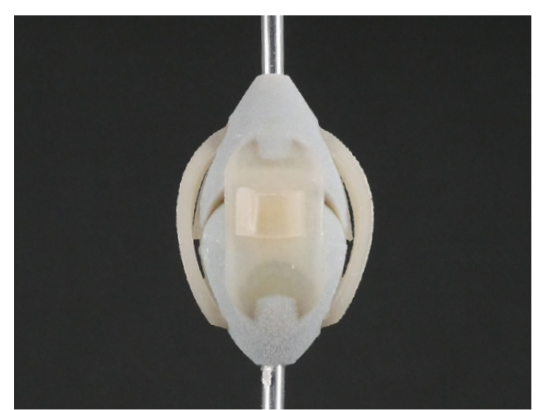

Figure 35 c, ten, front.

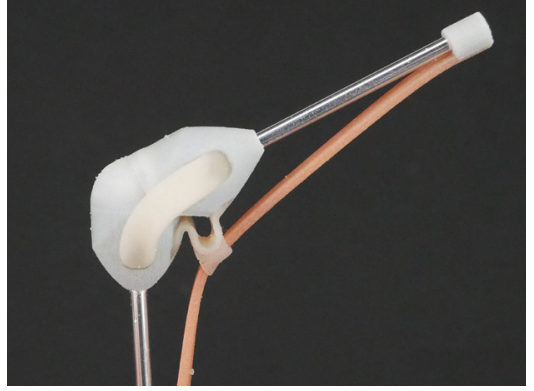

Figure 35 d, ten, tendon, bent.

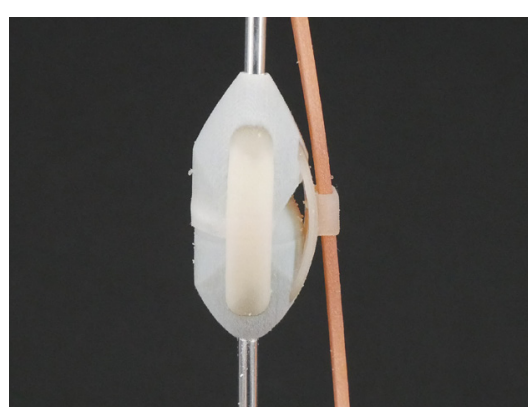

Figure 35 e, ten, tendon, side.

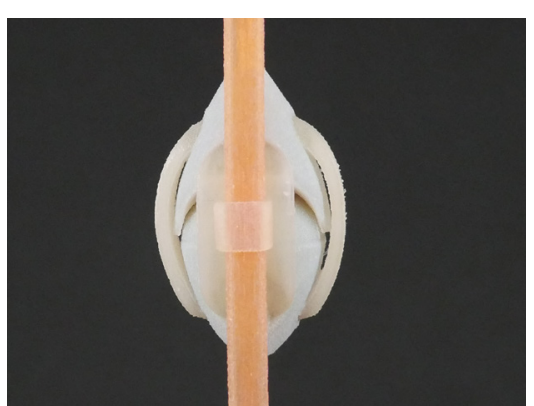

Figure $35 \mathrm{f}$, ten, tendon, front.
This test redesigned the thickness and shape of the tendon slip to perform better than the previous testing.

- Materials used:

- Bone, Vero. (grey)

Ligaments, Shore Hardness 40. (off white)

- Tendon slip, Shore Hardness 85. (off white)

Cartilage, Shore Hardness 30. (white)

- The slip was lengthened.

- $\quad$ Printed in Shore Hardness 50.

- Was successful as it did not break immediately when the tendon was pulled.

- Splitting did start to occur at the bottom of the slip when pulled.

The addition of skin might resolve this issue as it will add support to the structure.

Documented in figure 35 a to c. 


\section{Tendon Five.}

This test was to determine if an extensor tendon will be necessary within the model.

- Materials used:

Connection point, Vero. (white)

Tendon, Shore Hardness 85. (orange)

- Tested on joint ten.

- Added extension tendon.

- Agilus is an elastic material and will go back to its original printed position.

- Extender tension is not needed as the joint returns to its straight position.

Documented in figure 36 a to $d$.

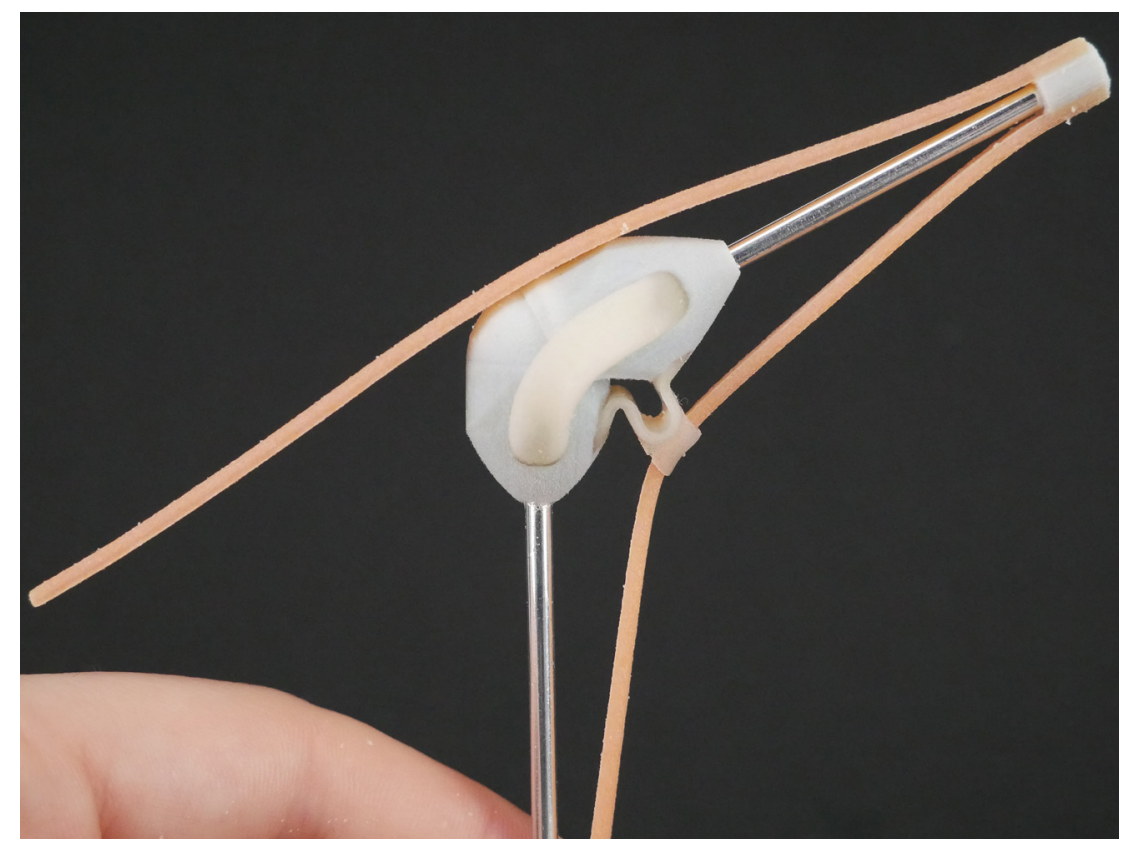

Figure 36 a, tendon five, bent.

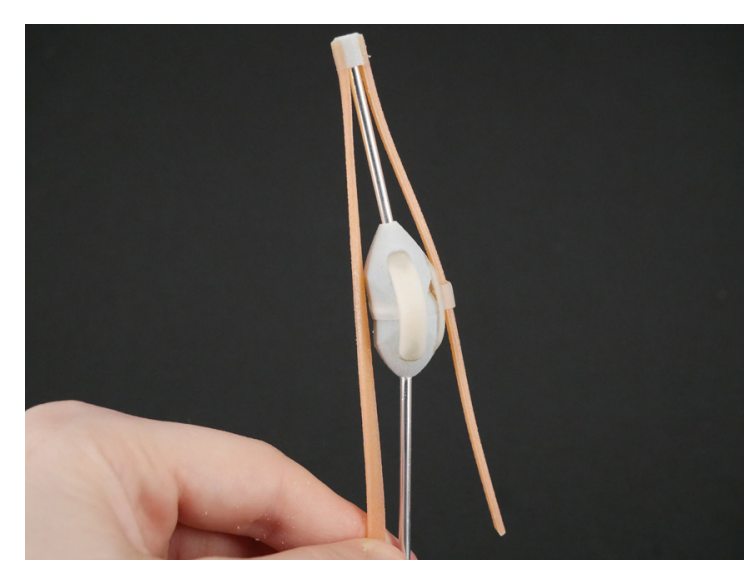

Figure 36 b, tendon five, bent back.

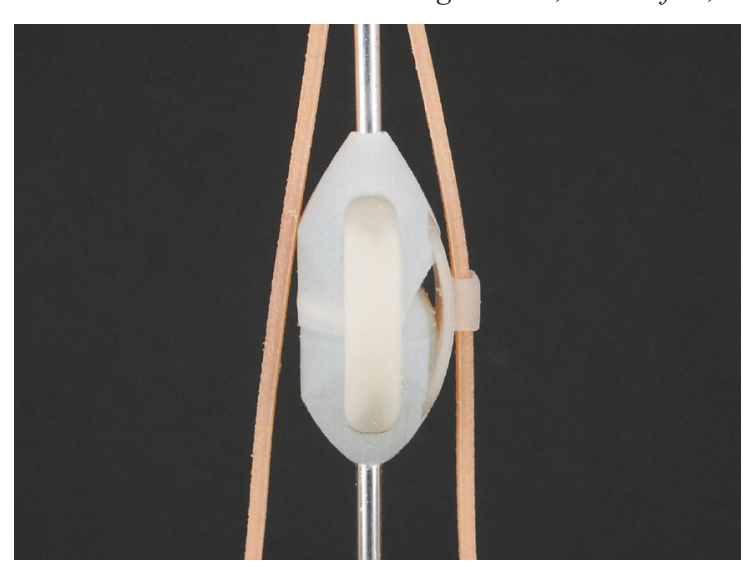

Figure 36 c, tendon five, side.

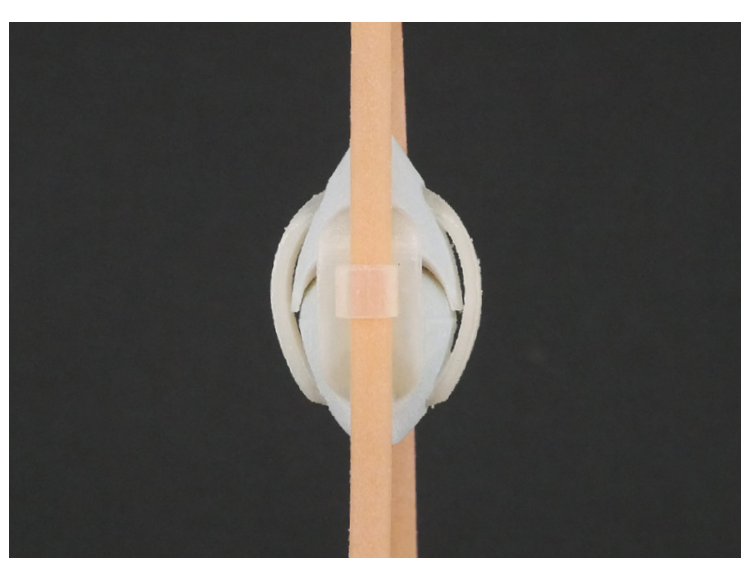

Figure 36 , tendon five, front. 


\section{Eleven \& Twelve.}
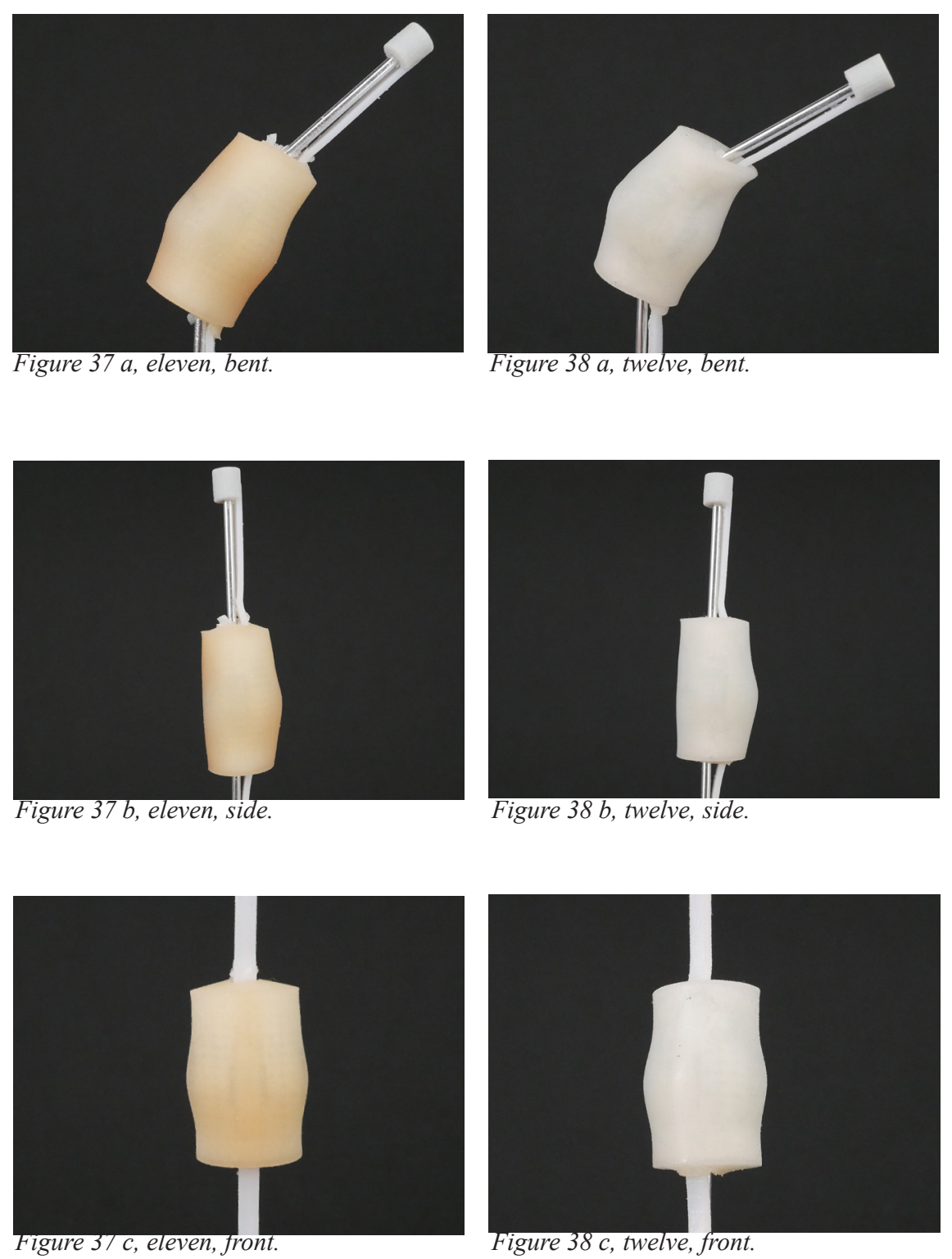

This test is to determine what material works best for the skin aspect.

- Materials used:

- Bone, Vero. (white)

- Ligaments, Shore Hardness 40. (off wight)

Cartilage, Shore Hardness 30. (white)

Tendon, Shore Hardness 85. (white)

\section{Eleven (Left).}

- Shore Hardness 40 for the slip.

- Shore Hardness 50 for the skin.

The model has thinner side ligaments.

The skin did restrict movement due to the material mass and support material. The skin also split at the base due to tension caused by the tendon moving.

Documented in figure 37 a to $\mathrm{c}$.

\section{Twelve (Right).}

- $\quad$ Shore Hardness 40 for the slip.

- Shore Hardness 40 for the skin.

- The skin restricted movement due to the material mass and support material.

Most of the support material was removed from the inside. More successful than test eleven.

Tearing occurred at the base of the skin when the tendon was pulled, this might be solved by extending the skin section and adding fat.

Documented in figure 38 a to $\mathrm{c}$. 


\section{Thirteen \& Fourteen.}

These tests are similar to eleven and twelve with added cut out detail in the skin to determine if this affects the folding and movement of the overall joint. These tests were printed in the same material as test eleven and twelve.

\section{Thirteen (Left).}

- Added folds similar to the ones found on the bends of the finger.

- $\quad$ Shore Hardness 40 for the slip.

- Shore Hardness 50 for the skin.

- Restricted movement due to material mass and support material.

- $\quad$ Skin splitting at the base where the tendon moves.

The folds did not perform as expected, reassessment of the shapes and depth of them needs to occur in the next batch of testing.

Documented in figure 39 a to $\mathrm{c}$.

\section{Fourteen (Right).}

- Same design as thirteen.

- $\quad$ Shore Hardness 40 for the slip.

- $\quad$ Shore Hardness 40 for the skin.

- Restricted movement due to material mass and support material.

- $\quad$ Skin splitting at the base where the tendon moves.

The folds did not work as intended. This model did tear down the side during the cleaning process. This did not happen with the other three, which all consist of the same wall thickness.

Documented in figure 40 a to c.

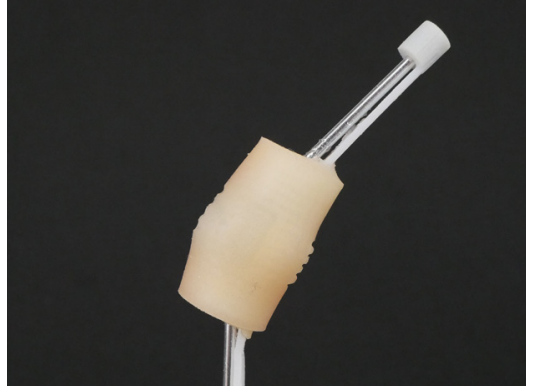

Figure 39 a, thirteen, bent.

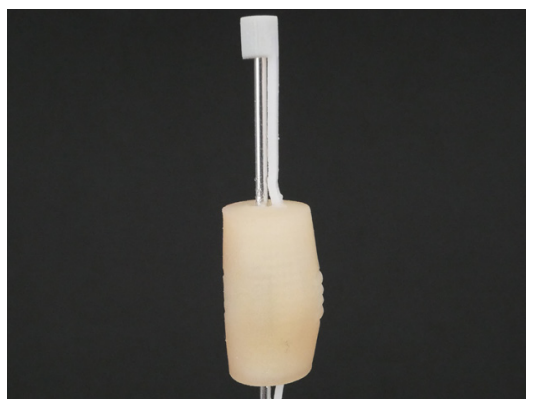

Figure 39 b, thirteen, side.

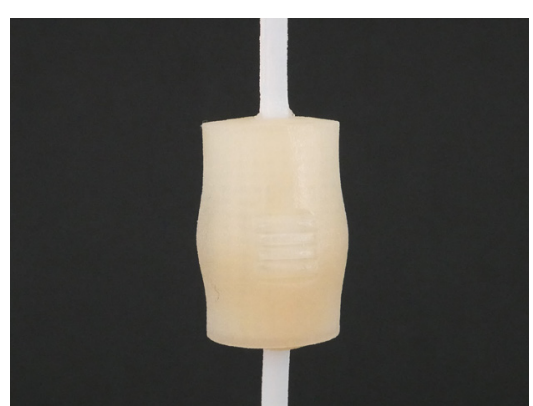

Figure 39 c, thirteen, front.

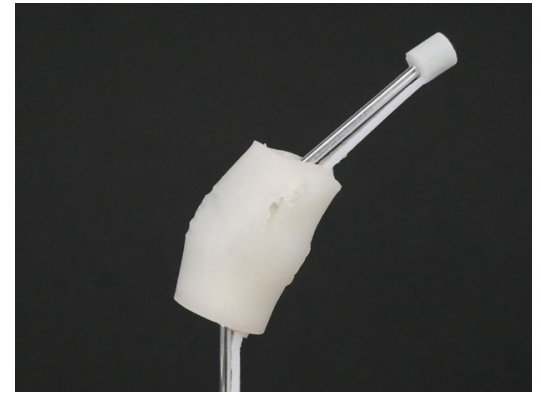

Figure 40 a, fourteen, bent.

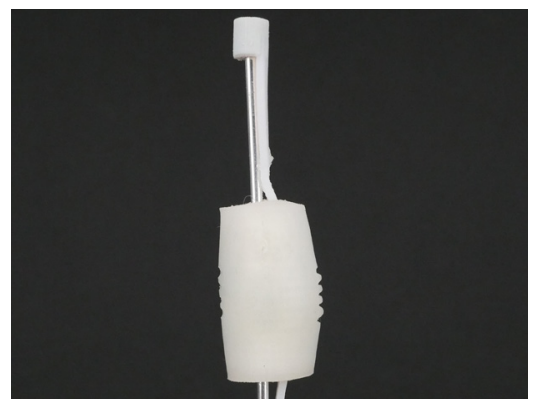

Figure 40 b, fourteen, side.

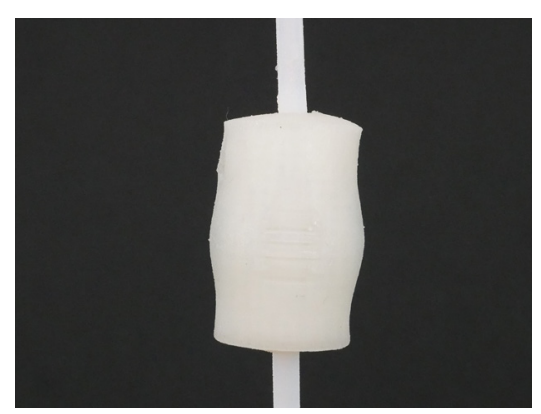

Figure 40 c, fourteen, front. 
Fifteen.

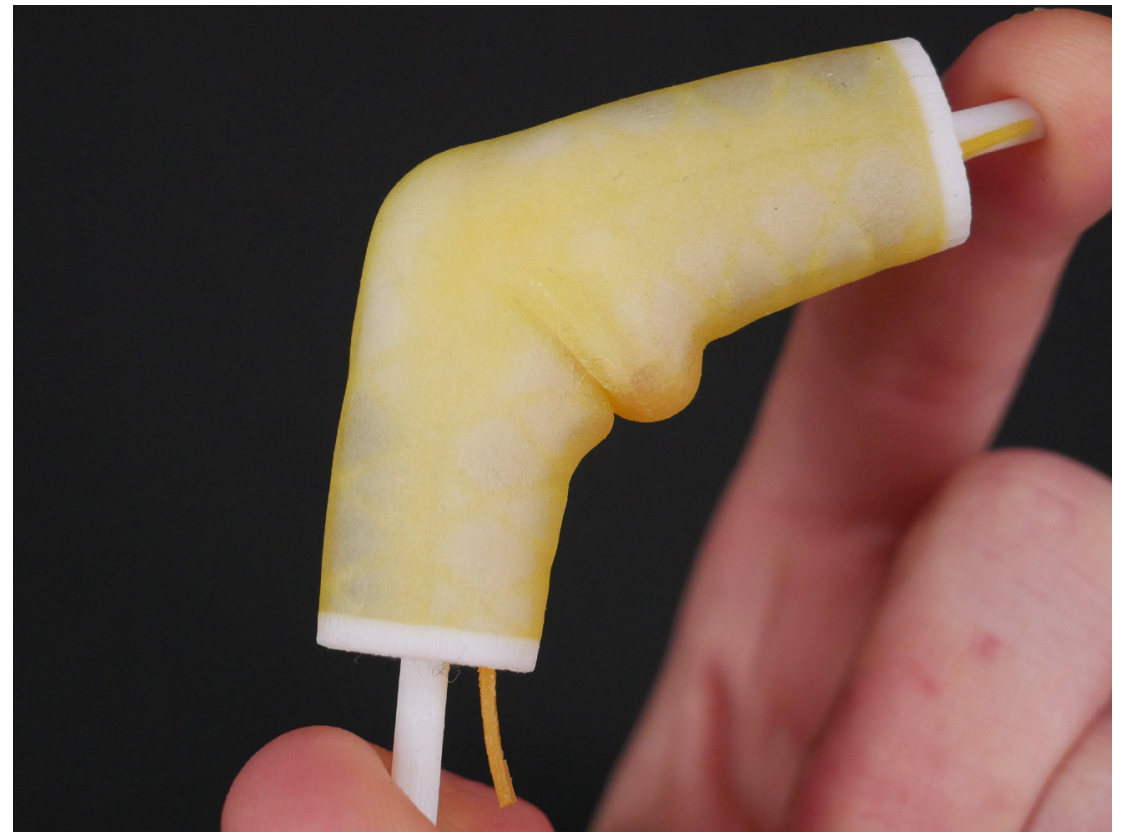

Figure 41 a, fifteen, bent.

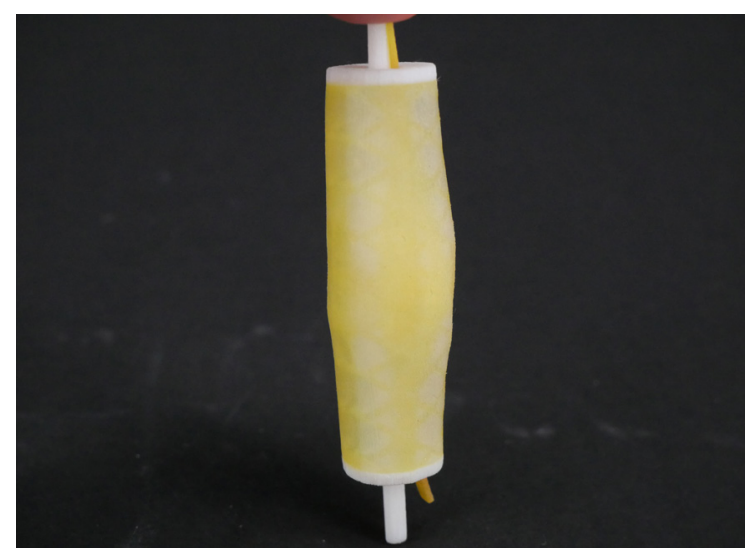

Figure 41 b, fifteen, side.

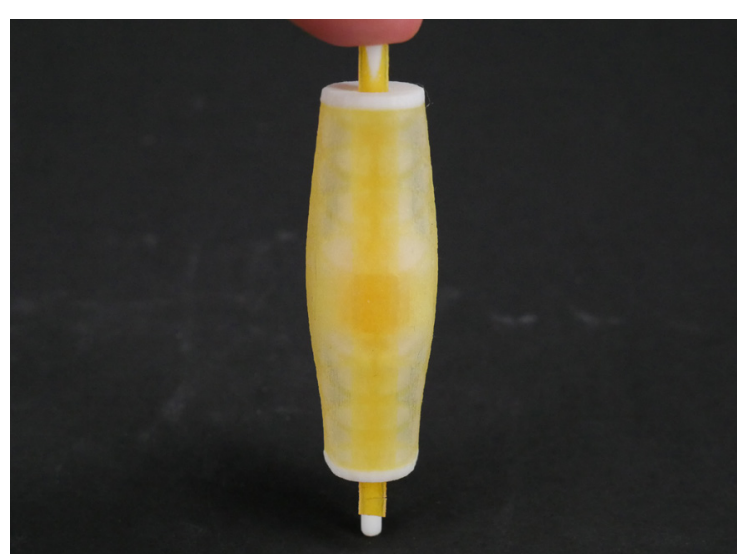

Figure 41 c, fifteen, Front
This test is to determine how extending the skin and adding a fat pattern will affect the ability to bend and tendon strength. Scaleddown by $10 \%$.

- Materials used:

- Cartilage and fat, Shore Hardness 30. (clear)

- $\quad$ Ligament and tendon slip, Shore Hardness 40.

(clear)

. Tendon, Shore Hardness 85. (yellow)

Skin, Shore Hardness 50. (yellow)

- The tendon broke at the base due to low strength.

- The movement was better than past testing, still restricted.

- The fat pattern was too bulky.

- Redesigned the pattern and tendon to reduce bulk and create strength.

This test did not have skin creases which need to be added in the next model to fully determine if this will affect the way the 'skin' stretches over the joint. Documented in figure 41 a to $\mathrm{d}$. 


\section{Sixteen A\&B.}

This comparison test was to assess which form of pattern generation works best for creating the fat element. The primary purpose of the fat is to reduce the amount of printed support material that can not be removed.

- Materials used:

$$
\text { Skin, Shore Hardness 50. (white) }
$$$$
\text { - Fat, Shore Hardness 30. (yellow) }
$$

A.

Pattern creation due to cutting a pattern out of a solid object in Solidworks CAD program.

A large amount of fat mass.

- $\quad$ Restricted flexibility in the overall test.

- Significant gaps between each section allowed for more hard support material to form.

Documented in figure $42 \mathrm{a} \& \mathrm{~b}$ and Figure $43 \mathrm{a} \& \mathrm{~b}$.

B.

- Pattern creation using the CAD software Autodesk Netfabb premium lattice creator function.

- Smaller, more consistent pattern.

- Limited the amount of support material that could form, but there was still a significant amount

- Improved movement.

Documented in figure $42 \mathrm{a} \& \mathrm{~b}$ and Figure $44 \mathrm{a} \& \mathrm{~b}$.

The next prints will use the lattice from B but will have increased pattern size and density.
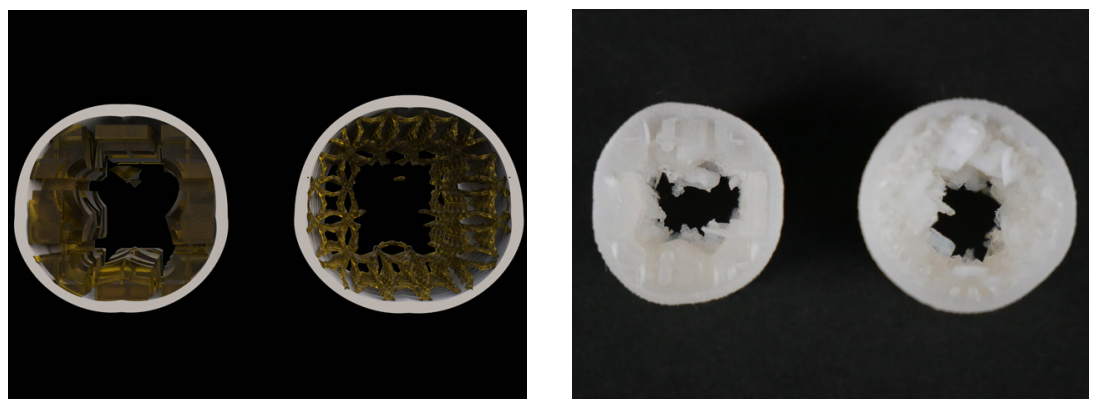

Figure 42 a, sixteen, render

Figure 42 b, sixteen, physical.
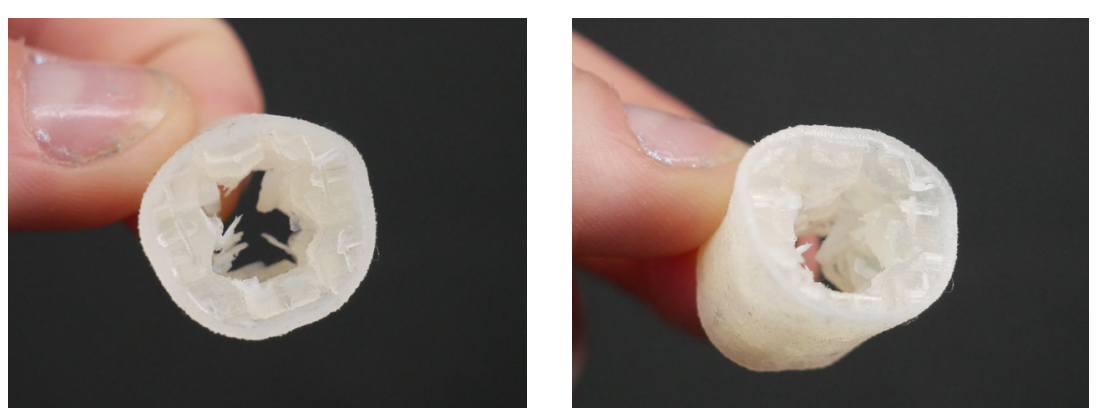

Figure 43 a, sixteen A, front.

Figure 43 b, sixteen A, angled.
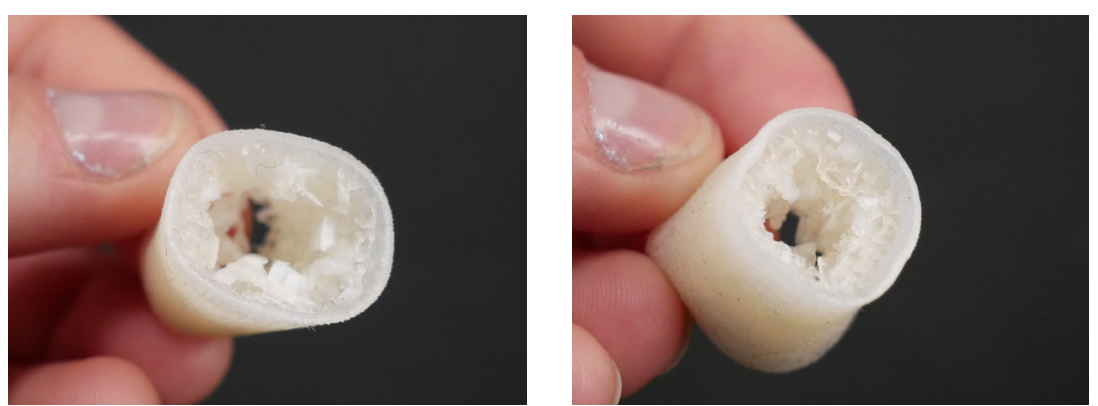

Figure 44 a, sixteen B, front.

Figure 44 b, sixteen B, angled. 
Seventeen.

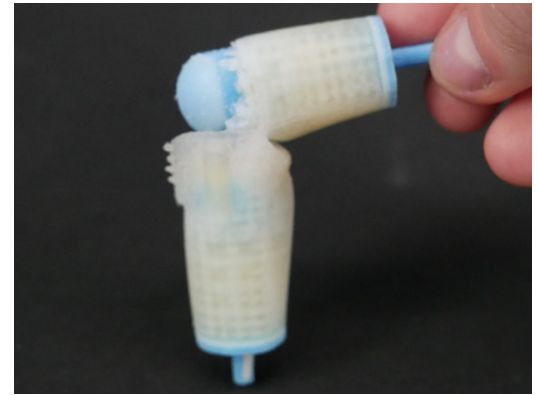

Figure 45 a, seventeen, bent.

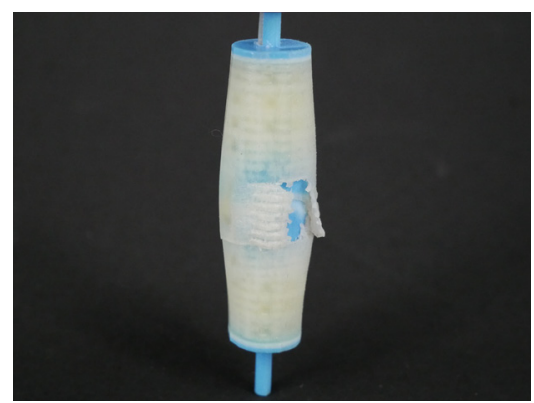

Figure 45 c, seventeen, front.

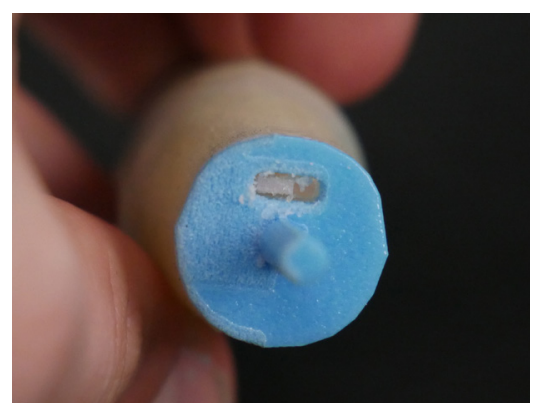

Figure 45 e, seventeen, tendon exiting point.

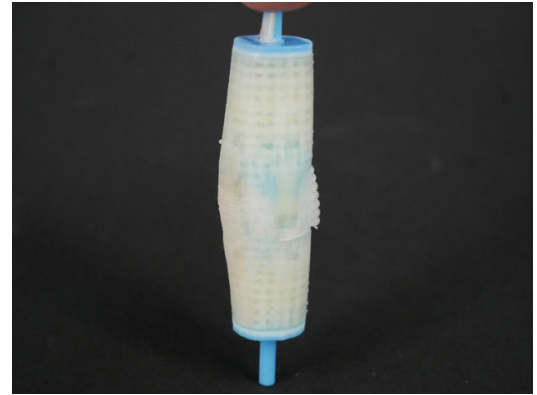

Figure 45 b, seventeen, side.

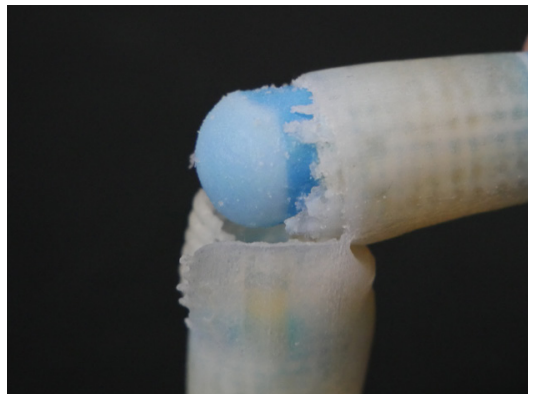

Figure 45 d, seventeen, broken detail.

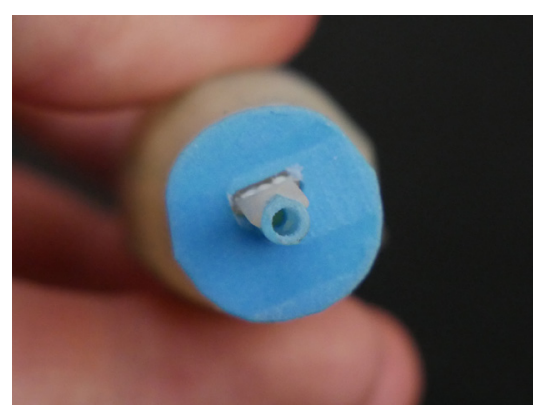

Figure 45 , seventeen, injection point.
This test was to test how the creases on both sides would affect the movement of the skin as it flexes.

- Materials used:

- Skin, Shore Hardness 40. (clear)

- Tendon, Shore Hardness 85. (clear)

- Creases on the palm side were too small and misaligned.

- Creases on the top or back of the finger disintegrated in the cleaning process.

- $\quad$ This could be due to being printed with the gloss setting.

- A stent was incorporated into the model for access to the internal joint for lubrication.

This was not tested because of skin breakage.

- The tendon lasted longer and created better movement in the joint before eventually breaking.

- The skin was printed in a softer Shore Hardness that allows for better movement.

- $\quad$ The bigger fat lattice did not remove enough support. Documented in figure 45 a to $\mathrm{f}$.

\section{Next test.}

- The skin will be printed in Shore Hardness 35.

- Will use matt finish for the print setting.

- The creases will be removed.

- $\quad$ Skin will be moved slightly outwards to allow for more room to stretch.

- The tendon material will remain Shore Hardness 85 but will have Vero ribbing added.

- The fat lattice will be removed to see how the support material acts within the closed form. 


\section{Eighteen.}

This test was a redesign of test seventeen with different skin material and printing settings.

- Materials used:

\section{Skin, Shore Hardness 35. (clear)}

Tendon, Shore Hardness 85. (yellow)

- $\quad$ Skin with new creases at the joint.

- Model was scaled down by $5 \%$.

- No fat within the form.

- The pink tendon hard support material shifted during the printing process and fused with the bone sections.

- It also intersected with the stent resulting in not being able to be removed, resisting the joints ability to move.

- This also restricted the joints ability to bend.

- The skin at the bend point tore potentially due to cleaning error.

Documented in figure 46 a to $\mathrm{f}$.

For the next testing, the tendon support will be moved to not intersect with other parts. Moreover, further assessment of different material combinations for the skin, fat and lubrication testing will occur.

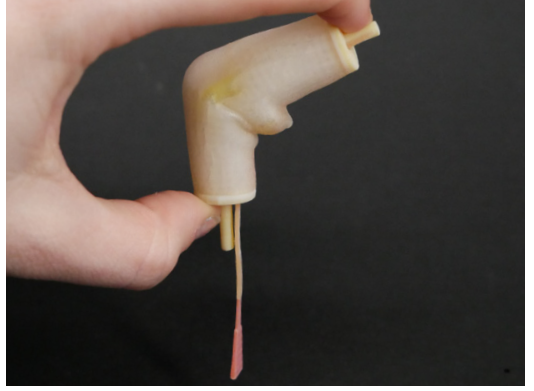

Figure 46 a, eighteen, bent.

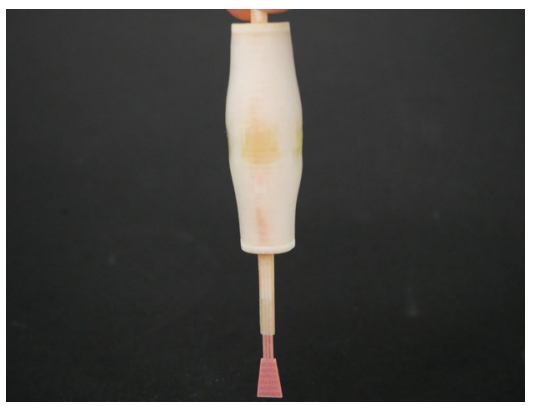

Figure 46 c, eighteen, front.

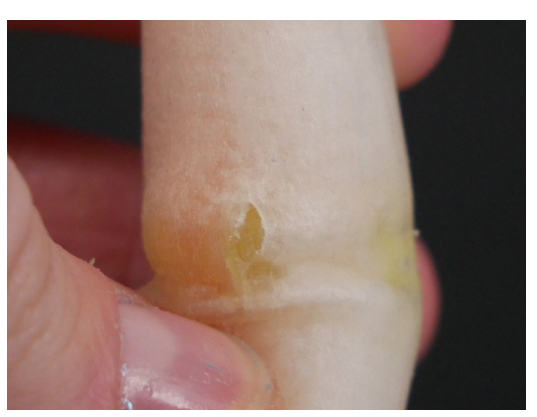

Figure 46 e, eighteen, tore section.

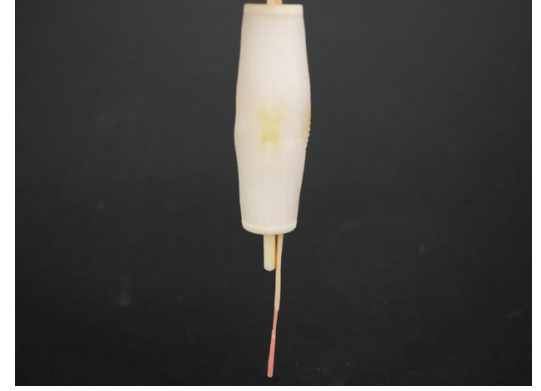

Figure 46 b, eighteen, side.

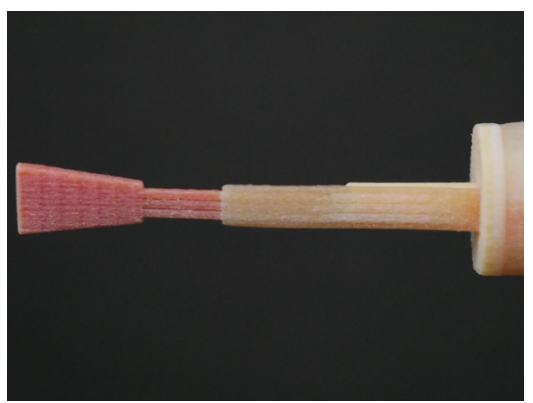

Figure $46 d$, eighteen, tendon support.

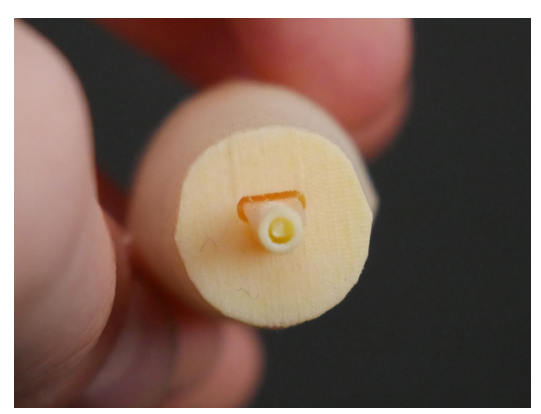

Figure $46 f$, eighteen, stint stuck. 


\section{Tendon Six.}

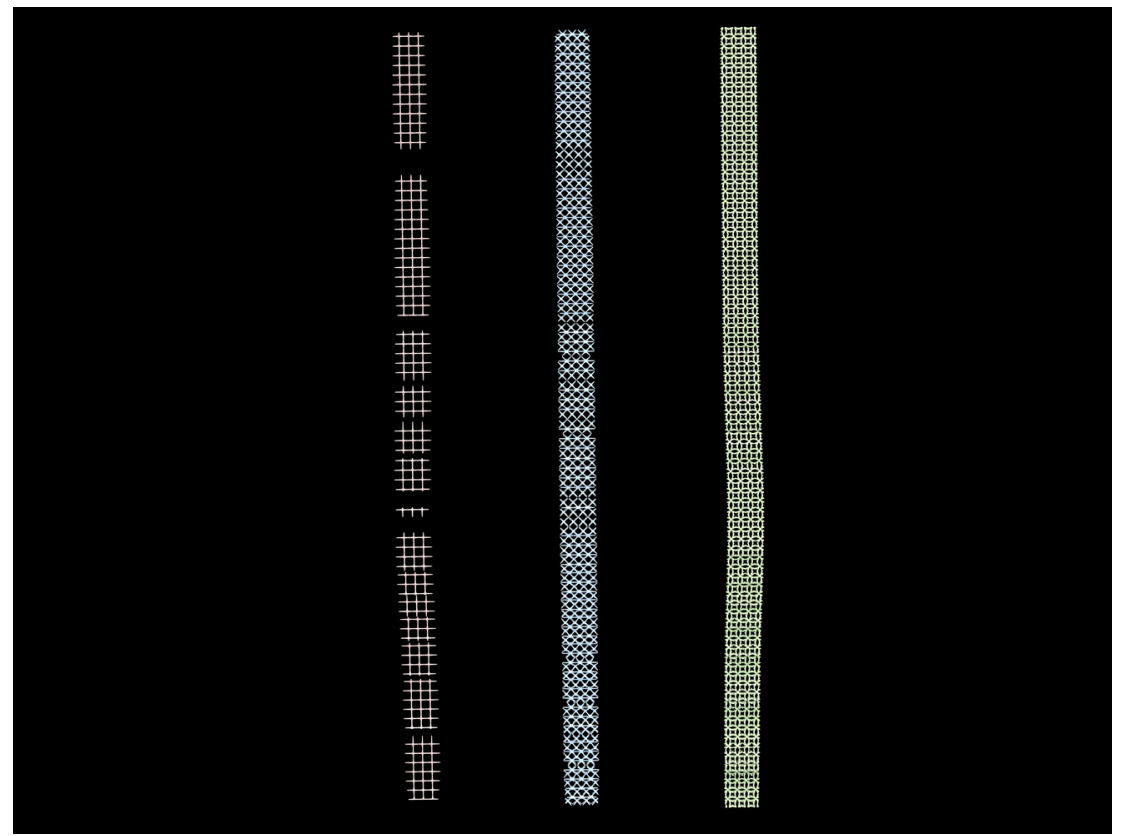

These tests were inconclusive as the lattice pattern that was intended to be within the tendon did not show up in the designated colour specified.

Materials used:

Tendon, Shore Hardness 85. (clear)

Support pattern, Vero. (red, green \& blue)

- The tendon Shore Hardness 85 material washed out the colour of the hard patterns.

- Vero support material within the soft tendon did improve the strength of the part.

- A new liner ribbing will be used in place of the lattice design.

Documented in figure 47 a to $\mathrm{d}$.

Figure 47 a, tendon six, render.

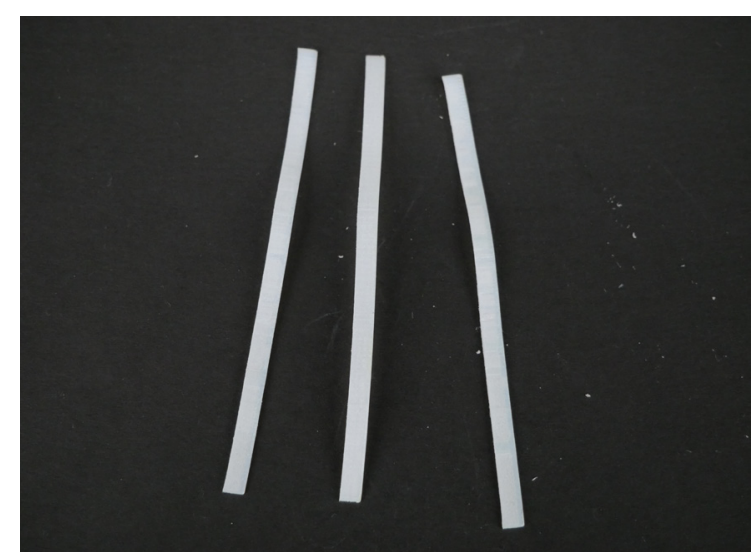

Figure 47 b, tendon six, physical.

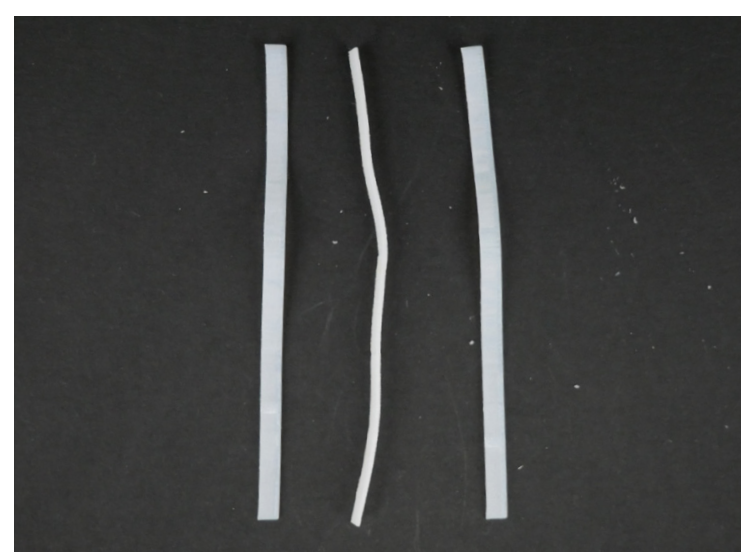

Figure 47 c, tendon six, side view.

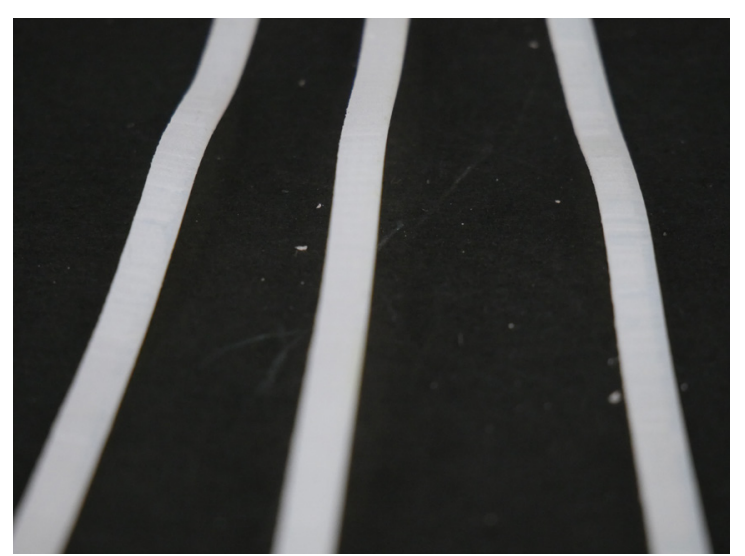

Figure $47 d$, tendon six, close up detail. 


\section{Nineteen A.}

This test compared which material combination worked best in regards to the model's ability to bend.

- Materials used:

Skin, Shore Hardness 30. (clear)

Fat, Shore Hardness 40. (yellow)

- Bent further than test B.

- The tendon did break but after multiple manipulations.

- Broke in the same place as test B where there was only one strand of hard tendon support material.

- This test was manipulated with water, and separately with Armor-All.

- Lubrication was injected into the cavity formed from the removable stent, which helped with fluid movement.

Documented in figure 48 a to $\mathrm{d}$.
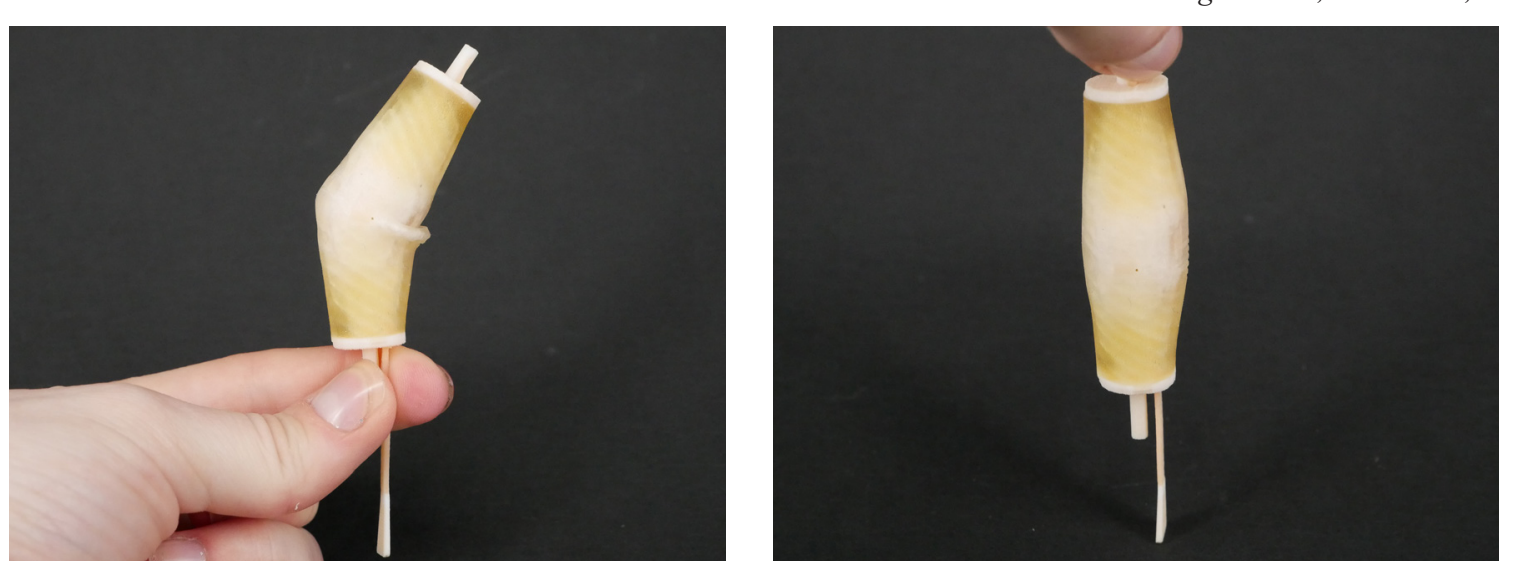

Figure 48 b, nineteen A, slightly bent.

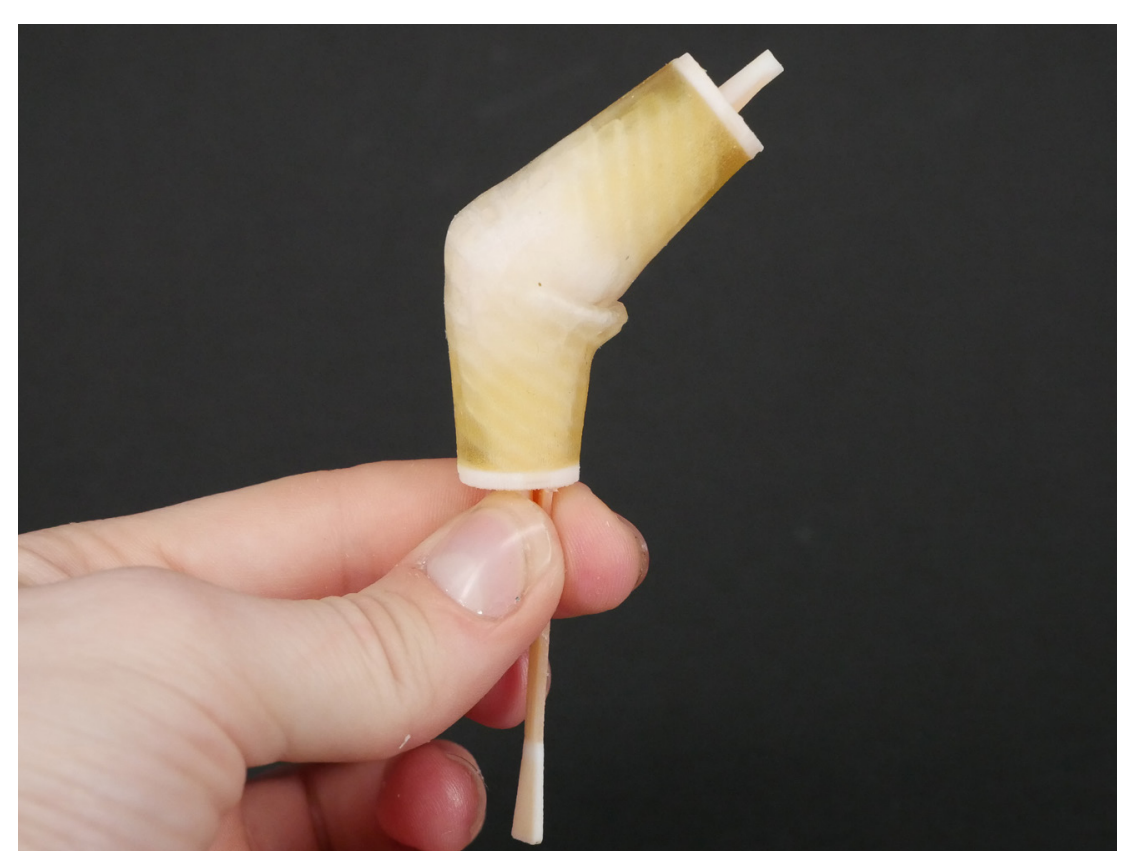

Figure 48 a, nineteen A, bent.

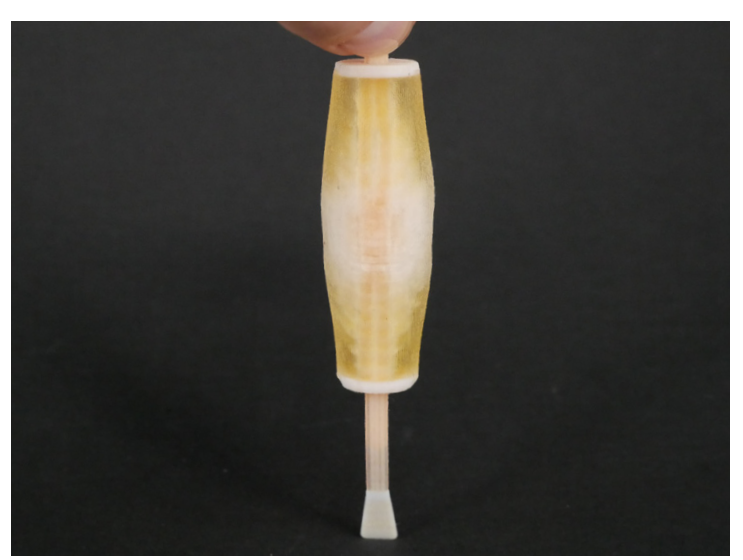

Figure $48 d$, nineteen A, front. 


\section{Nineteen B.}

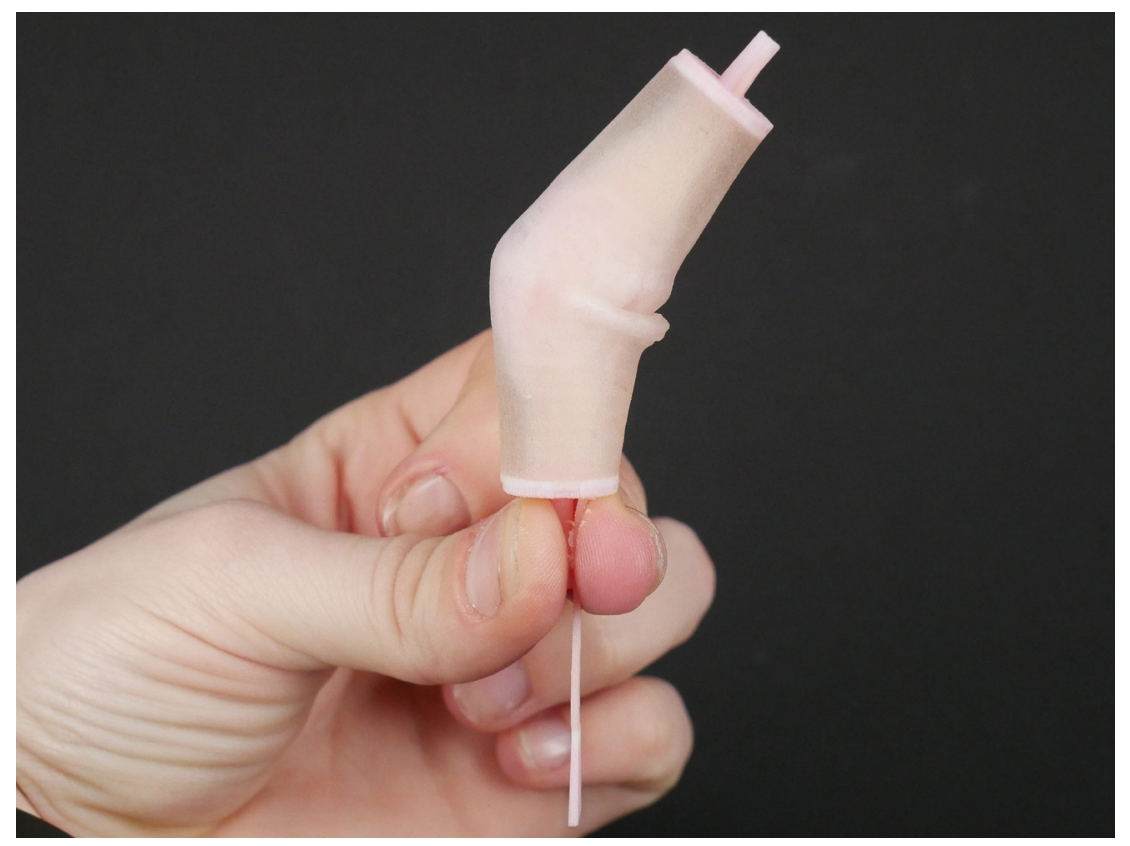

Figure 49 a, nineteen $B$, side bent.

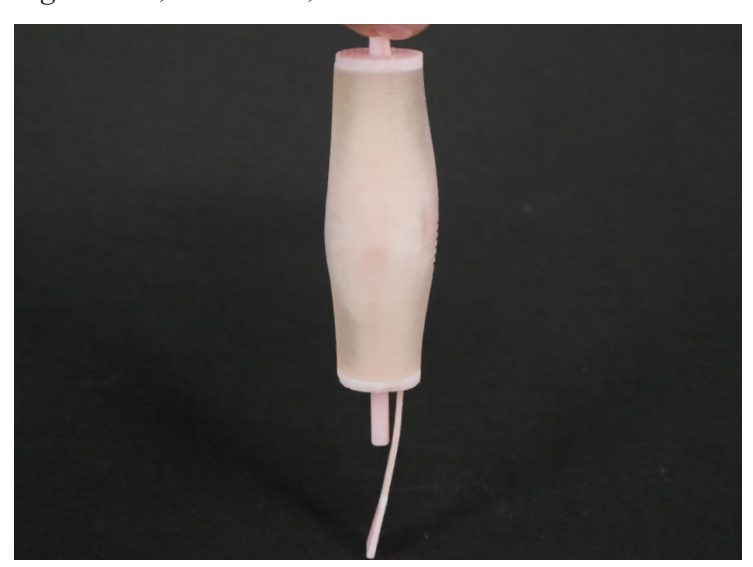

Figure 49 b, nineteen $B$, side.
This test was to compare which material combination worked best in regards to the model's ability to bend.

- Materials used:

Skin, Shore Hardness 40. (pink)

Fat, Shore Hardness 30. (clear)

- The tendon broke soon after printing and manipulation testing.

- $\quad$ Skin was a harder so material the joint struggled to bend.

- Both tests have small refined creases on the palm side where the material folds over the top of each other.

- $\quad$ They do not change or help the folding of material so will be removed from further testing.

Next testing will be lubrication to reduce the friction that occurred between the two hard parts. The next full model will consist of multiple joints, a reassessed tendon and a fingertip with a nail.

Documented in figure 49 a to d.
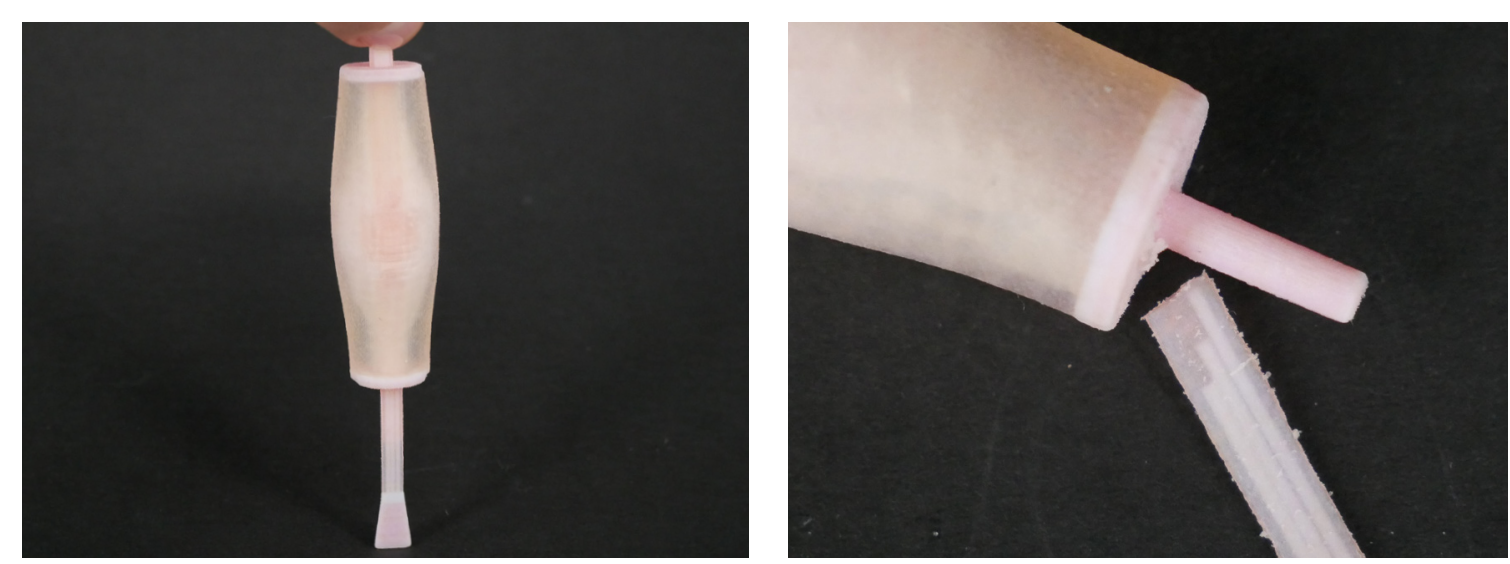

Figure 49 c, nineteen B, front.

Figure 49 d, nineteen B, tendon brake. 


\section{Lubrication, Water.}

This testing was suggested by Ross Stevens (2019) as a way to look at how the material reacts to different lubricants and exposure of these liquids to provide a smoother movement.

\section{Test Swatch.}

- $\quad$ Soaked for 24 hours.

- When the Agilus material is placed in water, the translucency is removed.

- The water is absorbed and allows the material to manipulate further than when dried.

- Due to the nature of water, it requires continuous submersion the model to prevent drying.

Documented in figure $50 \mathrm{a} \& \mathrm{~b}$

\section{Submersion.}

- All transparency is lost when material is exposed to water for a length of time.

- The joint does bend somewhat better.

- The water is only affecting the outer layers, whereas the external skin needs to remain dry, and the internal bones and ligaments need to be lubricated.

- The model dries out within 24 to 48 hours of exiting the bath.

Documented in figure 51 a \& b.

\section{Injection.}

- Delivery of lubrication works efficiently as it is directly injected into the joint where the friction occurs.

- Within the joint, there are two thin layers of pure Agilus material between the two bone structures that absorbs some of the liquid.

Documented in figure $52 \mathrm{a} \& \mathrm{~b}$.

Water works as short term lubrication but does dry out frequently.

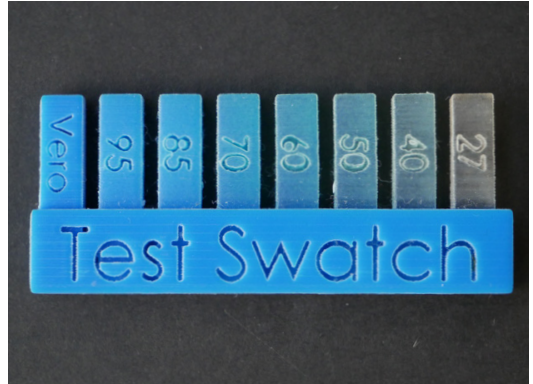

Figure 50 a, Lubrication water, dry.

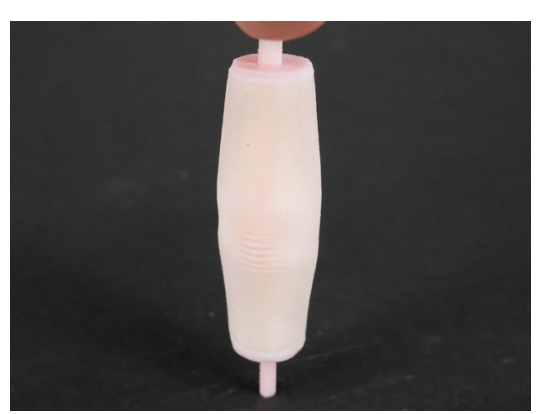

Figure 51 a, Lubrication water, submersion.

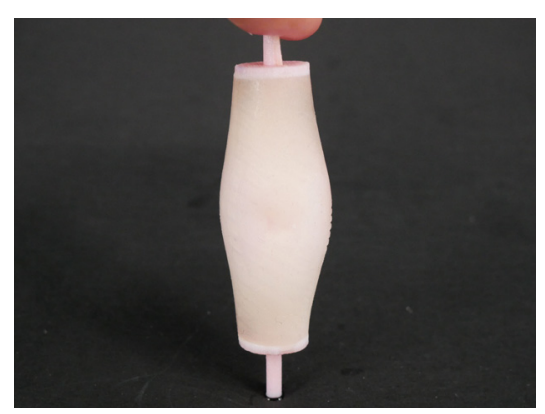

Figure 52 a, Lubrication water, injected.

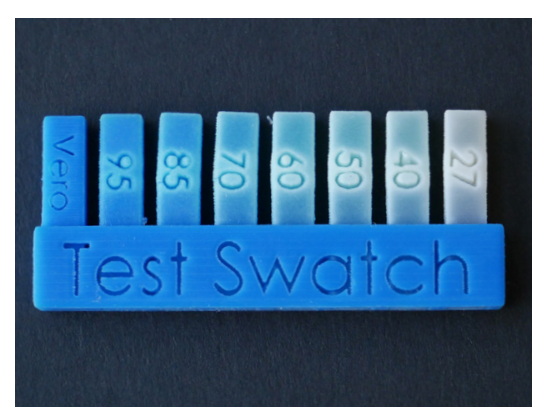

Figure 50 b, Lubrication water, wet.

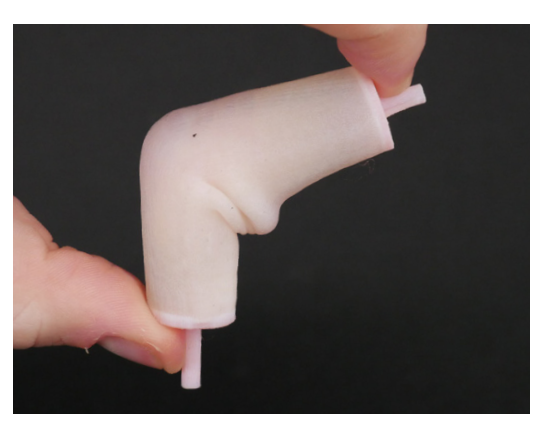

Figure 51 b, Lubrication water submersion.

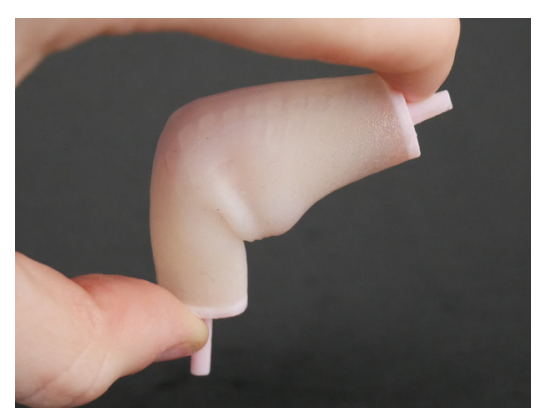

Figure 52 b, Lubrication water, injected. 
Lubrication, Armor-All.
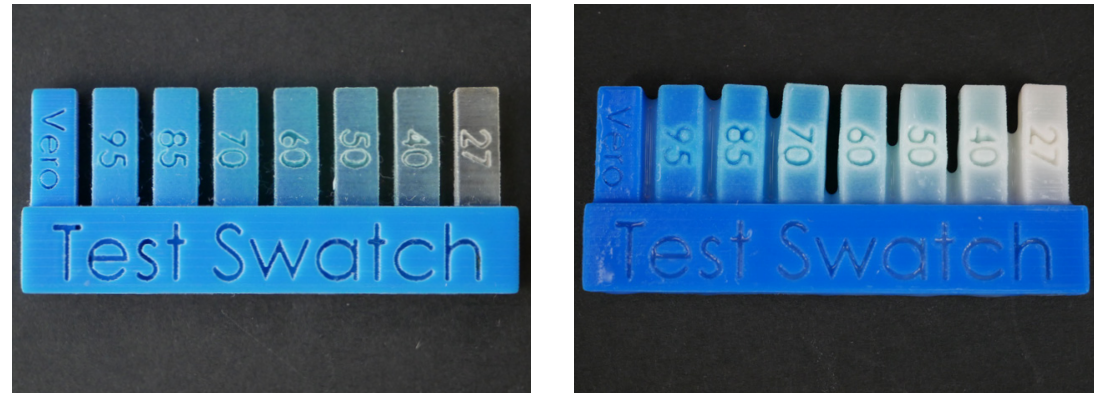

Figure 53 a, Lubrication Armor-All dry.

Figure 53 b, Lubrication Armor-All wet.

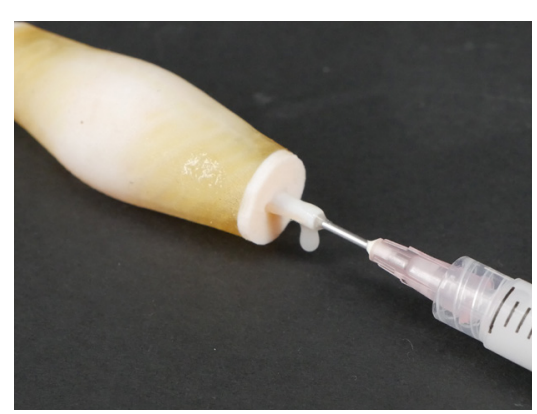

Figure 54 a, Lubrication Armor-All, submersion.

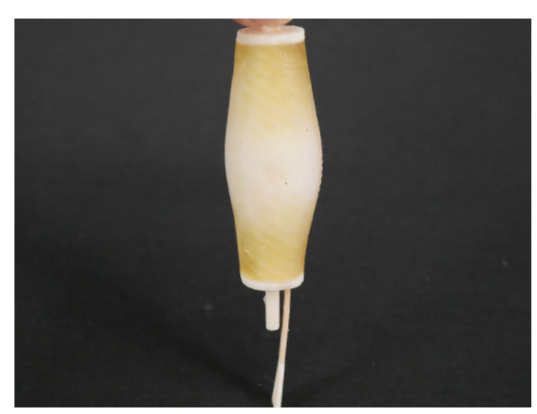

Figure 55 a, Lubrication Armor-All, injected.

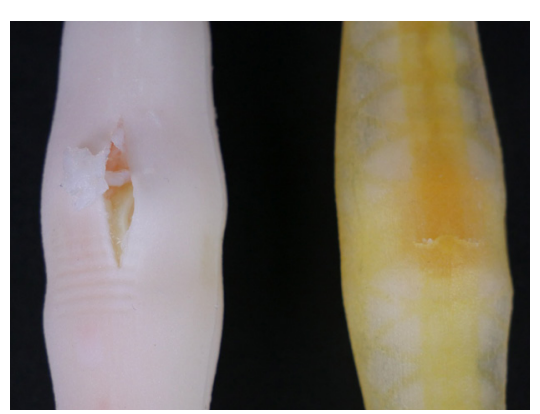

Figure 54 b, Lubrication Armor-All, submersion.

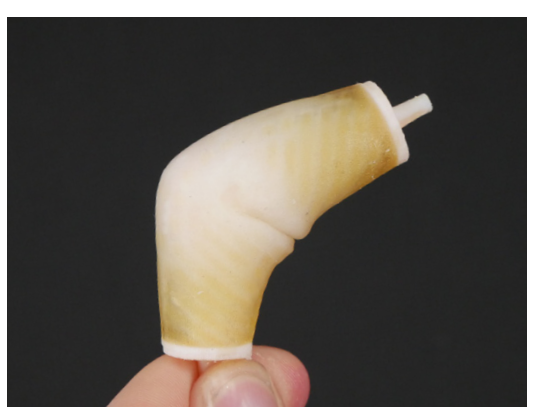

Figure 55 b, Lubrication Armor-All, injected.
Armor-All is a protectant liquid usually used for car interiors and does not evaporate as quickly as water, allowing for multiple days of lubrication before refilling the model.

\section{Test Swatch.}

- When the material is placed in Armor-All, the translucent nature of the Agilus material is removed similar to water.

- The thick milky liquid is absorbed and allows the material to manipulate further than when dried or in water.

Documented in figure 53 a \& b.

\section{Submersion.}

- When a model has been submerged into the liquid, a similar effect to the water test occurs.

- As the Armor-All does not come into contact with the joint, there is still friction.

- The model needs to be wiped dry after submersion as the Armor-All does not evaporate.

Documented in figure 54 a \& b.

\section{Injection.}

- When a liquid is directly injected into the joints, it allows for targeted lubrication.

- The Armor-All allowed for free movement of the joint, relieving the stress on the tendon caused by the two sections rubbing together.

Documented in figure 55 a \& b.

This was the most successful lubrication test and will be used for further full finger testing. 


\section{Twenty \& Fingertip.}

This test was to show how a fully enclosed finger with multiple joints might perform when manipulated with lubrication.

- Materials used:
Skin, Shore Hardness 30. (clear)
Nail, Vero. (white)
- Ligament, Shore Hardness 30. (clear)
Stent, Vero. (orange)

- $\quad$ Full finger with three joints.

- $\quad$ No fat just build support material.

- Middle joint fused to the skin, causing a small rip.

- Fingertip was full Agilus, making that section appear different.

- Needs to be hollowed out in the next print.

- The nail looks unrealistic and needs to be redesigned.

- $\quad$ Stent removal and injection of lubricant was a success.

- This test moved well, but a second tendon might be considered.

Documented in figure 56 a to $\mathrm{c}$.

The next test will consist of the same internal elements but placed in a skin that was created through scanning a cast of a finger. This scan was to gather the correct skin information such as creases and small details that were lacking in test 20 .

\section{Fingertip.}

This was a test to determine how a nail might be printed and how thin the Vero nail can be. Documented in figure 57 a to $\mathrm{c}$.

- The tip of the nail is frayed because of how thin the material is meant to be.

- $\quad$ Reshaping of the nail and nail tip is needed so that it looks realistic and does not fray.

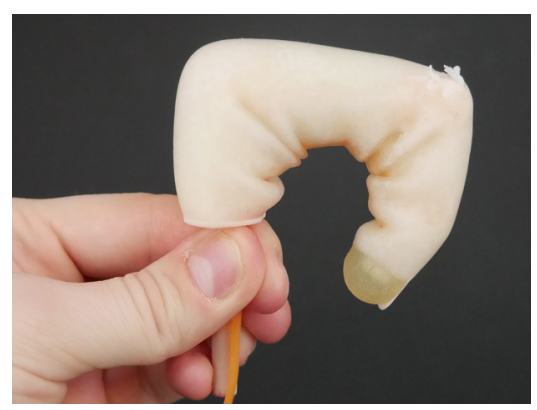

Figure 56 a, twenty, bent.

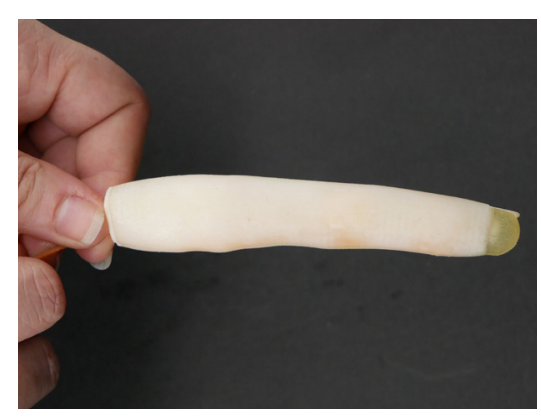

Figure 56 , twenty, side.

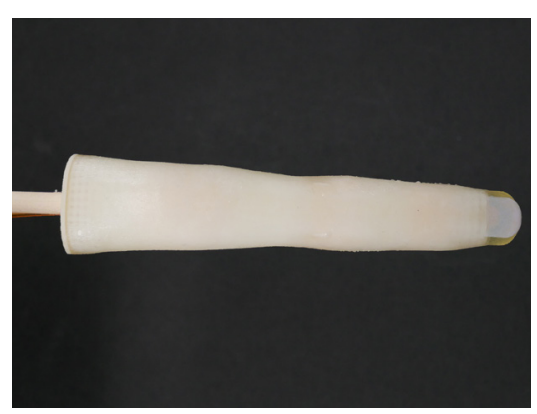

Figure $56 c$, twenty, top.

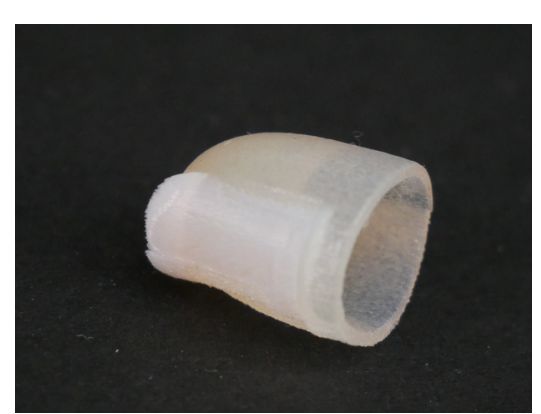

Figure 57 a, fingertip test, angled.

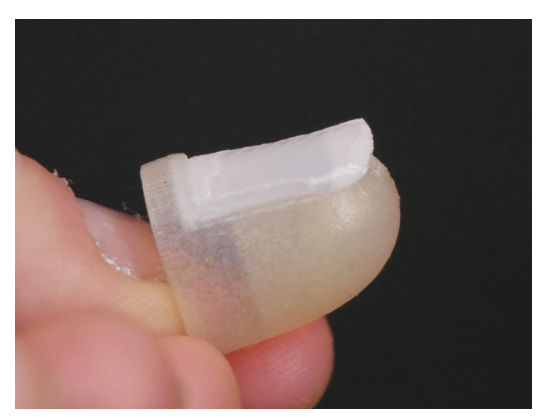

Figure 57 b, fingertip test, side.

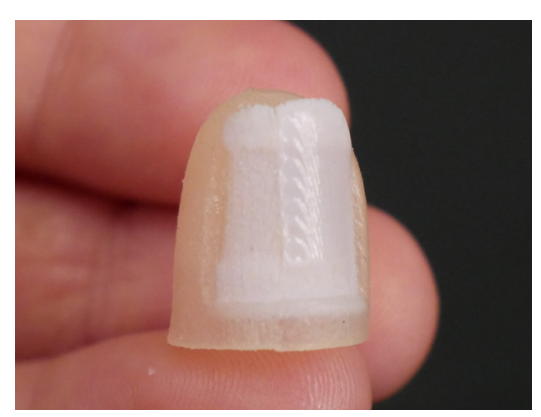

Figure 57 c, fingertip test, front. 


\section{Twenty-One.}

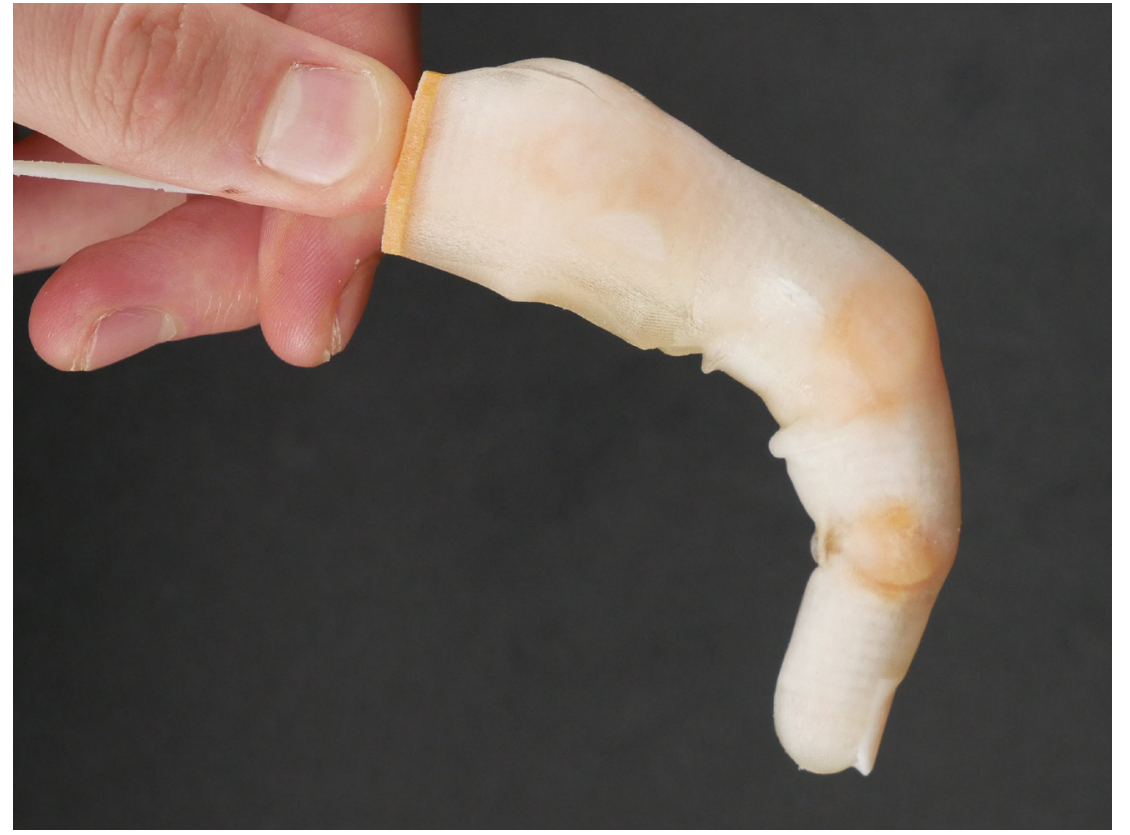

Figure 58 a, twenty-one, side bent.

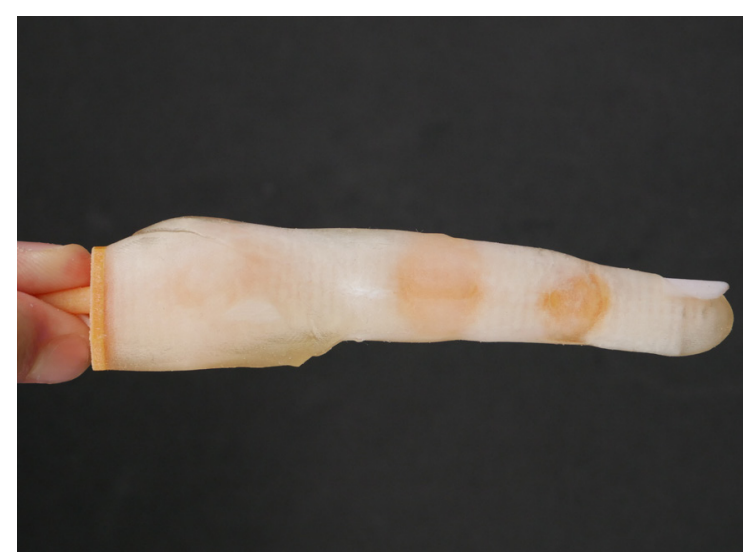

Figure 58 b, twenty-one, side.

Figure 58 c, twenty-one, top.
This test was to make a finger that's appearance is as close to a human finger as possible.

- Materials used:

$$
\text { Stent, Shore Hardness 85. (yellow) }
$$

- 3D scanned finger to capture the detail of the skin.

- The finger is an organic form which caused some issues when removing the internal structure of the scan to make a thin skin.

- The material was too thick in places where it restricted movements.

- The material was also too thin in other places and tore.

- The tendon support did not seem to print or was too small to be useful, resulting in the tendon breaking.

Documented in figure 58 a to $\mathrm{d}$.

The next test will also consist of a separate part that will eventually be attached to the final model for the filming process that needs to produce a watertight seal on the side of a small bath.

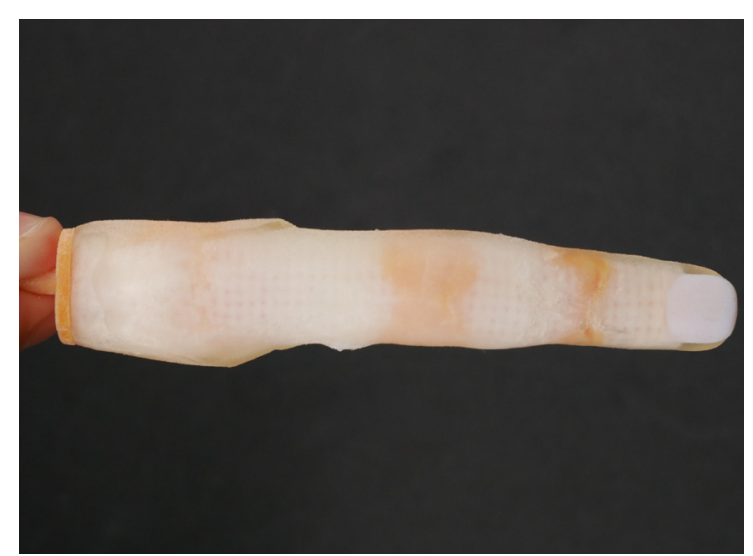

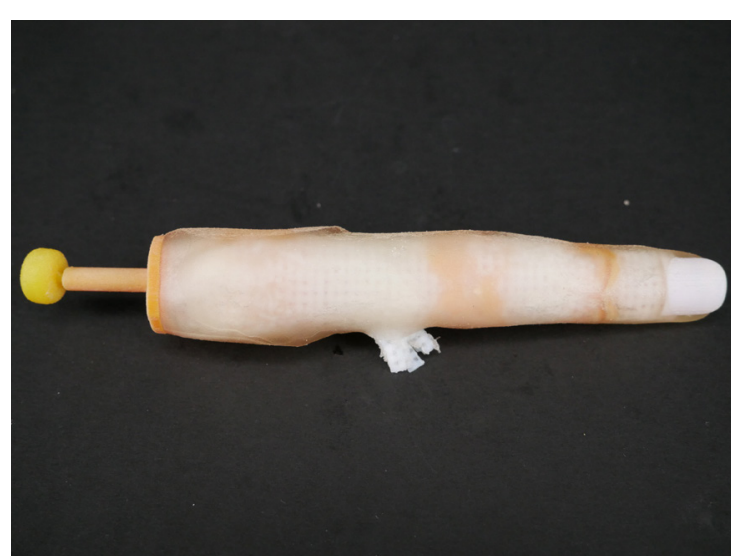

Figure 58 d, twenty-one, tear on the side. 


\section{Twenty-Two.}

This test was created to resolve issues from past testing.

- The material was too thin in one area, causing a singular break.

- The nail needs to be redesigned to represent the proper shape of a nail better how it forms on the skin.

- The tendon was recreated with a greater thickness and more significant internal support but again did not seem to print the internal hard support and broke.

- This design issue could be due to errors in the CAD file, so this will be changed for the next print.

- $\quad$ Skin thickness again needs to be adjusted.

- Move the placement of the internal structures to better line up with the skin details.

Documented in figure 59 a to $\mathrm{d}$.

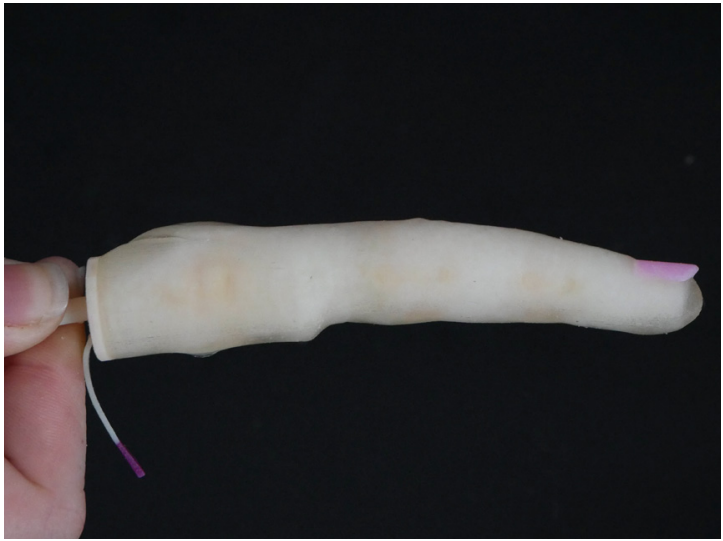

Figure 59 b, twenty-two, side

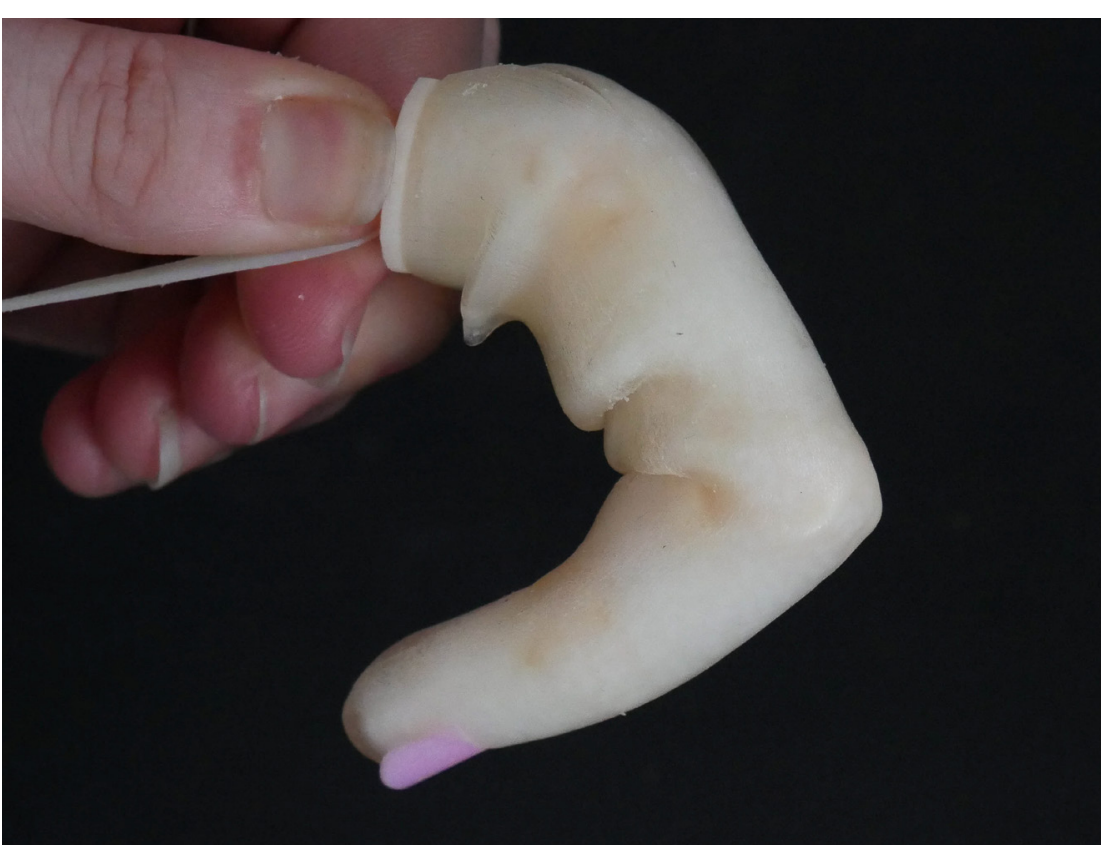

Figure 59 a, twenty-two, side bent.

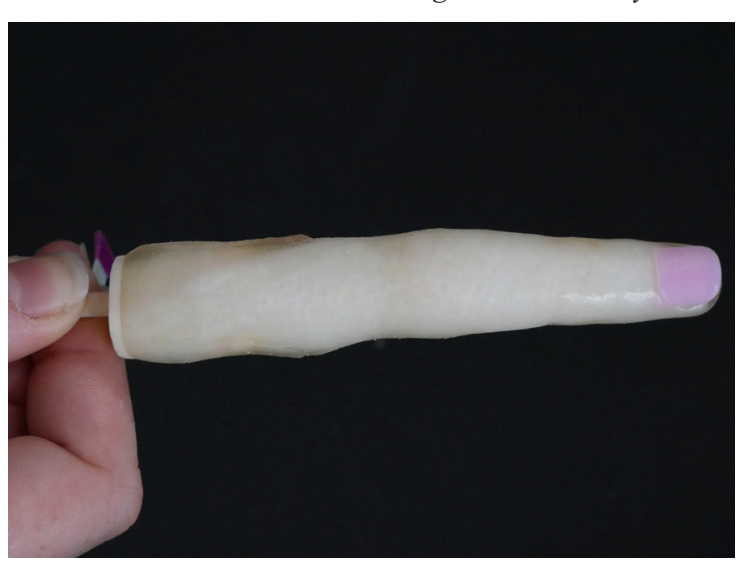

Figure $59 c$, twenty-two, top.

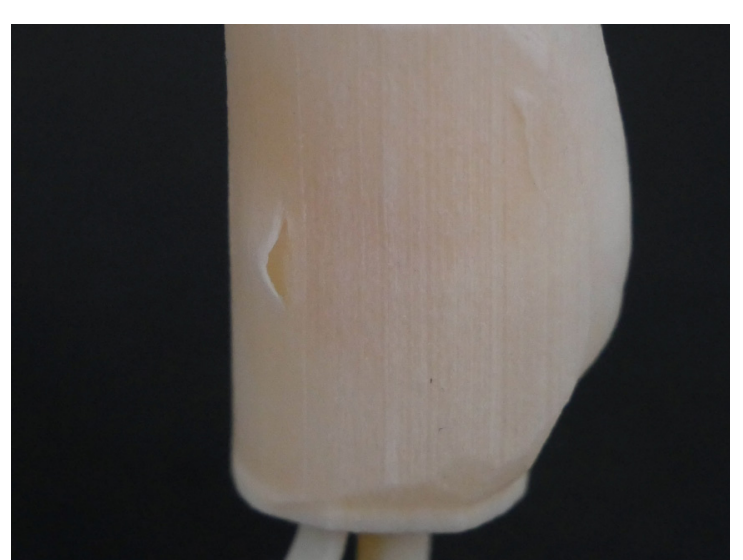

Figure 59 d, twenty-two, detail of brake. 


\section{Watertight Film Set.}

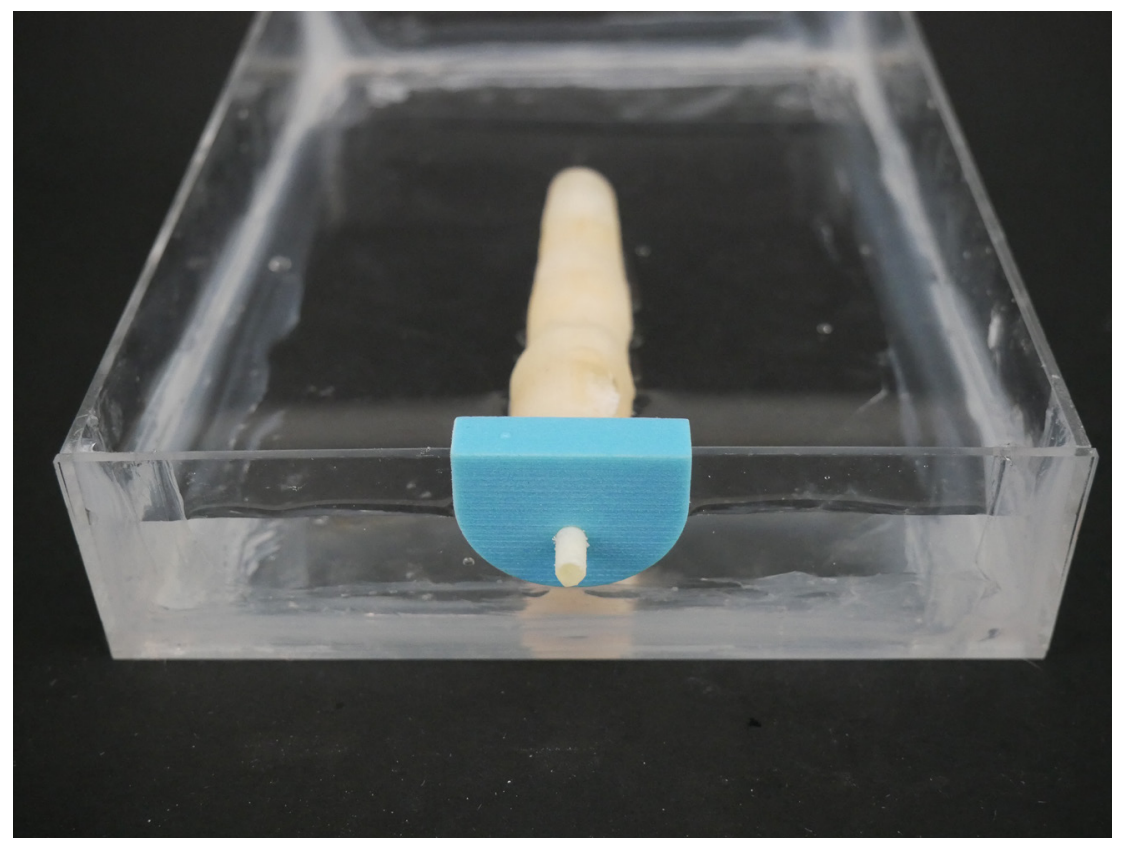

This test was very successful as it formed a watertight join where the figure can be mounted onto the side of a bath for the filming process. The finger needs to be positioned lower in the bath so that it is fully covered when straight and the point where the tendon exits the model need to be placed above the bone exit point.

Documented in figure 60 a to $\mathrm{d}$.

Figure 60 a, watertight, in water

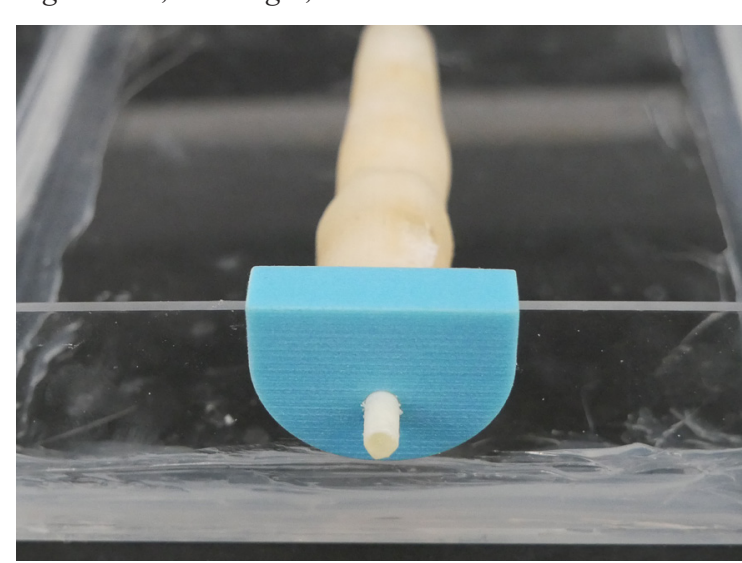

Figure $60 \mathrm{~b}$, watertight, no water.

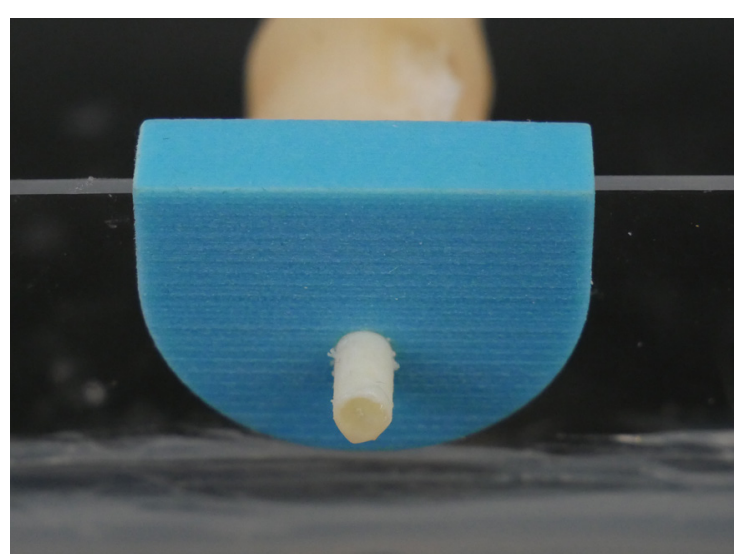

Figure 60 c, watertight, close up no water.

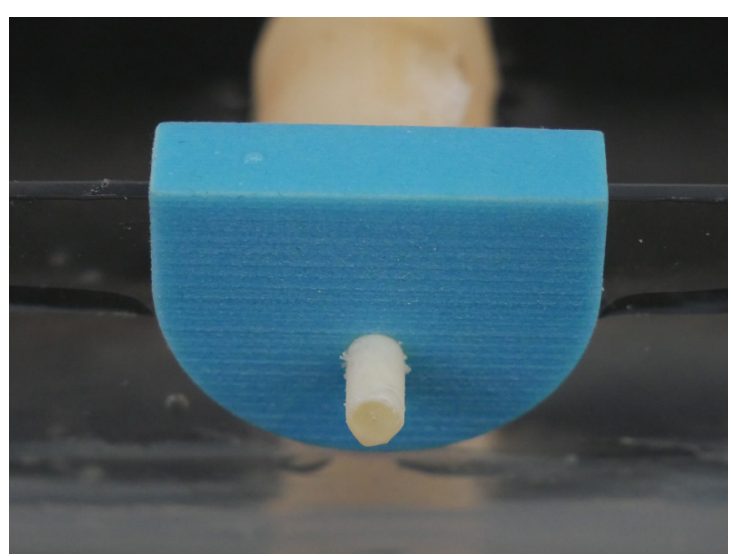

Figure $60 \mathrm{~d}$, watertight, close up water. 


\section{Twenty-Three.}

This test looks at using different materials as well as changing the placement of internal joints.

- Materials used:

$$
\text { Nail, Shore Hardness 75. (white) }
$$

- Shifting the internal structure to better align with the skin detail.

- Two tendons with hard inner support that was cut out of the soft tendon material.

- Tore in one place on the knuckle joint at the back of the model due to thin walls.

- The desired movement occurred, yet the top joint still does not bend as much as it should.

- The nail was printed in a softer material to achieve the translucency that a real nail has. It was too soft.

Documented in figure 61 a to $\mathrm{f}$.

The solid base, connected to the tendons and bones, snapped in two when tendons were pulled on as a large amount of force is applied to this point.v

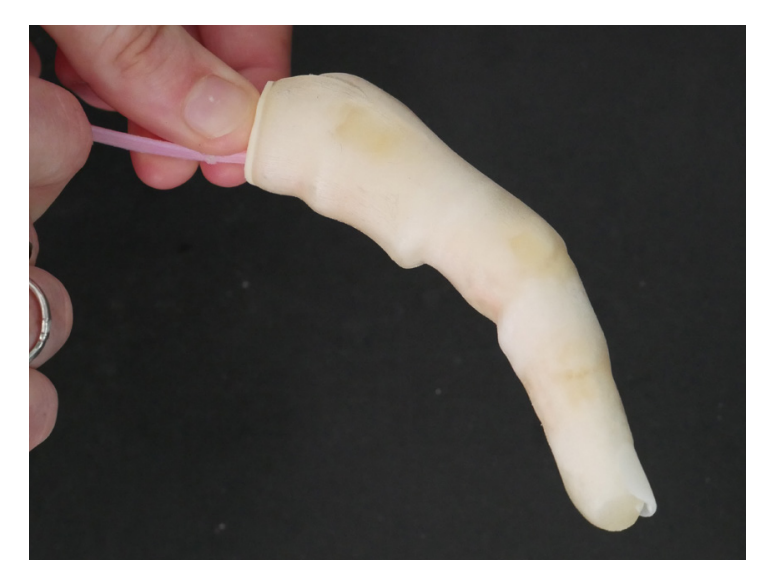

Figure 61 b, twenty-three, both tendon.

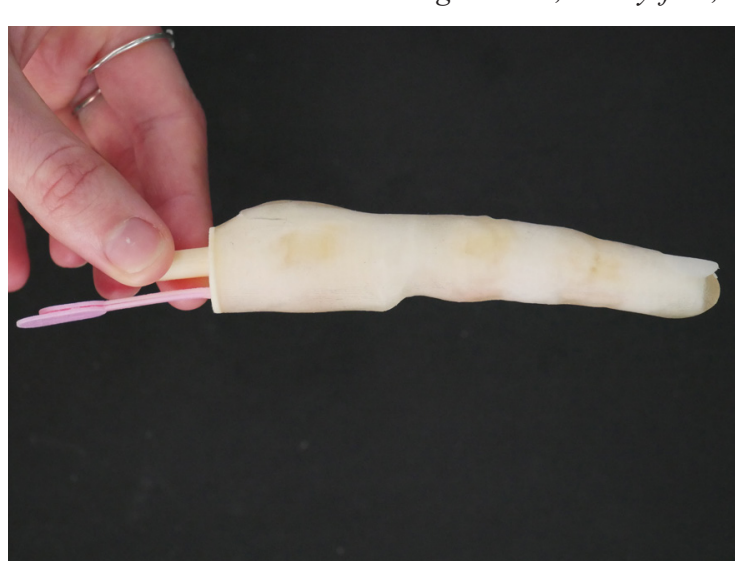

Figure 61 c, twenty-three, side.

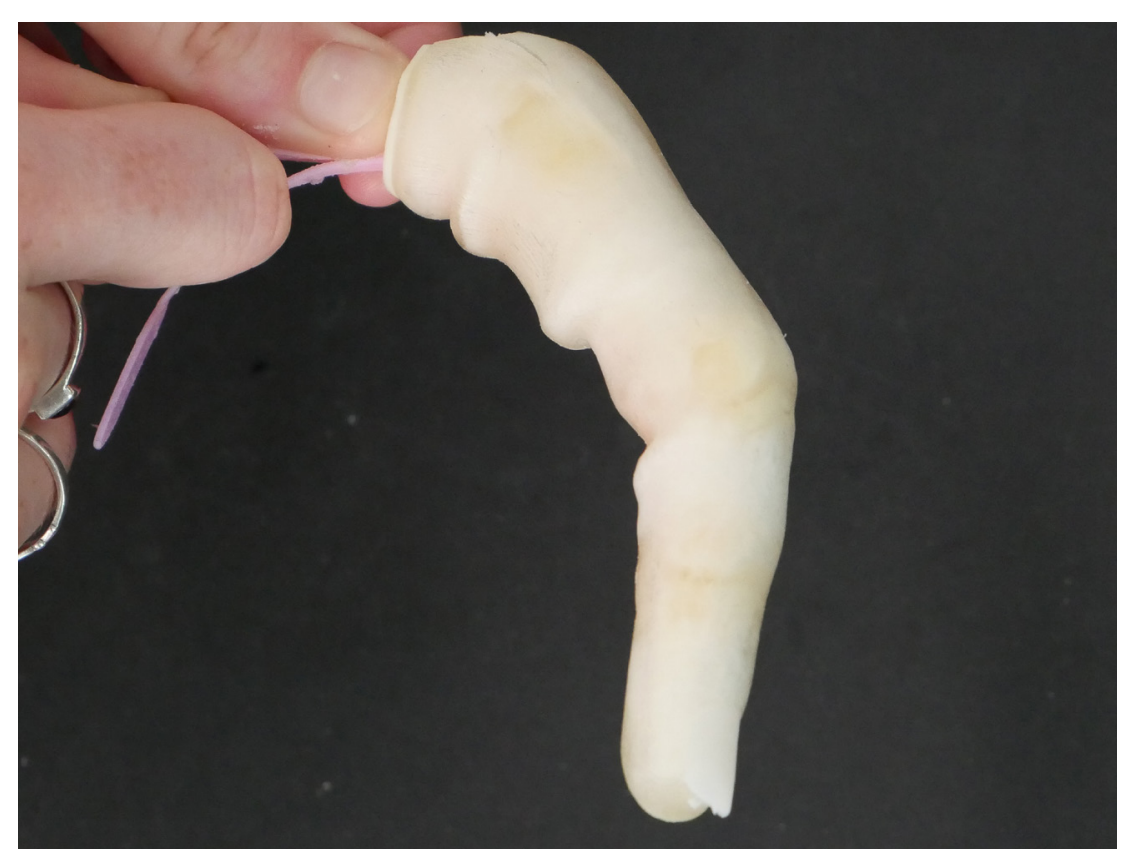

Figure 61 a, twenty-four, one tendon.

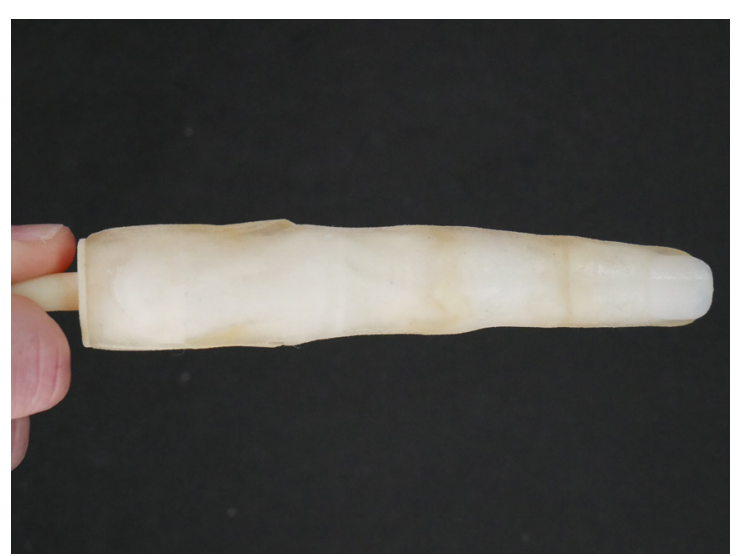

Figure $61 d$, twenty-three, top. 
Colour Trial.

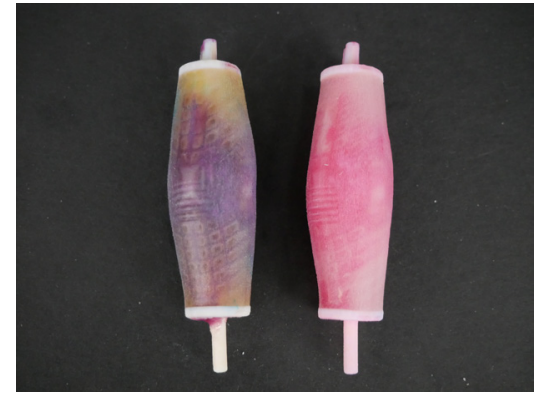

Figure 62 a, $A \&$ \& , food colouring.

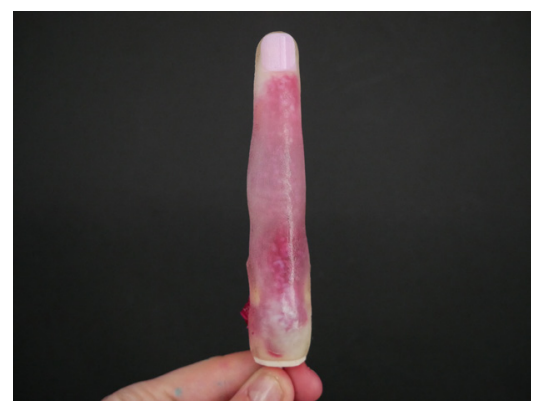

Figure 63 a, C, food colouring.

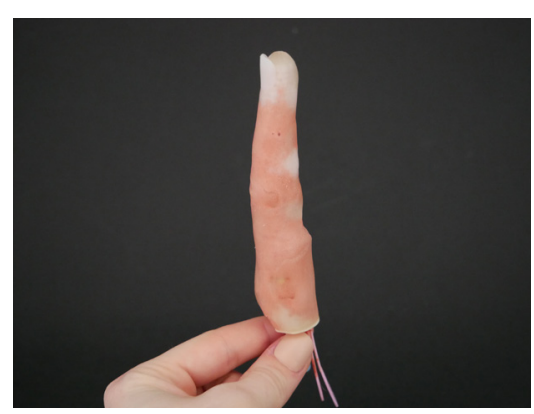

Figure 64 a, D, acrylic

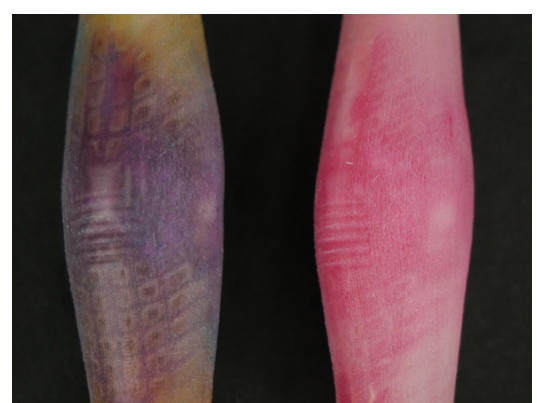

Figure $62 b, A \& B$, food colouring

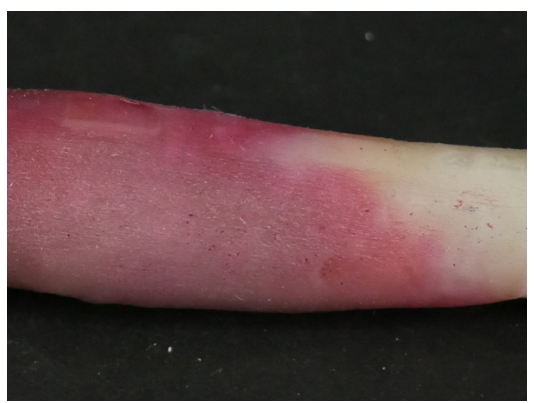

Figure 63 b, C, food colouring.

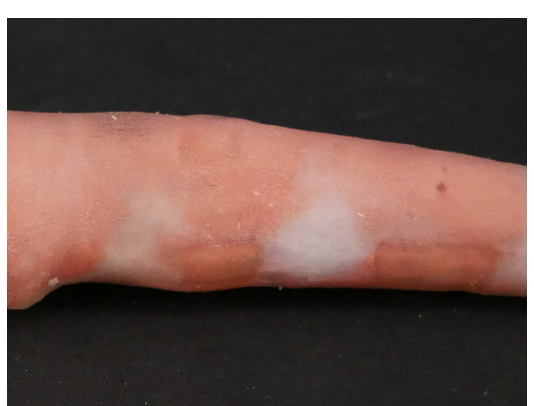

Figure 64 b, D, acrylic
The purpose of this test was to determine if colouring the lubrication would make the design look more realistic by adding skin tone.

A.

- $\quad$ Food colouring, red and blue.

- Colour stayed locally to the area of injection.

Documented in figure 62 a \& b.

B.

- Food colouring, red.

- When the red is mixed with the white lubricant and injected into the model, it turns pink.

Documented in figure $62 \mathrm{a} \& \mathrm{~b}$.

C.

- Food colouring, red and blue.

- This test had more red than blue injected into the form.

- Again this colour combination made the finger look bruised.

- The model appeared swollen due to the additional colouring. Documented in figure 63 a \& b.

D.

- Acrylic paint, water and Armor-All.

- This colour is the closest to skin.

- Lubrication became thick and hard to disperse throughout - the design.

- A messy process that wasted lots of the lubricant.

Documented in figure $64 \mathrm{a} \& \mathrm{~b}$.

For all further testing plain Armor-All will be used without colour. 


\section{Twenty-Four.}

This test is a redesign of test twenty-three with thicker skin and added clip.

- Materials used:

$$
\text { Nail: Shore Hardness 85. (white) }
$$

- $\quad$ Added clip for filming and display worked well (did increase the cost).

- $\quad$ Split between top and middle joint.

- Added material on the skin of knuckle joint that broke in test twenty-three.

- $\quad$ Second joint bends the most when tendon is pulled.

- Tendons did not print correctly. This could be due to print placement.

- $\quad$ Nail material was correct thickness and appearance.

Documented in figure 65 a to $b$.

\section{Next model.}

- $\quad$ Fix the section that tore by increasing material thickness.

- Redesign the tendons shape and holder, return to one tendon.
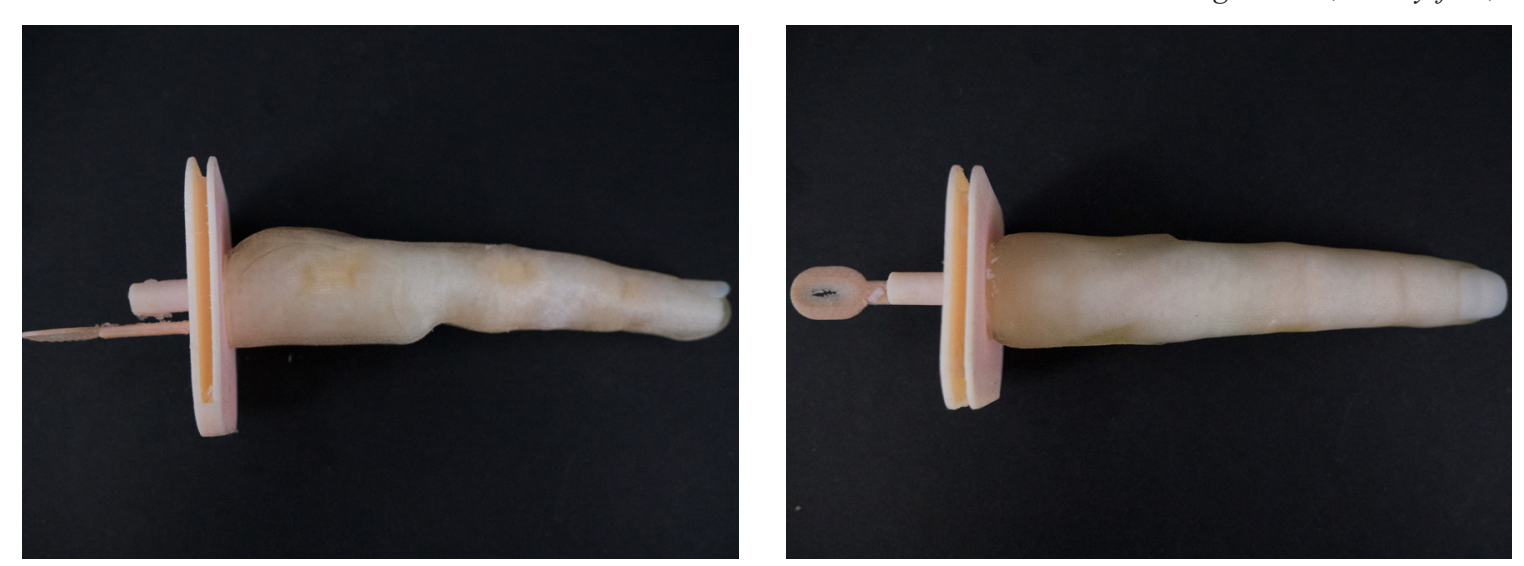

Figure 65 b, twenty-four, side.

Figure 65 c, twenty-four, top.

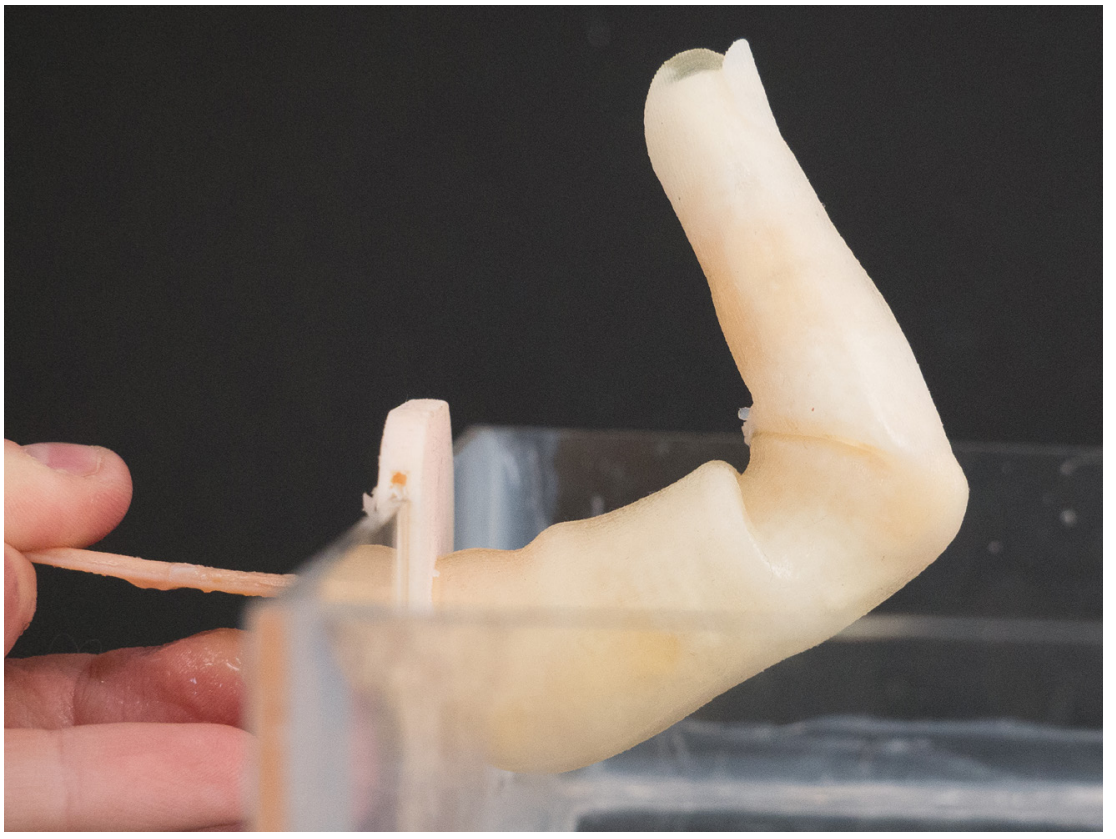

Figure 65 a, twenty-four, bent.

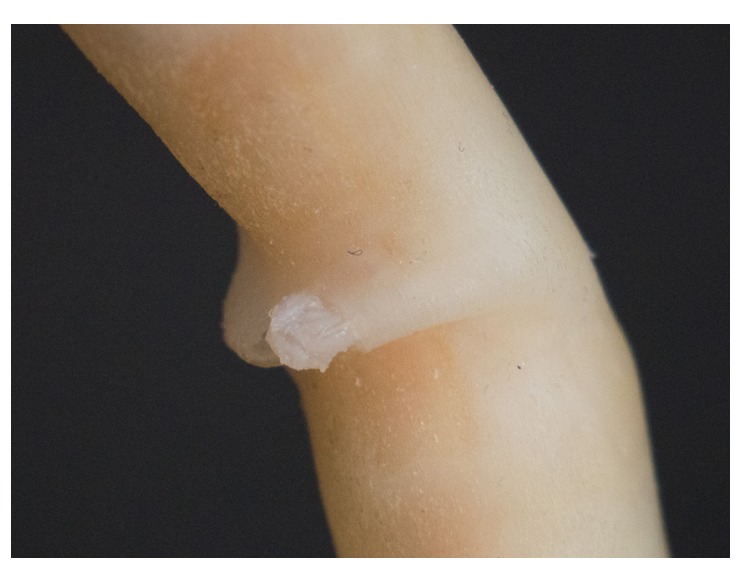

Figure $65 d$, twenty-four, tear. 


\section{Twenty-Five.}

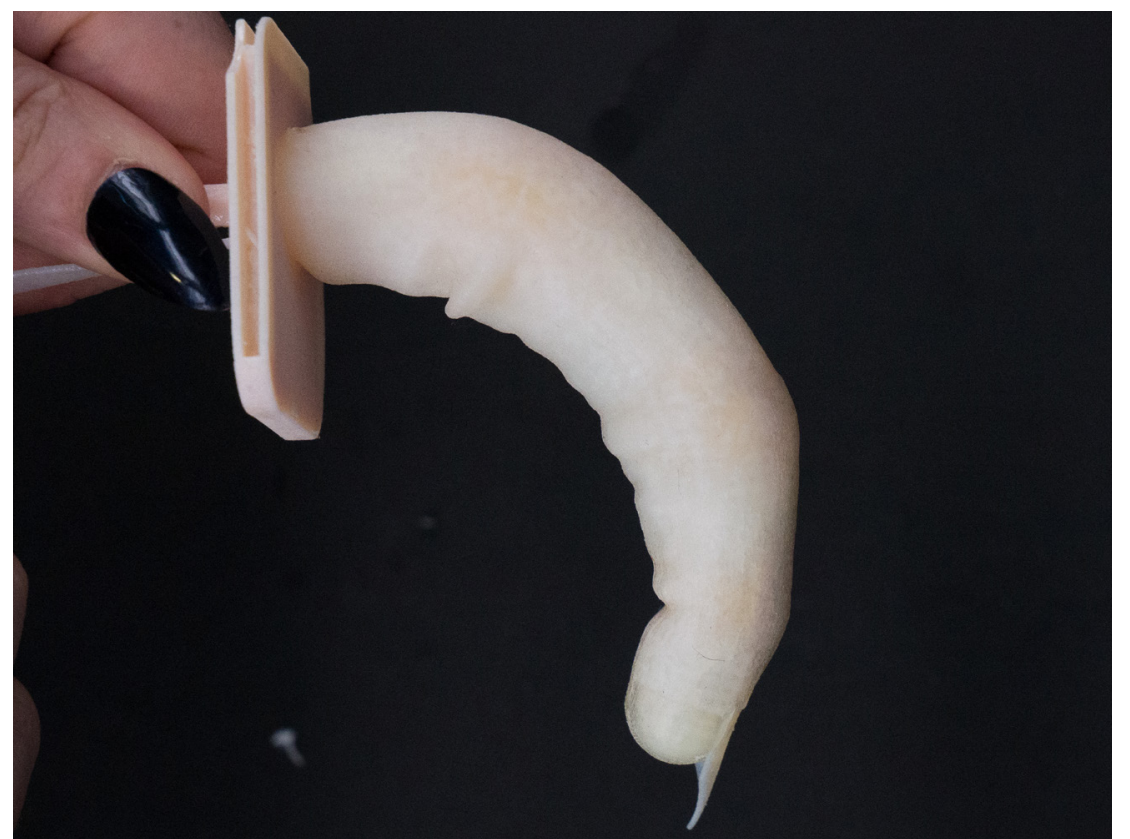

Figure 66 a, twenty-five, bent.

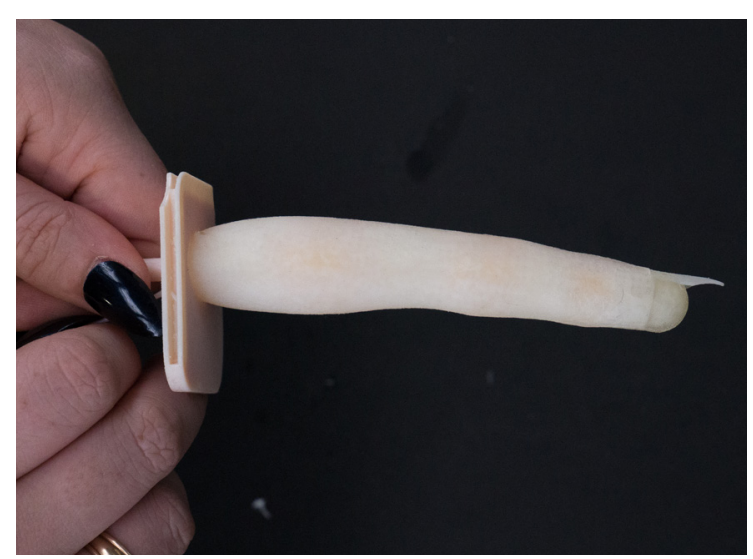

Figure 66 b, twenty-five, about to pull.

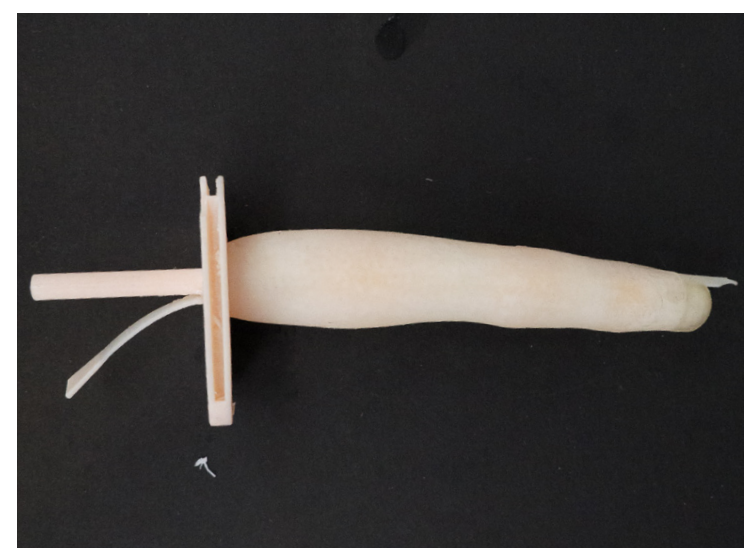

Figure $66 c$, twenty-five, side.

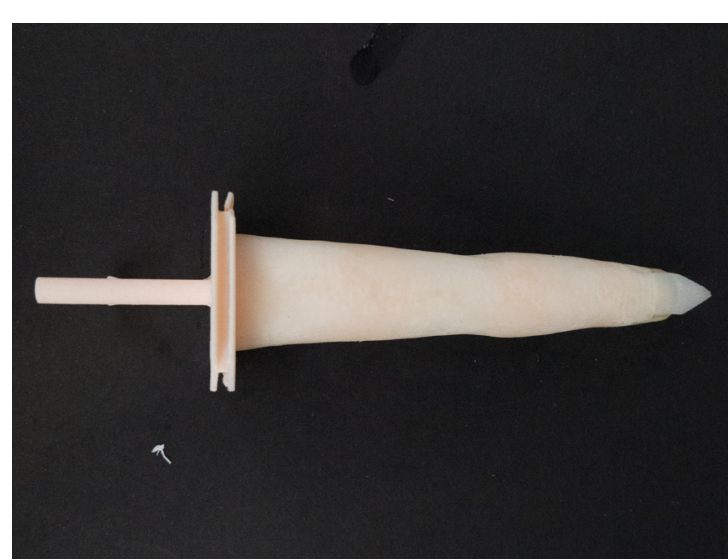

Figure $66 d$, twenty-five, top. 


\section{Twenty-Six.}

This test was to determine what had gone wrong with test twentyfive and to get a final design that did not fail.

- $\quad$ Reprint of test twenty-five, same material.

- Movements are precisely what was desired of this design.

- Small split at the tip of the finger.

- Nail material was too thin and fragile.

- Connection point of nail needs to be adjusted as it appears incorrect.

- Tendon soft material split from hard support.

\section{Next Model.}

- Reduce the amount of hard material.

- Thicken the overall tendon.

- $\quad$ Reassessing the connection point of the tendon and bone.

- Fix the nail and nail bed.

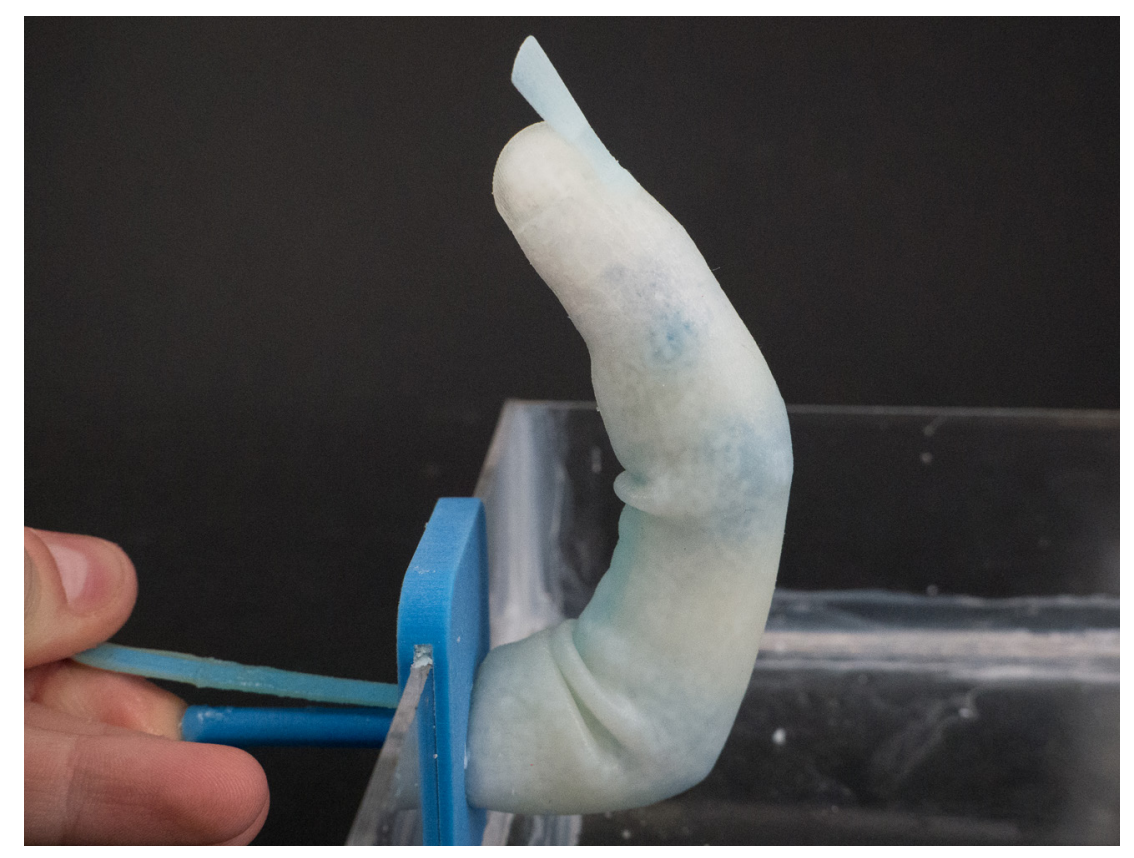

Documented in figure 67 a to $d$.
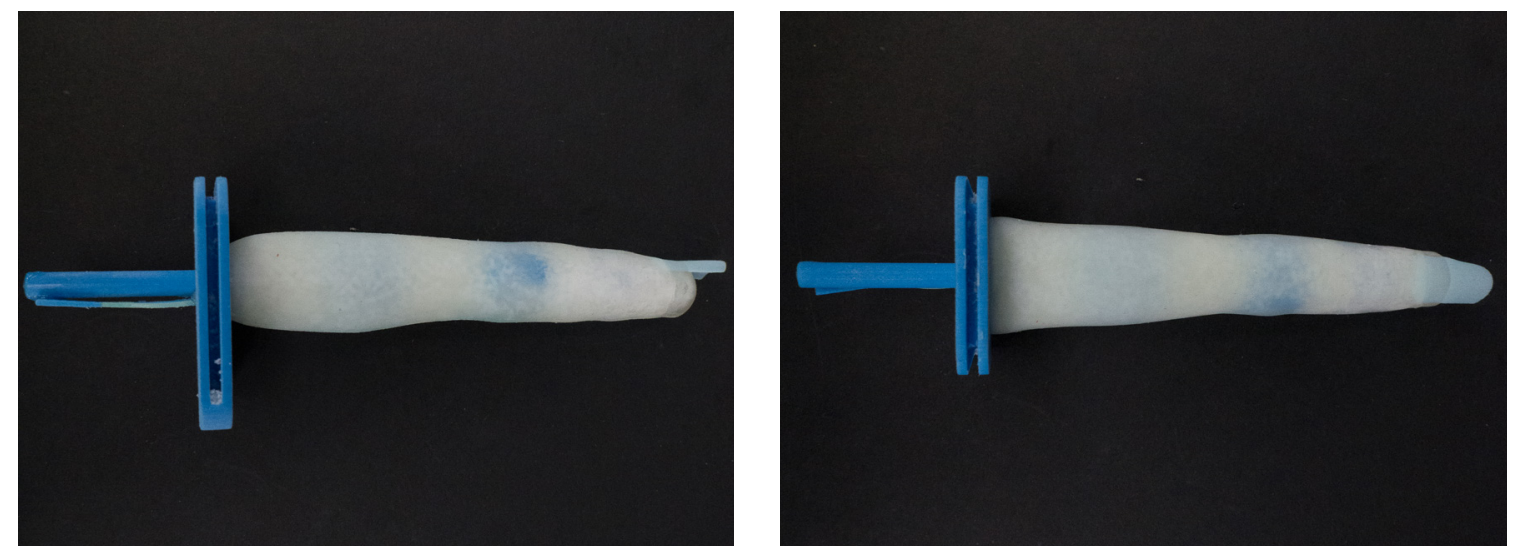

Figure 67 b, twenty-six, side.

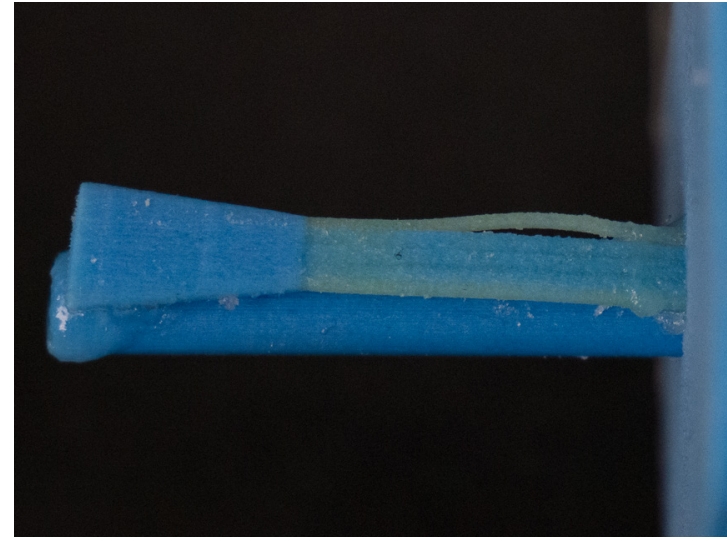

Figure $67 d$, twenty-six, tear 


\section{Twenty-Seven.}

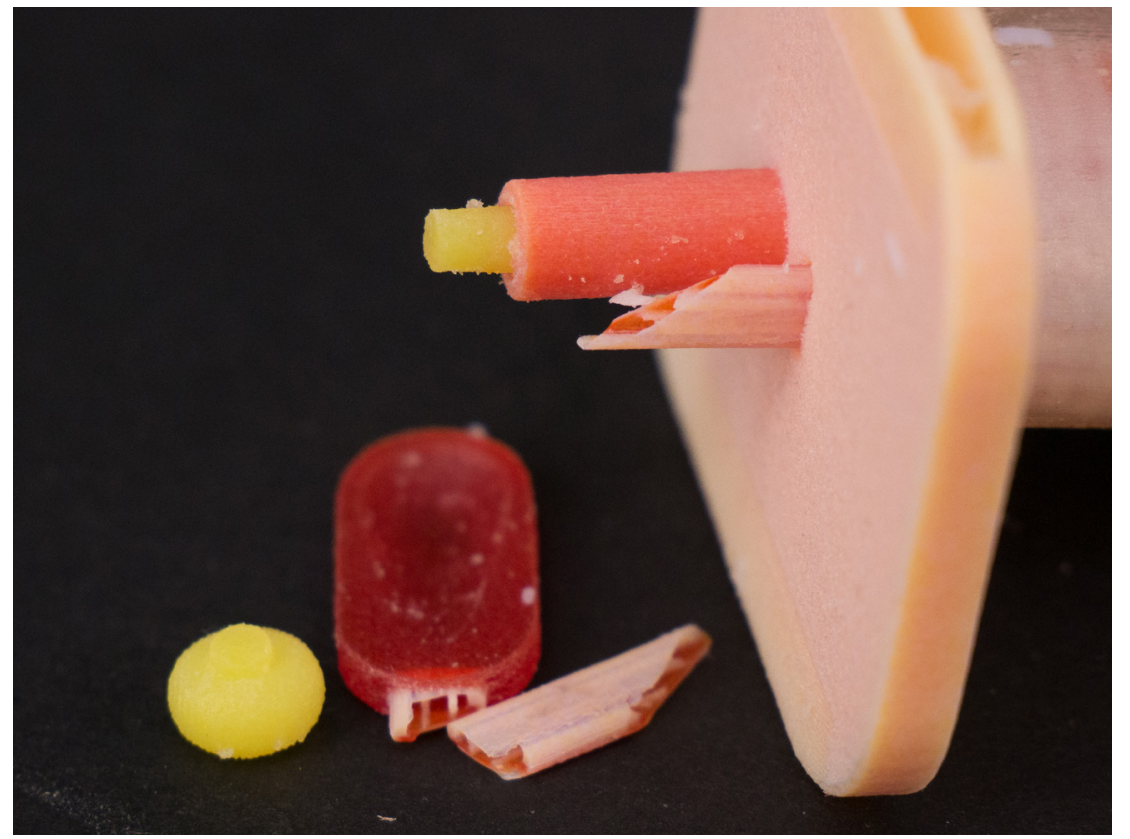

Figure 68 a, twenty-seven, broken detail.

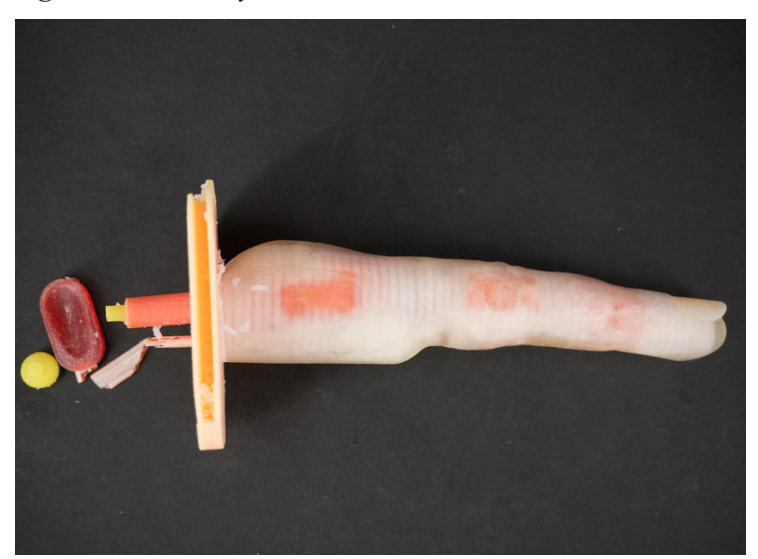

Figure 68 b, twenty-seven, side.

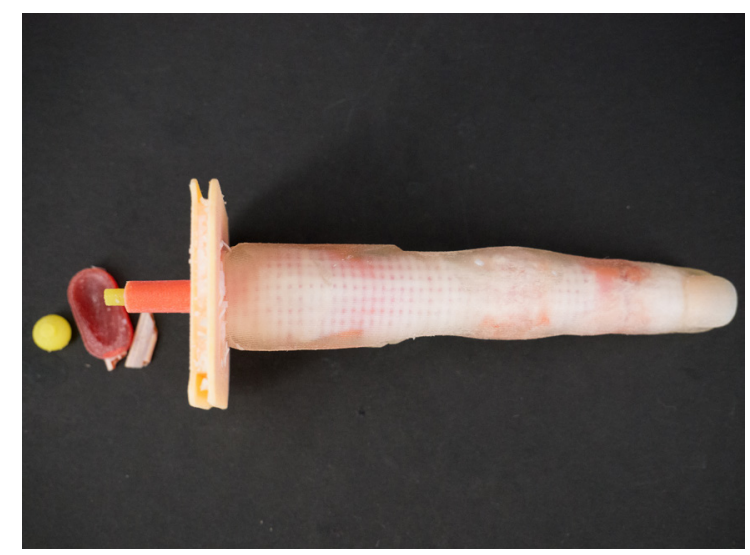

Figure 68 c, twenty-seven, top.

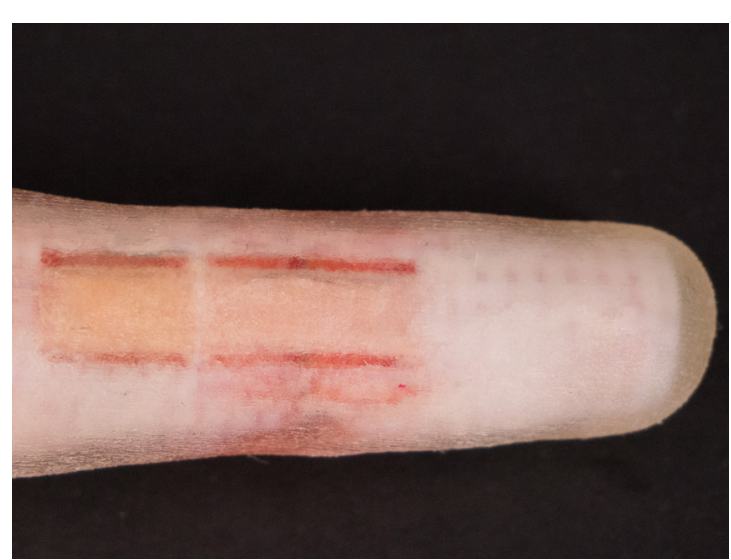

Figure $68 d$, twenty-seven, internal detail.
This test was meant to be the final print of the anatomically correct design.

- Half of the hard tendon support did not print.

- Ratio of hard and soft material for the tendon was incorrect, snapped during cleaning.

- Tendon intersected the stent so could not be removed.

- $\quad$ Clip broke during cleaning.

Documented in figure 68 a to $\mathrm{d}$. 


\section{Lubrication, How It Works.}

The main part of this research is the smooth movement of the 'dry' finger. A dry object, in this case, is a multi-material print that is not water-based like the projects conducted before. As this research portfolio looks at the recreation of human anatomy, the final object cannot be solely water-based. It must be able to function outside of a liquid bath. This posed an issue of how to provide lubrication to a fully enclosed object that will spend most of its time out of water.

This research portfolio utilised the ability to create complex structures to form a hollow tube created by removing a stent shown in Figure 69 and injecting the Armor-All through this cavity. As discussed before each bone section has pure Agilus material that absorbs the liquid demonstrated in Figure 70. The hole running through the bone structure also allows the Armor-All access to the fat area where the support material sits. This method works similar to how the vascular system supplies oxygenated blood that contains water to the joints throughout the body.

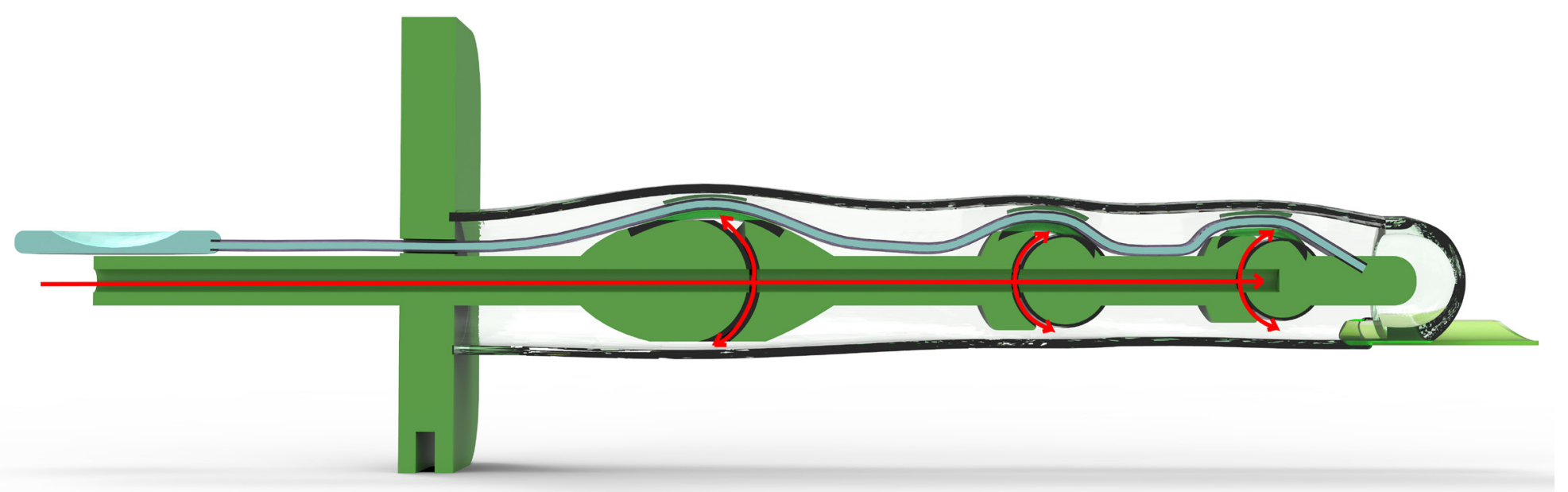

Figure 69, lubrication, stent

Figure 70, lubrication, liquid entrance path 


\section{All Experimentation.}

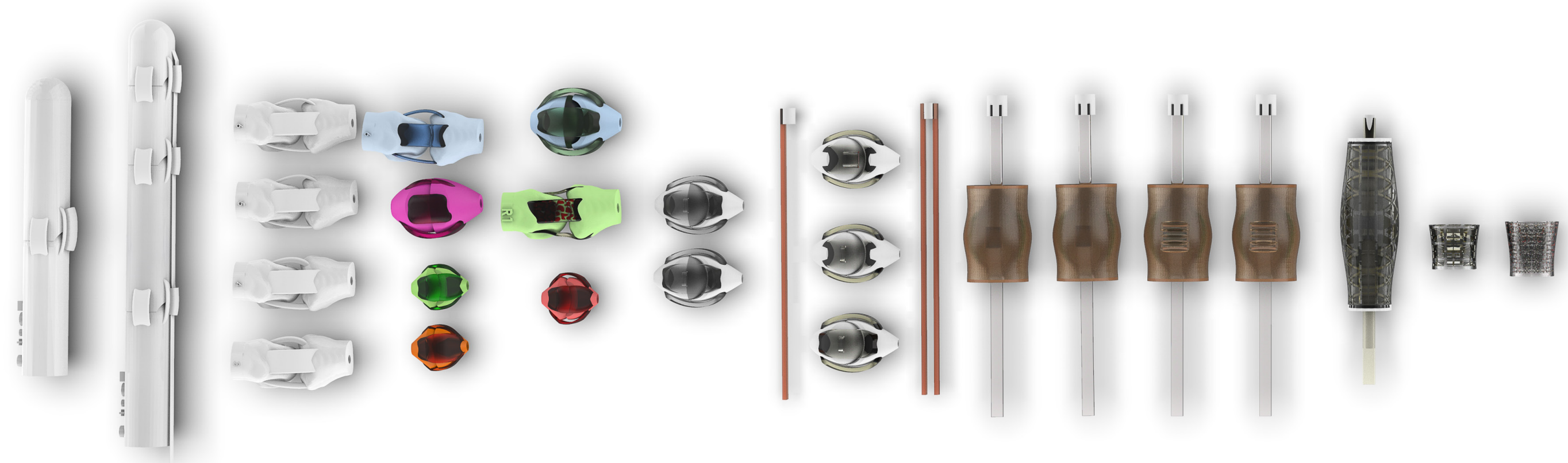




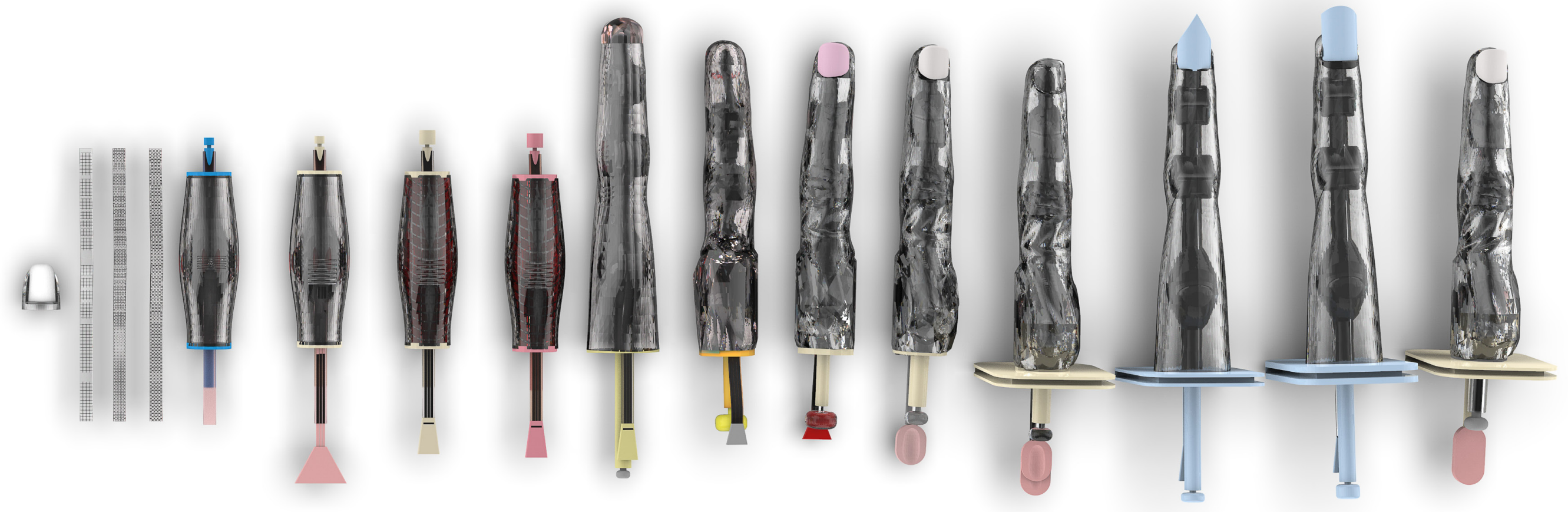


Part 3 
Final Designs. 


\section{Human.}

We are a complex race, fascinated with ourselves and how we might recreate our appearance and inject our thought patterns into inanimate objects. Humans strive to be better, stronger and more diverse in our abilities. This is possible by the extension of our anatomy. Born from the printer, Human Finger is a representation of what can be achieved through additive manufacturing in the recreation of human anatomy. We live in a changing environment where printing could become a key way of adapting ourselves for survival. Adding new physiology has never been so easy. We are in a new age of reproduction.

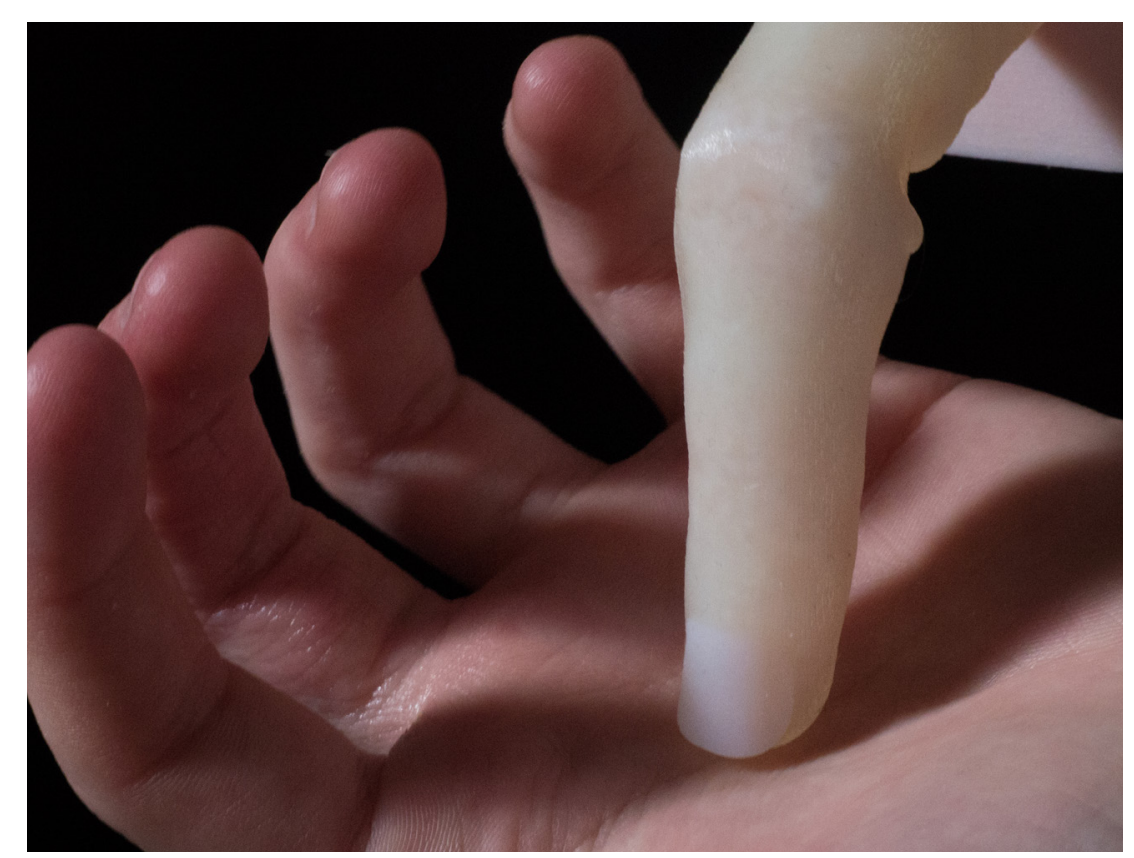

Figure 73, human, touch.
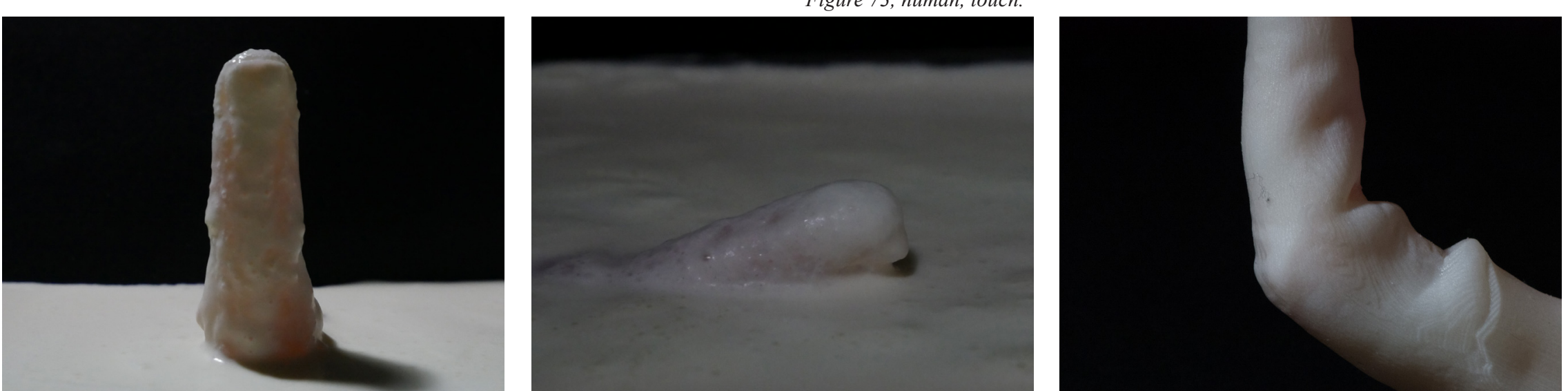

Figure 74, human, emerging.

Figure 76, human, skin 


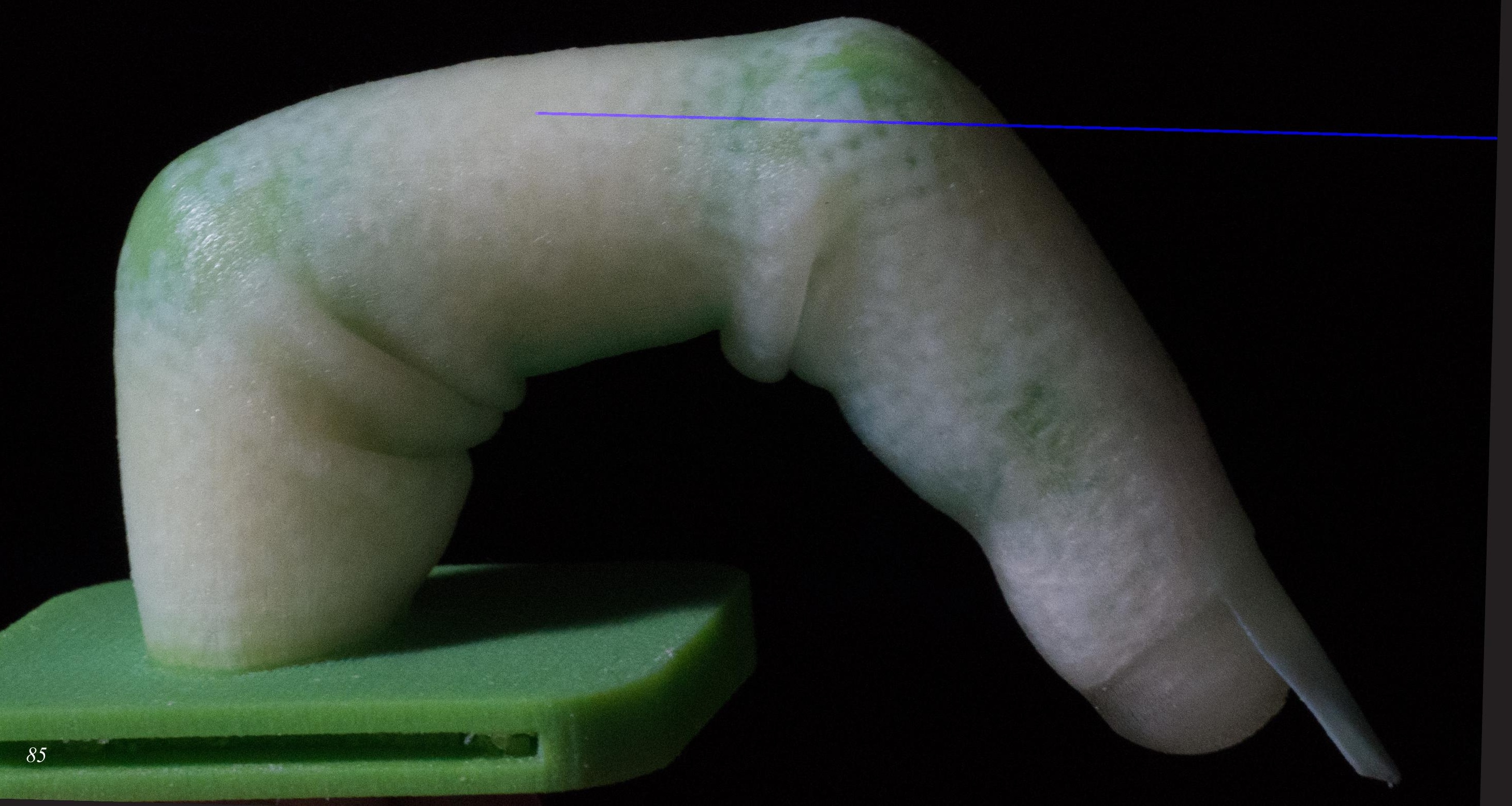




\section{Creature.}

A creature like us but different. No wrinkles or fingerprints. A creature from the depths of digital creation was born with a long nail and appearance that makes your skin crawl. The skin folds and moves like nothing that has been seen before, below the surface fat moves freely in the malleable form creating patterns and revealing bones. When contact occurs, the soft translucent skin moves under your touch. You can see everything but understand so little about how this creature comes to life. It is both dead and alive, unsettling those who lay their eyes on the creation.

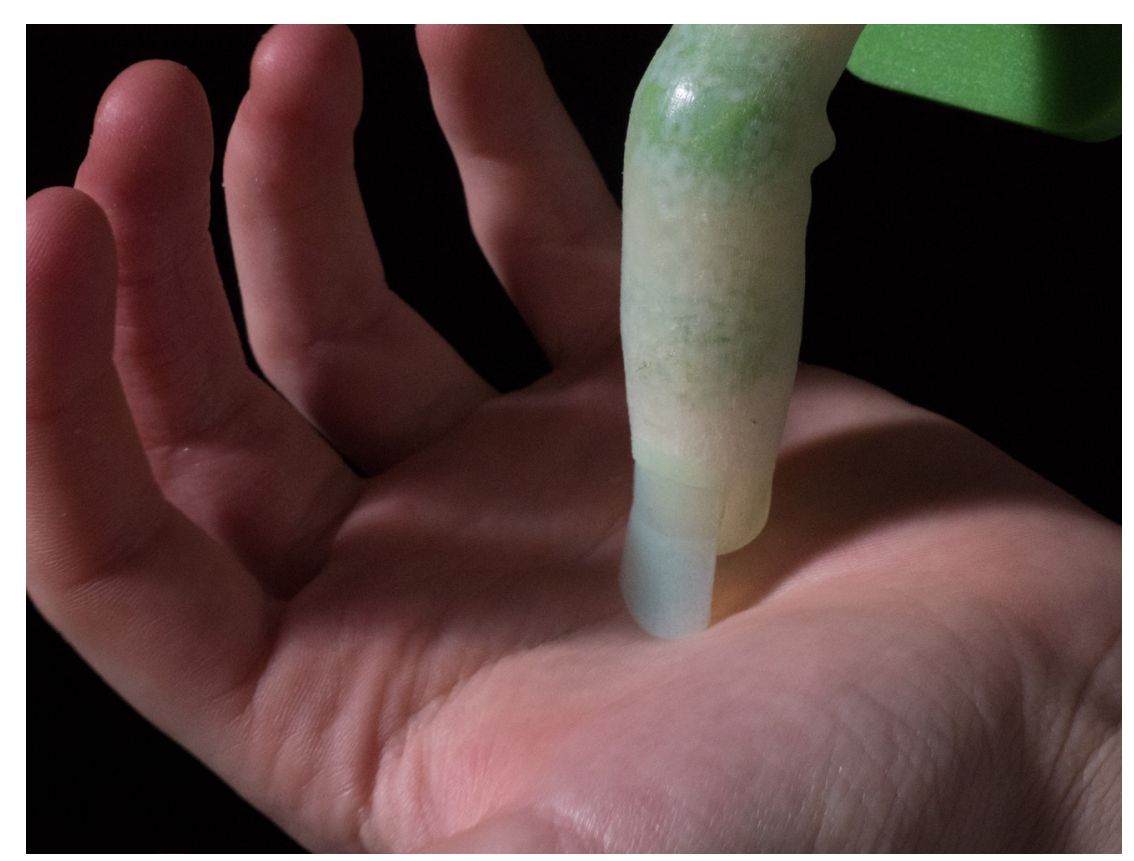

Figure 78, creature, first contact.

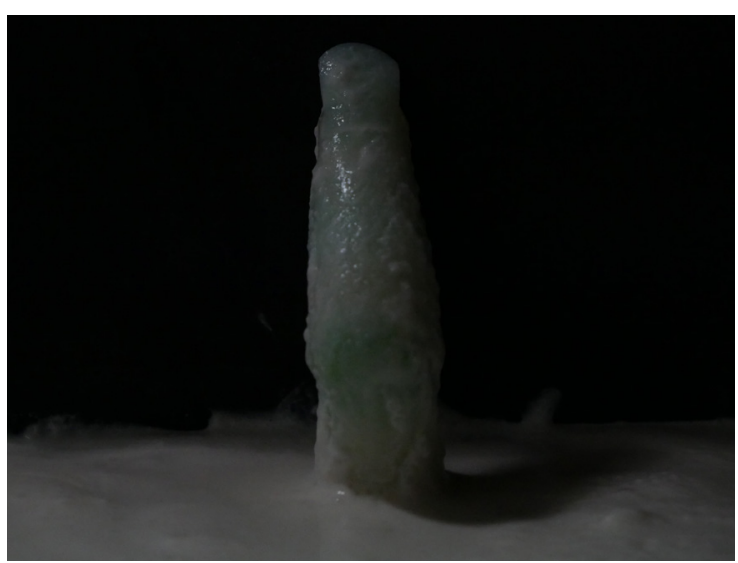

Figure 79, creature, coming for you.

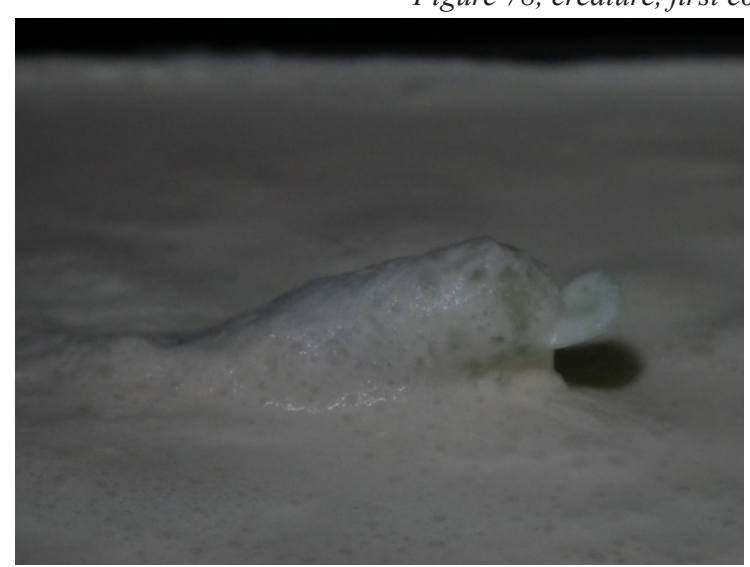

Figure 80, creature, growing from that depths.

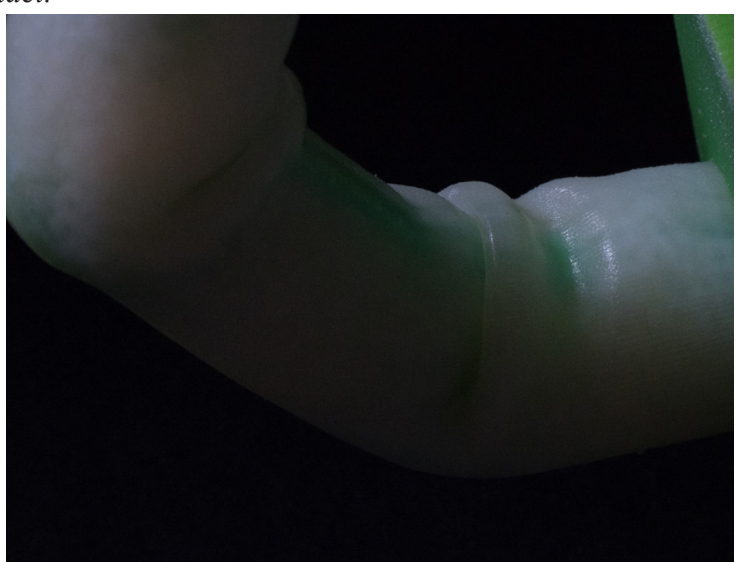

Figure 81, creature, coming for you in the dark. 
Part 4. 
Discussion. 


\subsection{Discussion.}

This research portfolio researched how the Stratasys J750 printer might be used in the creation of a dynamic heterogeneous multiproperty finger. The main aim of this research portfolio was to answer the question; What could multi-property, 3D/4D printing bring to the way the film prop manufacturing industry creates physical props? By establishing an area of study, and how the final output will be utilised, a clearer idea of what is expected of the final design was created.

\section{Iteration.}

The study determined that it is possible to create four-dimensional (4D) heterogeneous humanoid anatomy through the 3D printing technology of the J750 printer and Agilus material. These tests followed closely to the methodology of Research Through Design, creating knowledge through the use of design practice and the 4 D's plan of the iterative design process and create, evaluate method. By designing and evaluating the success and failures of each test; cohesive research was formed that can further be built upon. The step by step process of the 4 D's was a strong influence in the way each section was assessed and how the final designs were produced. This research portfolio firstly aimed to investigate the current use of human anatomy in the creation of physical models and character enhancements in the prop manufacturing industry.

This was covered in Part One, Background Review, where the assessment of the literature and past projects occurred. Part Two and Three focuses on Aim Two which explores the capabilities of heterogeneous multi-property, colour 3D printing in the production of an anatomical finger through exploration of materials, colour and overall form. This research created a design that can be easily adapted, allowing for many opportunities in regards to colour difference, controlled by the printer, and overall shape or size. Additionally this project can be applied to other areas of the body as the model consists of one ovoid joint, similar to a ball and socket such as in the shoulder, and two hinge joints like the knee or elbow. These internal workings can be scaled up and a new skin applied to form almost all the joints in the body.

\section{Understanding of past research.}

This project was expected to produce a finger that moves similar to a human and then push this idea further in the creation of a creature finger. As this research portfolio was able to create two different fingers, one that resembles real human anatomy and the other more abstract/ simplified in its overall form the initial expectation was met. This research portfolio was strongly influenced by the research conducted on the anatomy of the finger. It was important that each section housed below the skin was incorporated into the model so that realistic movement could occur.

Additionally an understanding of the technology helped in the creation of the design criteria and provided knowledge on the abilities and limitations of the Stratasys J750 Polyjet printer. An area that was important to assess was past projects in the $3 \mathrm{D} / 4 \mathrm{D}$ printing field. These projects affected the final outcome as they helped in the choice of subject matter and reduced the number of test failures in regards to material qualities and Shore Hardness assignment.

Knowing the context a design will be applied in is crucial as it will heavily influence the parameters. Design features such as ease of 
editing, size, cost and the amount of use need to be established so that a successful product can be produced. CGI also needed to be assessed as it is the main competitor to the idea of this research portfolio. CGI allows for creatures and objects. It was known that this research portfolio's final humanoid anatomical finger would fall into the realm of the Uncanny Valley. By understanding the aspects of what makes a design uncanny it allowed for the creation of a coherent and creepy outcome which was desired for this project.

\section{Lubrication.}

This research portfolio found a significant gap in the research surrounding the lubrication of multi-property 4D objects. Many of the projects created in the 4D area have either been changed due to water or have been designed as a water creature. As many aspects of design projects found in the film industry do not come in contact with water it was important to determine another way to produce 4D designs that can move externally from liquid baths. Many objects that consist of two hard surfaces rubbing together require some form of lubrication to reduce wear and tear. This is also true with the joints found in the human body. This posed an issue as the final designs are a fully enclosed finger made of a porous material which reacts well to strain when exposed to a liquid. This was determined in past projects.

This research was able to remove the bath by replacing the need for external liquid exposure with the ability to inject the Armor-All oil into the cavity formed by breaking up the stick support material. This allowed for the soft internal structure to absorb the lubricant and reduced the strain and potential for breakage. This new knowledge opens up a pathway to the production of multi-property, $3 \mathrm{D} / 4 \mathrm{D}$ printed soft robotics for the film industry as lubrication of a 'dry' multi-property print is fundamental for successful smooth movement. It was expected that further research would arise from this research portfolio as this project looked into new ideas about using Agilus in the creation of humanoid anatomics.

\section{Additive Manufacturing.}

3D printing has allowed for quick prototyping and adaptation of designs in minutes or hours rather than days. Companies such as Weta Workshop are at the forefront of utilising the abilities of additive manufacturing and single material printing for the production of props. Nonetheless, the ability to now make designs multi-property which are ready straight out of the cleaning process is possible with the knowledge created within the research portfolio. The primary importance of this research portfolio was to look at how might multi-property technology affect the prop industry as it is a field of study that has not yet been explored to its fullest. By creating new research and producing a design that can be further developed the opportunities of this research portfolio's final outcome are limitless.

What could multi-property, 3D/4D printing bring to the way the film prop manufacturing industry creates physical props? Multiproperty printing allows for the potential of the creation of $4 \mathrm{D}$ printed props. It allows digitally created designs to become a reality that would not have been possible before. Multi-property printing can change how props are made in the future. 
This research portfolio was not fully resolved as several unforeseen errors during the experimentation phase led to a lack of time to create two fully resolved fingers.

\section{Limitations.}

Several limitations arise from this research, the foremost being cost and time. There is a standard print running price, so when there is only one print it pushes up the price, the more prints the less individual cost. There was a confined budget for this research that was quickly used on all the experiments that could not be avoided due to the iterative process of Research Through Design, the final cost over $\$ 3000$. With more funding this project can further develop. Time also played a significant factor in the ability to fulfil the full expectations of this project. The research was expected to be completed within one year and what has been produced is a good representation of what can be completed. However, there are still many aspects of this project that requires further research potential in the form of a $\mathrm{PhD}$ or smaller research projects. There is still more that can be learnt in regards to the use of the J750 Agilus printing and lubrication.

\section{J750.}

There are still issues with the skin material tearing at the point where it must fold over itself or stretch over the internal working. This has been reduced down to a small isolated area that would be fixed with further material testing. There are still issues regarding the tendon strength mainly within the Human design as it constantly snaps at the connection point where the tendon meets the bone. Additionally, there were printing/ file exporting issues that formed from this research. What was found was that when a section of material is printed within another, the tendon is the primary example, only one material will print (in this case the Shore Hardness 85). This can be resolved by cutting an internal section out of the outer material; however, up until test twenty, this was not necessary. Further exploration into what could be causing this issue is needed as it is yet to be determined if this is a printing or exporting software error. 


\subsection{Conclusion.}

This research sought to explore how multi-property 3D printing can be used in the creation of heterogeneous humanoid props for the film industry. CGI is a big part of how films are made at the moment, but with the advancements in high detail printing the ability to produce computer-generated object (CGO) physically is possible. With the emerging field of $4 \mathrm{D}$ printing, there is potential to design movement either independently or by hand. In this research, an iterative design process is implemented to develop new 3D/4D printing techniques that can bring objects to life. Two fingers were created, 3D printed and filmed to show the capabilities of human recreation through additive manufacturing. These designs create a narrative from being brought out of the cleaning bath and into the world as a 'dry' object that carries emotive qualities.
The fingers create a sense of unease as they perform similar to a human, but there is still a divide between real, and computer made. 4D printing allows the designer to both be the maker and choreographer of the movement of the form. Although this can not be thoroughly planned as there is always an external environment affecting the movement. The final outputs show how digitally created humanoid objects can create a compelling on-screen presence. Multi-property 3D/4D printing of humanoid anatomics can bring a lot to the prop manufacturing industry. 
Part 5. 


\section{References \& Appendix.}




\subsection{References.}

.Challies, Z. \& Stevens, R., (2017) Flexible creature prosthetic, Victoria University of Wellington, Copyright 2019 by Challies, Z., \&Victoria University of Wellington.

Clarkson, R., (2012), Cross section renders of the flowers, from Behance, Retrieved from, https://www.behance.net/ gallery/17513219/Blossom, Copyright 2019 by Richard Clarkson.

.Clayton, M., Phiol, R., (2012) Leonardo da Vinci: Anatomist, Royal Collection Publications, London.

.Cross, N. (2006). Designerly ways of knowing. London, England: Springer. DOI: 10.1007/1-84628-301-9

.Das, C. S., Ranganathan, R., Murugan, N., (2018), Effect of build orientation on the strength and cost of polyjet $3 D$ printed parts, Rapid Prototyping Journal, Vol. 24 Issue: 5, 832-839, https://doi.org/10.1108/RPJ-08-2016-0137

.Durrant, A. \& Price, J. [RTD Conference Series]. (2015, June 4). RTD 2015 Provocation by Sir Christopher Frayling Part 3: Unpacking craft knowledge [Video file]. Retrieved October 23rd, 2018, from, https://vimeo.com/129777503

.Frankel, L. \& Racine, M. (2010), The complex field of research: For design, through design, and about design. Proceedings of the DRS 2010 in Montreal, Canada, 518-529, Retrieved from, https://www.scribd.com/doc/147567202/DRS-2010Montreal-Conference-Proceedings-pdf
Frayling, C. (1993). Research in art and design, Royal College of Art Research Papers, 1(1), 1-5. Retrieved from, http://researchonline.rca.ac.uk/384/3/frayling_research_in art_and_design_1993.pdf

Friedman, K., (2008) Research into, by and for design, Journal of visual arts practice, 7(2), 153-160, DOI: 10.1386/jvap.7.2.153_1

George M, Whitesides, (2018), Soft robotics, Angewandte Chemie International Edition, Vol.57(16),4258-4273, DOI: 10.1002/ anie. 201800907

.Goldberg, D., (2018) History of 3D printing: It's older than you are (that is, if you're under 30), retrieved April 30th 2019 from https://www.autodesk.com/redshift/history-of-3d-printing/

.Hart, E., (2012) Theatre history, Eric Heart's prop agenda, Retrieved april 30th 2019 from, http://www.props.eric-hart. com/tag/theatre-history/

Hiller, J., Lipson, H., (2009). Design and analysis of digital materials for physical $3 D$ voxel printing, Rapid Prototyping Journal, 15 ( 2), 137-149, DOI 13552540910943441

.Hockaday, L. A., Kang, K. H., Colangelo,N W., Cheung, P. Y. C., Duan, B., Malone, E., Wu, J., Girardi, L. N., Bonassar, L. J., Lipson, H., Chu, C. C., Butcher, J. T., (2012), Rapid 3D printing of anatomically accurate and mechanically heterogeneous aortic valve hydrogel scaffolds, Biofabrication. Vol.4(3), p.035005, DOI: 10.1088/1758-5082/4/3/035005 
.Hone, N., (2018) Cross section of heaven flower with assigned material combination, from Nicole Hone industrial designer, Retrieved from, https://www.nicolehone.com/hydrophytes. Copyright 2019 by Nicole Hone.

.Hurst, N., (2012), 3-D printing giants Stratasys and Objet merge to create \$3 Billion firm, Retreved april 30th 2019 from https:// www.wired.com/2012/12/stratasys-objet-merger/

Inner Body (n.d) Inner body research team, anatomy, retrieved August 20th, 2018, from https://www.innerbody.com/htm/ body.html

.Inflow technology (2018) Computer aided technology, retrieved November 16th, 2018, from, https://www.cati.com/3d-printing/ polyjet-technology/

.Kaneria, R., (2015, October 26,) Why props matter. [video file]. Retrieved from https://vimeo.com/143619334

.Keating, S. J., Gariboldi, M. I., Patrick, W. G., Sharma, S., Kong, D. S., Oxman, N., (2016). 3D Printed multi-material microfluidic valve, PLOS ONE, 11(8): e0160624, https://doi. org/10.1371/journal.pone.0160624

.Kim, J., (2017) Mars needs moms and the uncanny valley, HuffPost, Retrieved May 21, 2019, from, https://www.huffpost. com/entry/mars-needs-moms-ucanny-valley_b_841018

.Lipson, H., Hurman, M. (2013) Fabricated: The new world of $3 d$ printing, John Wiley \& Sons, Inc, Indianapolis, Indiana.
.Lonjon, C., (2017), The history of 3 d printer: from rapid prototyping to additive fabrication, Sculpteo, Retrieved May 10th, 2019, from, https://www.sculpteo.com/blog/2017/03/01/whosbehind-the-three-main-3d-printing-technologies/

.Maroudas, A., Bullough, P., Swanson, S. A. V., Freeman, M. A. R., (1968), The permeability of articular cartilage, The bone and joint journal: Pathology and basic sciences, Retrieved from, https://doi.org/10.1302/0301-620X.50B1.166

.Martin, B., \& Hanington, B. (2012). Universal methods of design: 100 ways to research complex problems, develop innovative ideas, and design effective solutions. Beverly, MA: Rockport Publishers. ISBN: 9781592537563

.Mayor, A., (2018), The Concept of the 'Uncanny Valley' Dates to 1970. The Phenomenon Is Thousands of Years Older, Time, Retrieved May 21st, 2019, from, http://time.com/5452383/ uncanny-valley-ancient-greece/

.MIT, (n.d) Self-assembly lab: $4 D$ printing, Retrieved December 3rd 2018, from, https://selfassemblylab.mit.edu/4d-printing/

. Nadernezhad, A., Khani, N., Skvortsov, G. A., Toprakhisar, B., Bakirci, E., Menceloglu, Y., Koc, B. (2016). Multifunctional $3 D$ printing of heterogeneous hydrogel structure, Scientific Reports, 6(1). https://doi.org/10.1038/srep33178

.Nervous system (2014), Kinematics dress, Retrieved May 14th, 2019, from, https://n-e-r-v-o-u-s.com/projects/sets/kinematicsdress/ 
.Oxman, N., (2010). Material-based design computation. Thesis $(\mathrm{PhD})$, Massachusetts Institute of Technology.

.Oxman, N., Tsai, E., \& Firstenberg, M., (2012). Digital anisotropy: A variable elasticity rapid prototyping platform,

Virtual and Physical Prototyping, 7:(4), 261-274, DOI: $10.1080 / 17452759.2012 .731369$

.Oxnard, C. (2012) The scientific bases of human anatomy, Hoboken, NJ, USA: John Wiley \& Sons, Inc, DOI: 10.1002/9781118789223

.Pei, E., (2014), 4D printing - Revolution or fad?, Assembly Automation, Vol.34(2), 123-127, DOI: 10.1108/AA-02-2014014

.Porter, M. M., Ravikumar, N., Barthelat, f., Martini, R., (2017) $3 D$-printing and mechanics of bio-inspired articulated and multi-material structures, Journal of the Mechanical Behavior of Biomedical Materials 73 114-126, http://dx.doi.org/10.1016/j. jmbbm.2016.12.016

.Rodríguez Ramírez, E. (2017). A postgraduate thesis model for research through design based on design criteria. The International Journal of Designed Objects, 11(4), 11-27. https:// doi.org/10.18848/2325-1379/CGP/v11i04/11-27

Romano, N., (2018), Sesame Street introduces homeless Muppet to raise awareness, Entertainment weekly, Retrieved May 10th, 2019, from, https://ew.com/tv/2018/12/12/sesame-streethomeless-puppet-lily/
.Rowland, G. (2004). Shall we dance? A design epistemology for organizational learning and performance. Educational Technology Research and Development, 52(1), 33-48. Retrieved from https://link.springer.com/article/10.1007/ BF02504771

.Rouse, M., (2016) Uncanny valley, TechTarget, Retrieved May 10th, 2019, from, https://whatis.techtarget.com/definition/ uncanny-valley

Sechrest, R., (2012, October 14) Hand Anatomy Animated Tutorial, [Video file]. Retrieved from https://www.youtube. com/watch?v=zyl6eoU-3Rg\&list=PLbsfEVQd6Mj5tmQldRX DaX51fYrWK3nir\&index $=3 \& \mathrm{t}=0 \mathrm{~s}$

Smuszkiewicz, A., Kwasniewski, E., \& R. M. P., (1987). Props and their function in science fiction (Les accessoires et leur fonction en science-fiction), Science Fiction Studies, 14, (2), 222-229, DOI 130.195.253.17

Snikhovska, K., (n.d) Seven types of $3 D$ printing: The different types of $3 D$ printing technology, Pen and Plastic, Retrieved July 20th 2018, from, https://penandplastic.com/3d-printertypes/

Sokolowski, M., 2015, History of film education in Poland, The New Educational Review, Vol.41(3), 65(10), DOI: 10.15804/ tner.2015.41.3.05

Speaight, G., 2017, Puppetry, Britannica Academic INC, retrieved from, https://www.britannica.com/art/puppetry 
.Stone, T., L., (2010) Managing the design process: Concept development, an essential manual for the working designer, Rockport Publishers, United States of America, ISBN-13: 9781-59253-617-7

Tested, (2016 January 28), Adam Savage's one day builds: Making a puppet!, [Video file]. Retrieved from https://www. youtube. $\mathrm{com} /$ watch? $\mathrm{v}=\mathrm{JYwNuP7} \mathrm{cwJs} \& \mathrm{t}=537 \mathrm{~s}$

Tibbits, S., (2014) 4D Printing: Multi-material shape change, architectural design, January 2014, Vol.84(1), pp.116-121 https://doi.org/10.1002/ad.1710

Wallace, D., (2019) Sesame Street's Stacey Gordon says playing Julia, the Muppet with autism, 'Feels Like a Magical Dream', Parade, Retrieved May 10th, 2019, from, https://parade. com/867262/debrawallace/sesame-street-julia-muppet-autism/

Whissel, K., (2014). Spectacular digital effects: CGI and contemporary cinema, DukeUP, 213. ISBN 9780822355885.

Whitesides, G., M., (2018), Soft matter: soft robotics, Wiley-VCH Verlag GmbH \& Co.KGaA, Weinheim, Angew. Chem. Int. Ed., 57, 4258-4273, DOI: 10.1002/anie.201800907

.Whitham, S., (2019 July 11) Printing people, heterogeneous multiproperty printing of humanoid anatomics, [Video file]. Retrieved from https://youtu.be/DRWfYGbGepc

.Zimmerman, J., Stolterman, E., Forlizzi, J., (2010) An analysis and critique of Research through design: towards a formalization of a research approach, 8th ACM Conference on designing 
5.2 Appendix. 


\section{Body Worlds Vistal.}

The Body World Visual Exhibition is an experienced based around creating knowledge of the human anatomy. All the bodies were donated to science and conserved/ mummified in varying states of dissection. With the gathering of information for the thesis project the main focus of this trip was the hands, feet and jaw, as this was conducted in the first stages of the research. This exhibition consisted of several full human cadavers with individual parts also displayed. Each display focused on a different aspect of the human body ranging from the bone and blood supply arrangement shown in Figure 83 to full bodies with the skin removed that demonstrated the complex working that are under the skin, such as in Figure 84.

Each body came with a description highlighting the main reason for the display and a small amount of information about the person. Figure 82 shows a heart, this display looks at how bone and muscle intersect and talked about one of the most important muscles, the heart. The exhibition shed light on how smoking can affect the lungs, different forms of cancer, obesity and what happens when humans age. Overall it was an informative experience that created an aura of respect for the individuals on display as well as the workings of the human body itself.
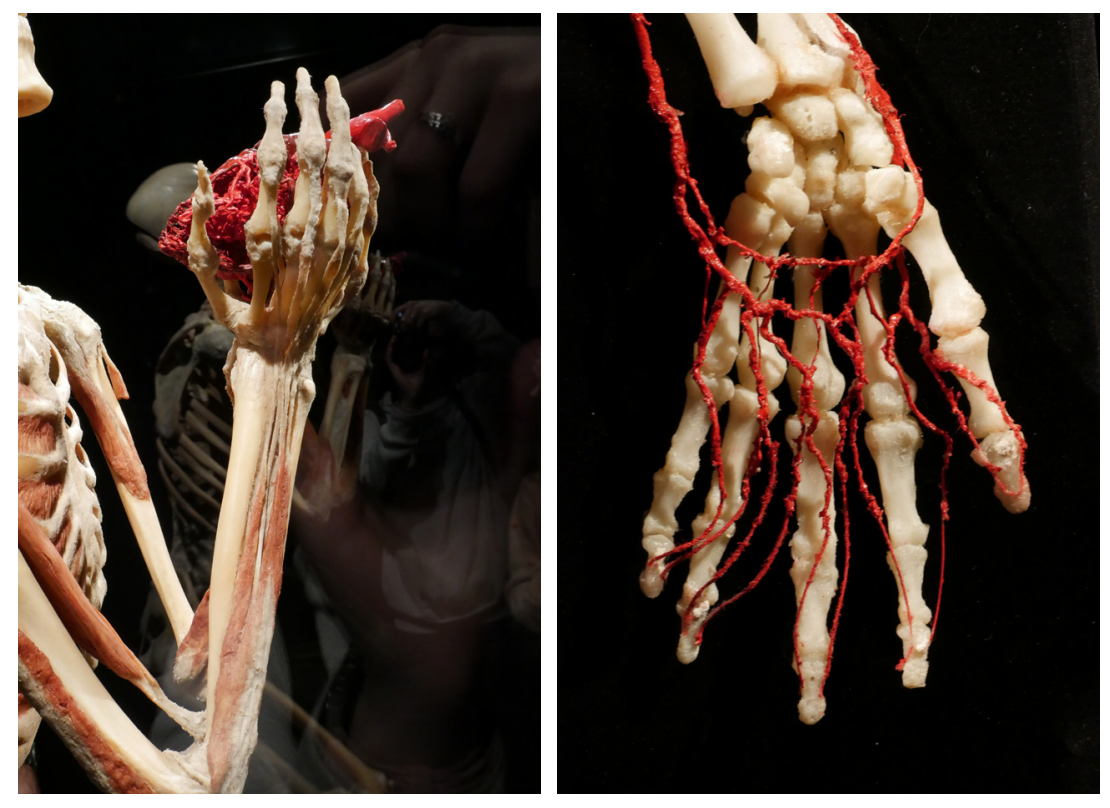

Figure 82, body world, heart in hand.

Figure 83, body world, bone \& blood.

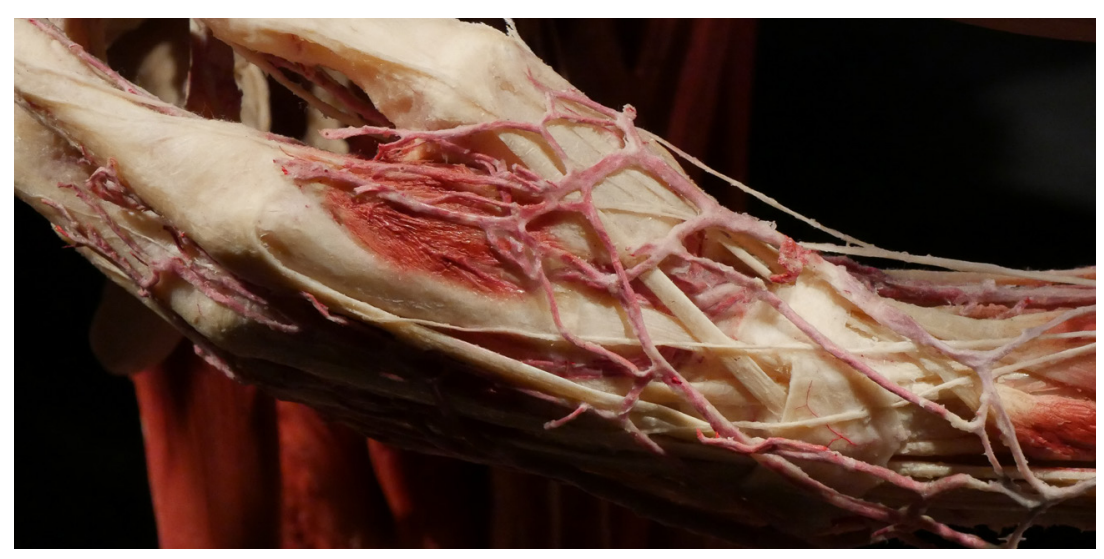

Figure 84, body world, no skin. 


\section{Already Existing 3D Models.}

To first understand how a finger might be constructed digitally it was important to first establish what was already existing in the public domain in regards to fully designed hands/fingers. These models were sourced from TurboSquid an online sharing platform for digital designs either free or paid for. What was determined was that there are indeed models of fingers and hands to consist of all the internal workings This thesis aims to recreate as demonstrated in Figure 85. However, these are all static designs that without adaptation would not move like a finger. This did provide valid information on how the final model might be produced.

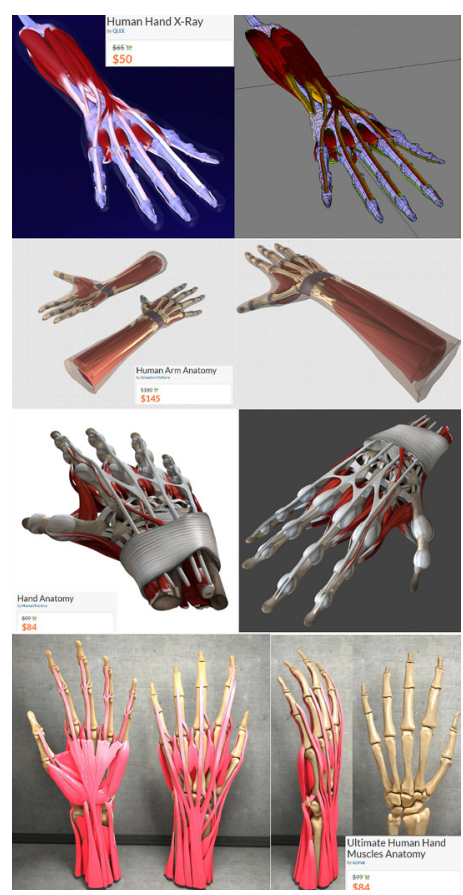

Figure 85, existing models, renders of hand.

\section{Making Process.}

The traditional process of prop making starts with a concept either drawn or modelled in a CAD program. From this, an initial sculpt or print is created and accessed by the artists and film directors. This process is iterated until the final design is chosen. A time consuming process is carried out when using the traditional sculpting method. With the CAD iterations small changes can be done in minutes and then printed that day. These final concepts are then moved into the production line where a first master cast is made, See Figure 86. A negative mold is made of the face to soon produce a positive cast. Commonly there will be the 'master' prop which is mainly used for close up shots. Other duplicates are made out of different materials for other parts of the film. For example, if a sword was being made the master would most likely be manufactured out of the correct metal that would be seen in the real world, whereas the duplicates might be made out of lighter material for fight scenes that are not overly close up. Once the cast is completed paint is applied to give the form depth or give the appearance that the object is aged or worn.

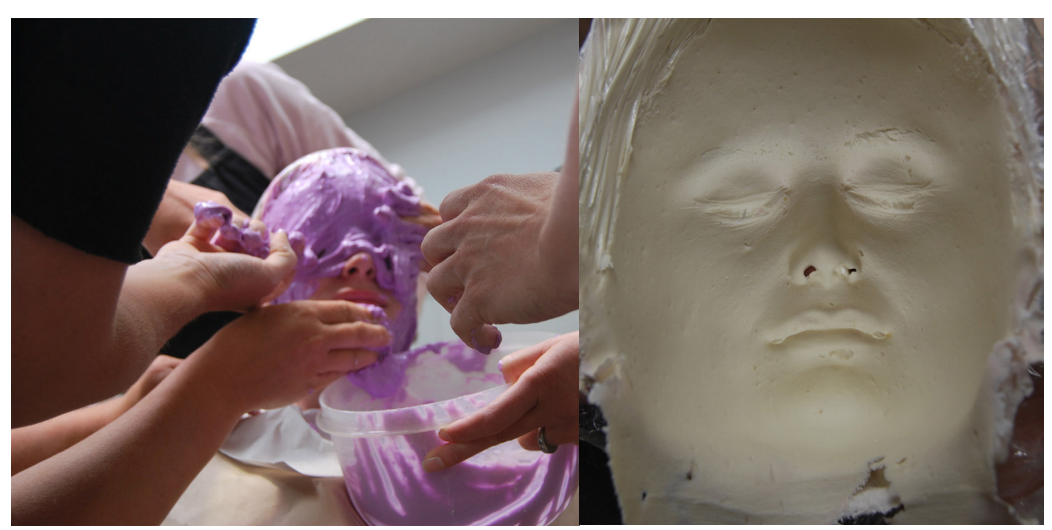

Figure 86, making process, casting of the face. 


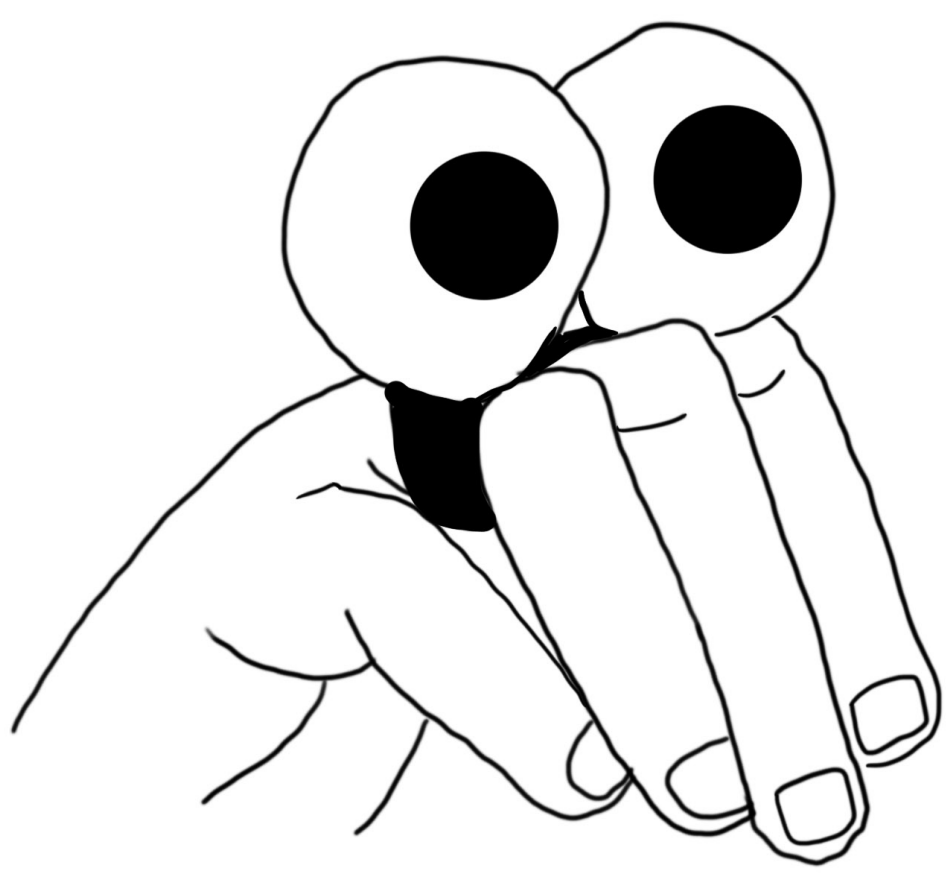

Figure 87, eyes on hand, drawing.

\section{Puppetry.}

Props are not just an object that an actor interacts with; a prop can represent a character or a figure that is manipulated. 'Puppetry shows seem to have existed in almost all civilisations, and in almost all periods' (Speaight 2017, p1). Masks and puppets were used in ritual magic, storytelling and entertainment. A puppet can be many things, two white balls with black dots sitting on top of a hand similar to Figure 87. Rick Lyon says in the Tested video (2016) "The human brain is so programmed that somehow just two spots of black somehow we recognise it as an eye" (3:49). One of the most recognised forms of puppetry is hand, glove or body puppets. Shows such as The Muppet Show, Sesame Street and movies such as Labyrinth and The Dark Crystal are an excellent representation of how puppets are used to portray a full story with emotion and depth. Sesame Street can cover complex issues in a way that young audiences can understand through the use of puppet character. Topics such as autism (Wallace, 2019) and homelessness (Romano, 2018) have been portrayed in a way that brings understanding to the different circumstances that one might face. This style has a few different ways that the character can be manipulated. This thesis will use the form of puppetry that uses bottom controlled strings in the creation of the desired movement.

\section{Cleaning Process.}

The printer creates a support material that is a combination of hard lattice Patton and soft material. Ideally the removal of the hard lattice material would be ideal as it affect the internal cavities and restrict movement. This has been resolved slightly as it is possible to break up the internal support material but there is still some restriction and the hand fragments are visible through the translucent skin. 
The cleaning process for the finger is simple and relatively quick. Step one is removing the prints from the printing bed, shown in Figure 89 and Figure 90, and to remove as much of the external support material as possible demonstrated in Figure 88. Step two is placing the model into the cleaning bath for around two hours, the recommended time is four, but as only a thin layer of clean support material needs to be removed, this is shortened. After the desired time in the bath, carefully remove and rinse the designs in clean water. Step three is possibly the most difficult as it consists of loosening up the internal support material and removal of the stent. The way to loosen up the internal material is by gently pushing on the skin to break the connections between the hard section as well as detaching the skin from the internal workings to allow for the space needed for the lubrication. Step four is where the lubrication is injected and full movement can occur.

Figure 91 is a photo of the printing head that emits six different material and one support material that is cured by the UV light.
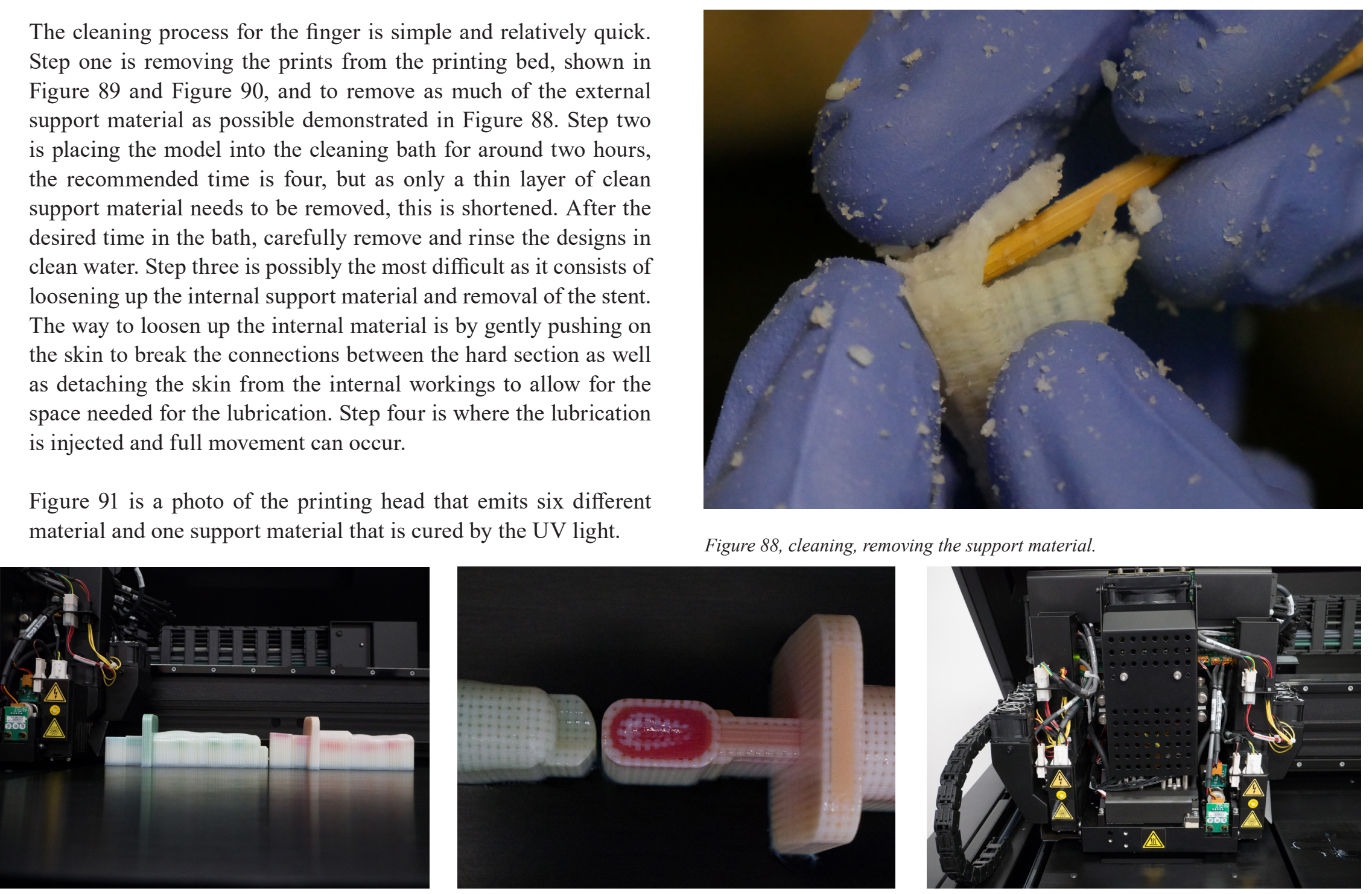

Figure 89, printing process, on the print bed.

Figure 90, printing process, detail of support lattice pattern.
Figure 91, printer, print head. 


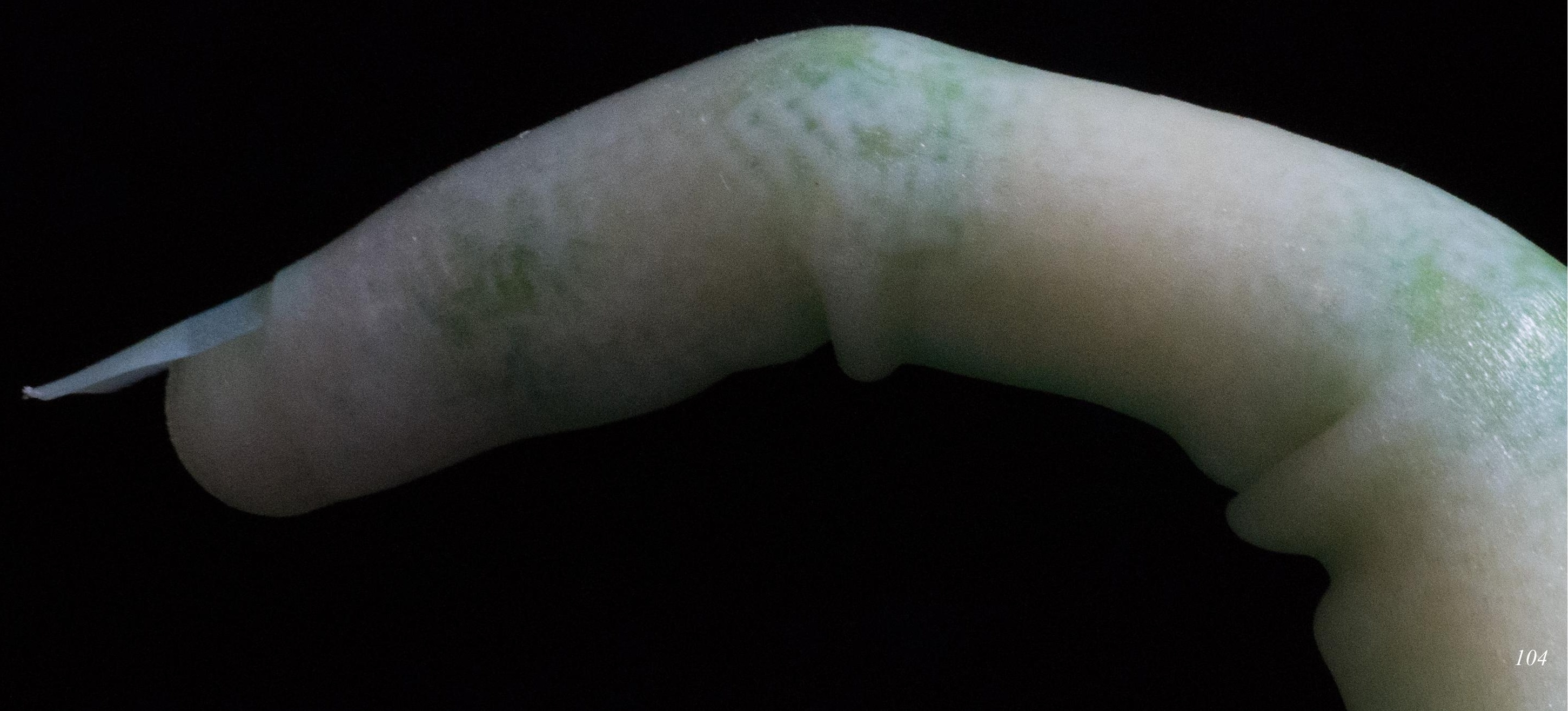

